Nevada

Environmental

Restoration

Project

\title{
Corrective Action Investigation Plan for Corrective Action Unit 106: Areas 5, 11 Frenchman Flat Atmospheric Sites \\ Nevada Test Site, Nevada
}

Controlled Copy No::

Revision No.: 0

April 2010

Approved for public release; further dissemination unlimited.

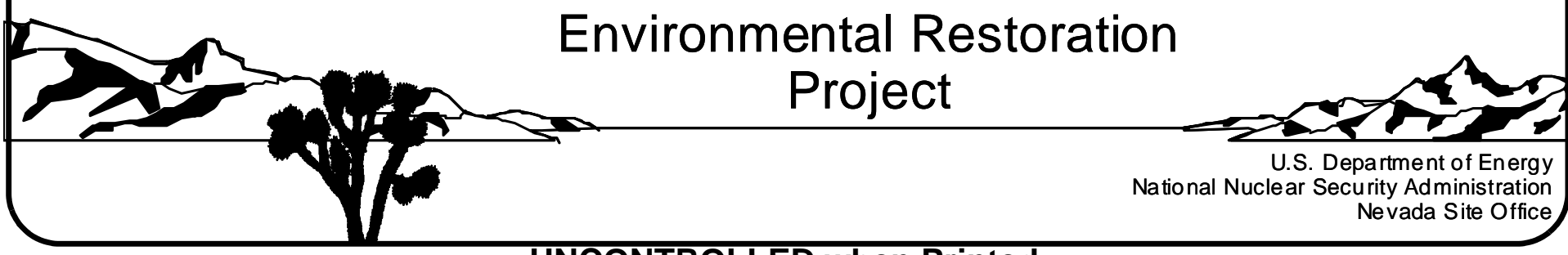


Available for sale to the public from:

U.S. Department of Commerce

National Technical Information Service

5301 Shawnee Road

Alexandria, VA 22312

Telephone: 800.553.6847

Fax: 703.605.6900

E-mail: orders@ntis.gov

Online Ordering: http://www.ntis.gov/help/ordermethods.aspx

Available electronically at http://www.osti.gov/bridge

Available for a processing fee to U.S. Department of Energy and its contractors, in paper, from:

U.S. Department of Energy

Office of Scientific and Technical Information

P.O. Box 62

Oak Ridge, TN 37831-0062

Phone: 865.576.8401

Fax: 865.576.5728

Email: reports@adonis.osti.gov

Reference herein to any specific commercial product, process, or service by trade name, trademark, manufacturer, or otherwise, does not necessarily constitute or imply its endorsement, recommendation, or favoring by the United States Government or any agency thereof or its contractors or subcontractors. 


\section{CORRECTIVE ACTION INVESTIGATION PLAN FOR CORRECTIVE ACTION UNIT 106: AREAS 5, 11 FRENCHMAN FLAT ATMOSPHERIC SITES NEVADA TEST SITE, NEVADA}

U.S. Department of Energy, National Nuclear Security Administration

Nevada Site Office

Las Vegas, Nevada

Controlled Copy No.:

Revision No.: 0

April 2010

Approved for public release; further dissemination unlimited.

Reviewed and determined to be UNCLASSIFIED.
Derivative Classifier: $\frac{\text { Joseph P. Johnston/NNES CO }}{\text { (Name/personal identifier and position title) }}$
Signature: $/ \mathrm{s} /$ Joseph P. Johnston
Date: $4 / 08 / 2010$




\title{
CORRECTIVE ACTION INVESTIGATION PLAN FOR \\ CORRECTIVE ACTION UNIT 106: \\ AREAS 5, 11 FRENCHMAN FLAT ATMOSPHERIC SITES \\ NEVADA TEST SITE, NEVADA
}

Approved by: /s/Kevin J. Cabble

Date: /s/ 4/8/2010

Kevin J. Cabble

Federal Sub-Project Director

Soils Sub-Project

\author{
Approved by: /s/Robert Boehlecke \\ Robert F. Boehlecke \\ Federal Project Director \\ Environmental Restoration Project
}

Date: $4 / 8 / 2010$ 


\section{Table of Contents}

List of Figures vi

List of Tables viii

List of Acronyms and Abbreviations ix

Executive Summary ES-1

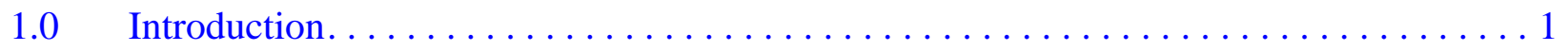

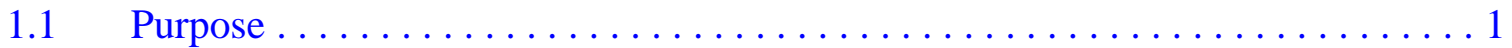

1.1.1 CAU 106 History and Description . . . . . . . . . . . . . . . 4

1.1.2 Data Quality Objective Summary ................... 4

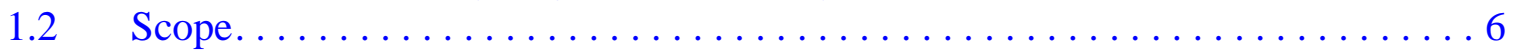

1.3 Corrective Action Investigation Plan Contents $\ldots \ldots \ldots \ldots \ldots \ldots \ldots \ldots$

$2.0 \quad$ Facility Description. . . . . . . . . . . . . . . . . . 8

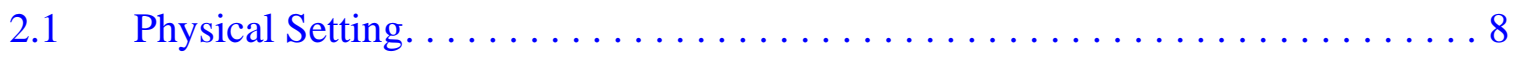

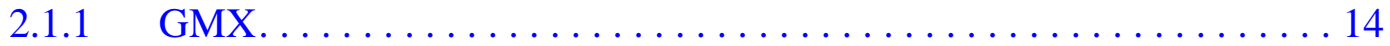

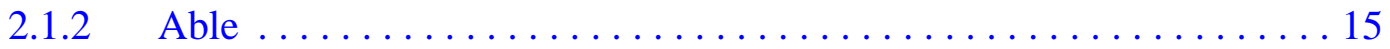

2.1 .3 Hamilton. . . . . . . . . . . . . . . . . . . . . . . . . . 15

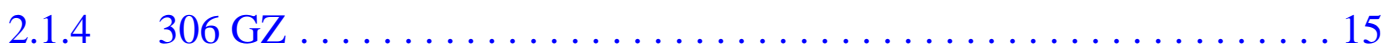

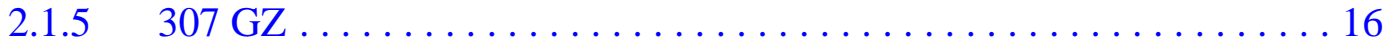

2.2 Operational History. . . . . . . . . . . . . . . . . . . . . 16

$2.2 .1 \quad$ GMX . . . . . . . . . . . . . . . . . . . . . 16

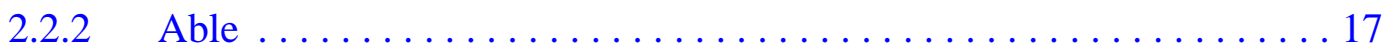

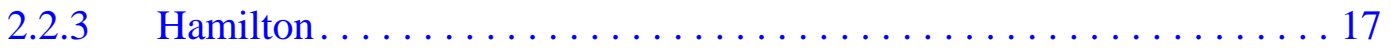

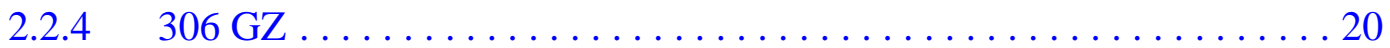

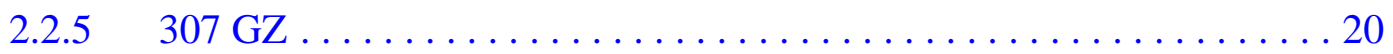

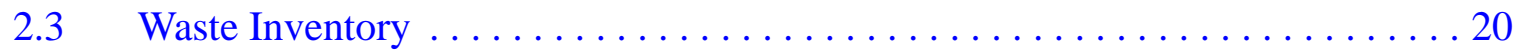

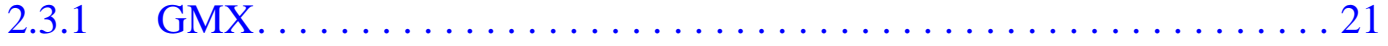

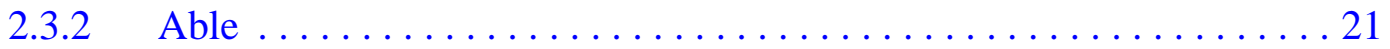

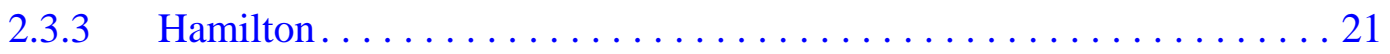

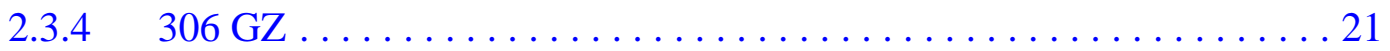

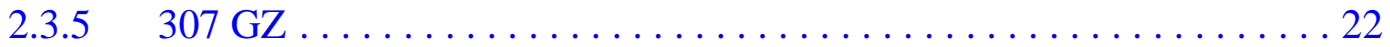

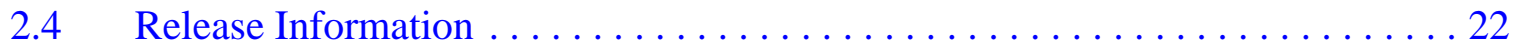

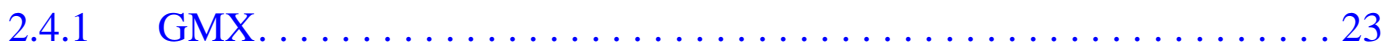

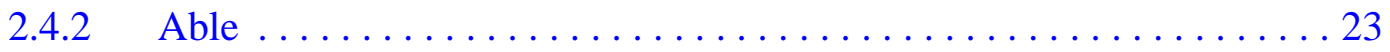

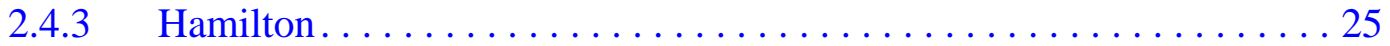

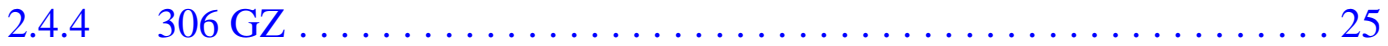

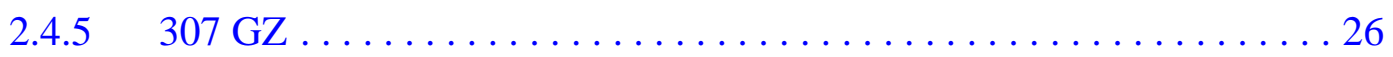

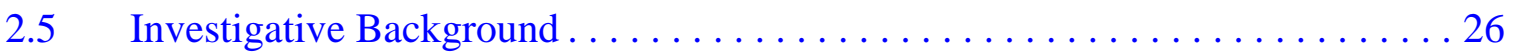

$2.5 .1 \quad$ GMX . . . . . . . . . . . . . . . . . . . . . 27

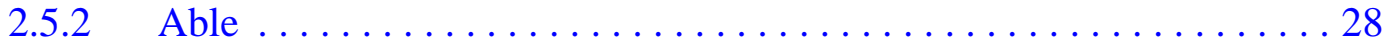

2.5 .3 Hamilton . . . . . . . . . . . . . . . . . . . . 30 


\section{Table of Contents (Continued)}

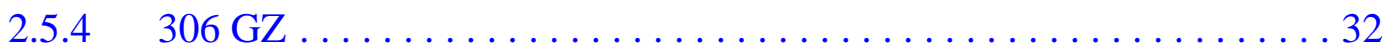

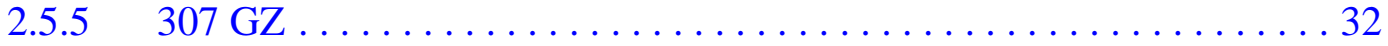

2.5.6 National Environmental Policy Act .................. 32

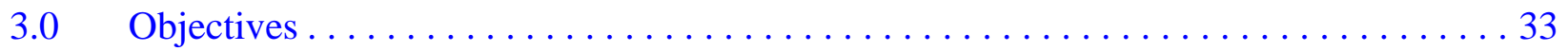

$3.1 \quad$ Conceptual Site Model ................................ 33

3.1.1 Land Use and Exposure Scenarios ................... 33

3.1.2 Contaminant Sources ............................ . 36

3.1.3 Release Mechanisms ........................... 37

3.1.4 Migration Pathways ............................ 37

3.1.5 Exposure Points ................................ 39

3.1.6 Exposure Routes.............................. 39

3.1.7 Additional Information.......................... 39

3.2 Contaminants of Potential Concern . . . . . . . . . . . . . . . . . . . . . 39

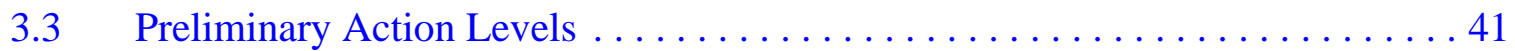

3.3.1 Chemical PALs............................. 44

3.3.2 Radionuclide PALs......................... 44

3.4 Data Quality Objective Process Discussion ..................... 45

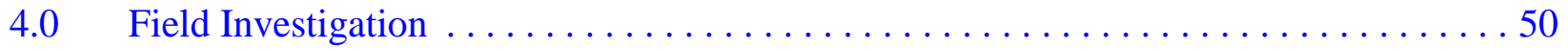

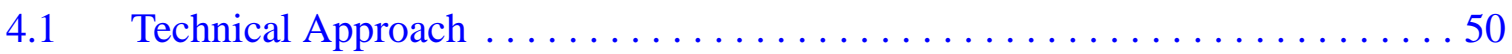

$4.2 \quad$ Field Activities . . . . . . . . . . . . . . . . . . . . . . . . . . . 51

4.2.1 Site Preparation Activities . . . . . . . . . . . . . . . . . . 51

4.2.2 Sample Location Selection........................ 51

4.2.2.1 Test Releases . . . . . . . . . . . . . . . . . . . . 52

4.2.2.2 Non-test Releases . . . . . . . . . . . . . . . . . . 52

4.2.3 Sample Collection ............................ 53

4.2.4 Sample Management .......................... 55

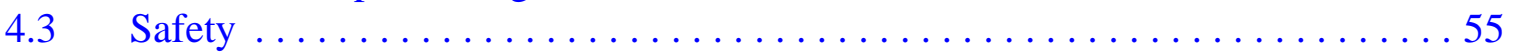

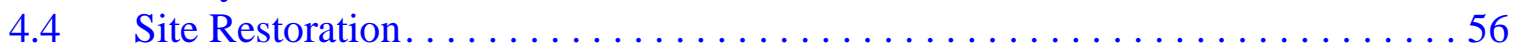

$5.0 \quad$ Waste Management..................................... 57

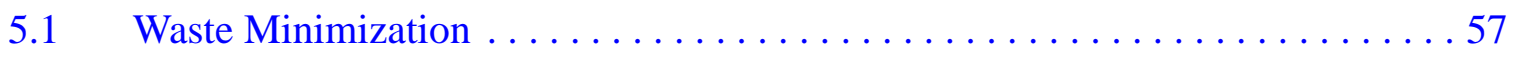

$5.2 \quad$ Potential Waste Streams . . . . . . . . . . . . . . . . . . . . . . . 58

$5.3 \quad$ Investigation-Derived Waste Management.................... 58

$5.3 .1 \quad$ Industrial Waste . . . . . . . . . . . . . . . . . . . . . . . . 58

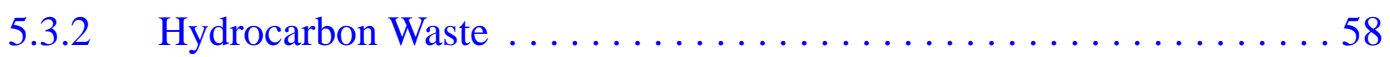

5.3.3 Low-Level Radioactive Waste . . . . . . . . . . . . . . . . . . 58

5.3 .4 Hazardous Waste ............................... 59

5.3 .5 Mixed Low-Level Waste ........................... 59

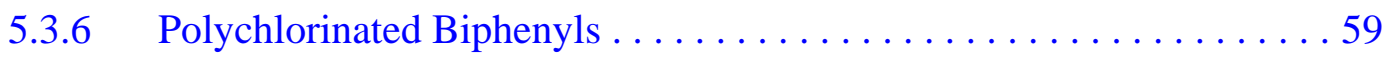




\section{Table of Contents (Continued)}

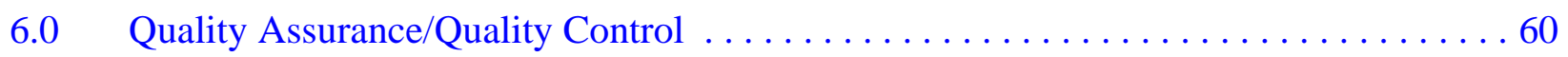

6.1 Quality Control Sampling Activities $\ldots \ldots \ldots \ldots \ldots \ldots \ldots \ldots \ldots \ldots \ldots \ldots \ldots \ldots \ldots$

6.2 Laboratory/Analytical Quality Assurance $\ldots \ldots \ldots \ldots \ldots \ldots \ldots \ldots \ldots 62$

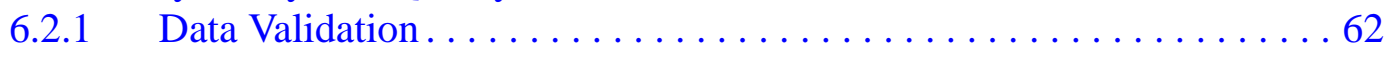

6.2 .2 Data Quality Indicators.......................... 62

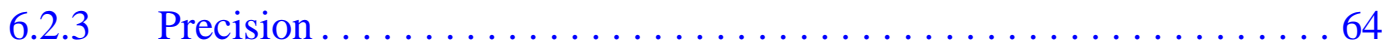

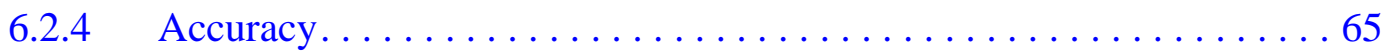

$6.2 .5 \quad$ Representativeness .........................66 66

6.2 .6 Completeness ..............................66

$6.2 .7 \quad$ Comparability ................................ 67

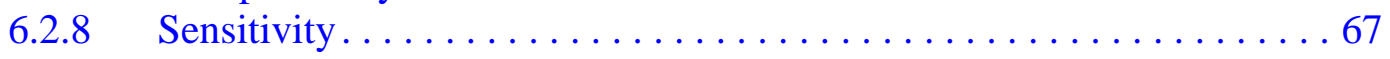

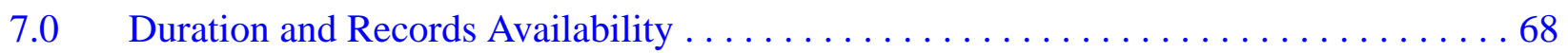

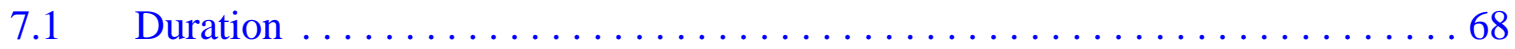

$7.2 \quad$ Records Availability . . . . . . . . . . . . . . . . . . . . . . . . 68

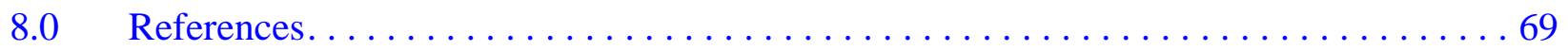

\section{Appendix A - Data Quality Objectives}

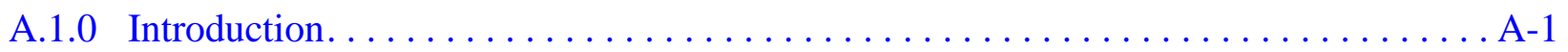

A.2.0 Step 1 - State the Problem............................. A

A.2.1 Planning Team Members $\ldots \ldots \ldots \ldots \ldots \ldots \ldots \ldots \ldots \ldots \ldots \ldots \ldots \ldots \ldots$

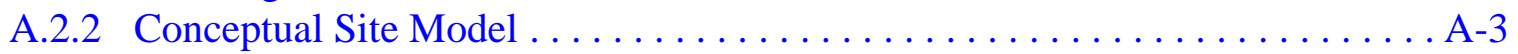

A.2.2.1 Release Sources ............................ A-9

A.2.2.1.1 GMX ............................. A

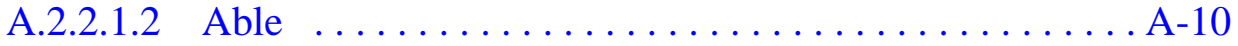

A.2.2.1.3 Hamilton ......................... A-10

A.2.2.1.4 $306 \mathrm{GZ} \ldots \ldots \ldots \ldots \ldots \ldots \ldots \ldots \ldots \ldots \ldots \ldots \ldots \ldots \ldots \ldots \ldots \ldots$

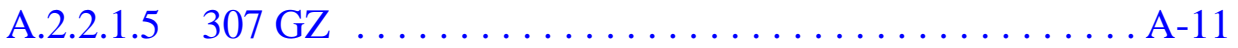

A.2.2.2 Potential Contaminants......................... A-12

A.2.2.3 Contaminant Characteristics.................... A-13

A.2.2.4 Site Characteristics........................ A-14

A.2.2.5 Migration Pathways and Transport Mechanisms ............ A-15

A.2.2.6 Exposure Scenarios ........................ A-16

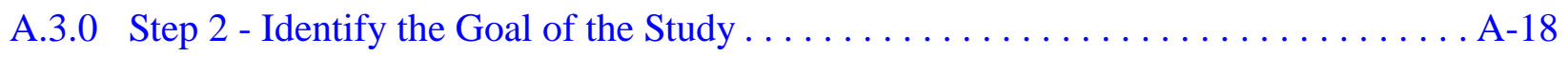

A.3.1 Decision Statements . ............................. A-18

A.3.2 Alternative Actions to the Decisions ..................... A-19 


\section{Table of Contents (Continued)}

A.3.2.1 Alternative Actions to Decision I. . . . . . . . . . . . . . . A-19

A.3.2.2 Alternative Actions to Decision II . . . . . . . . . . . . . . A-20

A.4.0 Step 3 - Identify Information Inputs $\ldots \ldots \ldots \ldots \ldots \ldots \ldots \ldots \ldots \ldots \ldots \ldots \ldots \ldots \ldots \ldots \ldots \ldots \ldots$

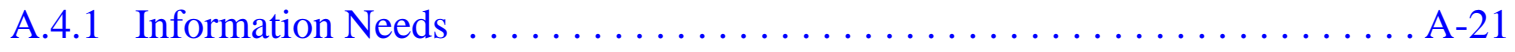

A.4.2 Sources of Information ..................................

A.4.2.1 Sample Locations ........................... A-22

A.4.2.2 Analytical Methods $\ldots \ldots \ldots \ldots \ldots \ldots \ldots \ldots \ldots \ldots \ldots \ldots \ldots \ldots \ldots \ldots$

A.5.0 Step 4 - Define the Boundaries of the Study. . . . . . . . . . . . . . . . A-24

A.5.1 Target Populations of Interest. . . . . . . . . . . . . . . . . . . A-24

A.5.2 Spatial Boundaries . . . . . . . . . . . . . . . . . . . . . . . . . .

A.5.3 Practical Constraints .................................. A-24

A.5.4 Define the Sampling Units . . . . . . . . . . . . . . . . . . . . A 25

A.6.0 Step 5 - Develop the Analytic Approach . . . . . . . . . . . . . . . . . . . . A-26

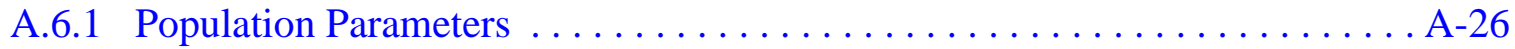

A.6.1.1 Judgmental Sampling Design..................... A-26

A.6.1.2 Probabilistic Sampling Design .................... A-26

A.6.2 Action Levels . ................................ A-27

A.6.2.1 Chemical PALs............................ A-28

A.6.2.2 Radionuclide PALs........................ A-29

A.6.3 Decision Rules . ................................ A-29

A.7.0 Step 6 - Specify Performance or Acceptance Criteria .................. A-31

A.7.1 Decision Hypotheses. . . . . . . . . . . . . . . . . . . . . . . . . . A-31

A.7.2 False Negative Decision Error $\ldots \ldots \ldots \ldots \ldots \ldots \ldots \ldots \ldots \ldots \ldots$ A-31

A.7.2.1 False Negative Decision Error for Judgmental Sampling ........ A A-32

A.7.2.2 False Negative Decision Error for Probabilistic Sampling ........ A-33

A.7.3 False Positive Decision Error . . . . . . . . . . . . . . . . . . . A-34

A.8.0 Step 7 - Develop the Plan for Obtaining Data $\ldots \ldots \ldots \ldots \ldots \ldots \ldots \ldots$ A-35

A.8.1 Internal Dose Sampling for Test Releases . . . . . . . . . . . . . . . . A-35

A.8.1.1 Judgmental Sample and Sample Plot Locations.............. A-35

A.8.1.2 Test Release Sampling ........................ A-37

A.8.1.3 Determination of Buried Contamination . . . . . . . . . . . . . . . A-42

A.8.2 External Dose Sampling for Test Releases . . . . . . . . . . . . . . . A-42

A.8.3 Evaluation of TED for Test Releases . . . . . . . . . . . . . . . . . A-44

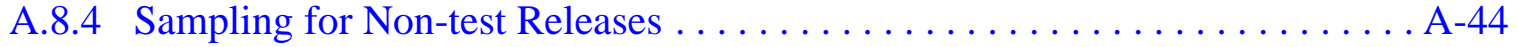

A.8.4.1 Decision I ................................. A 


\section{Table of Contents (Continued)}

A.8.4.1.1 GMX $\ldots \ldots \ldots \ldots \ldots \ldots \ldots \ldots \ldots \ldots \ldots \ldots \ldots . . .46$

A.8.4.1.2 Hamilton .......................... A-48

A.8.4.1.3 $306 \mathrm{GZ}$ and $307 \mathrm{GZ} \ldots \ldots \ldots \ldots \ldots \ldots \ldots$. A-48

A.8.4.1.4 Other Potential Releases ..................... A-51

A.8.4.2 Decision II . . . . . ........................ A-51

A.8.5 Establishment of Final Corrective Action Boundary ............... A-53

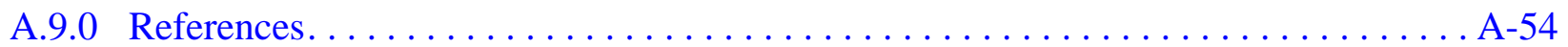

\section{Appendix B - Project Organization}

B.1.0 Project Organization .....................................

Appendix C - Nevada Division of Environmental Protection Comment Responses 


\section{List of Figures}

Number

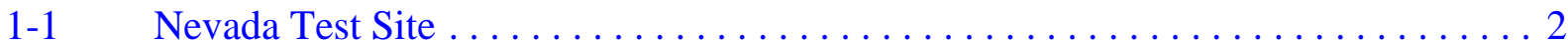

1-2 CAU 106, CAS Location Map .............................. 3

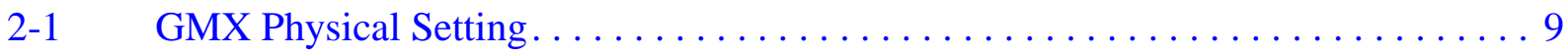

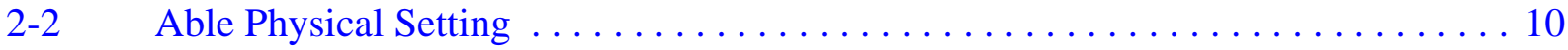

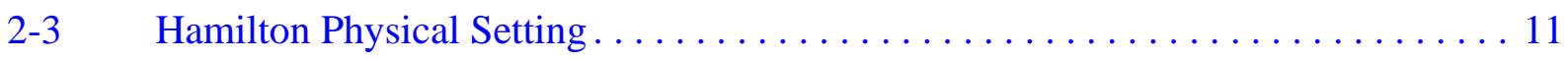

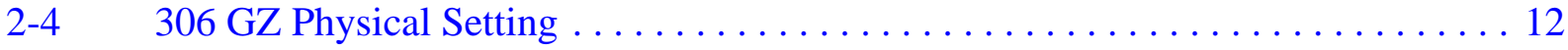

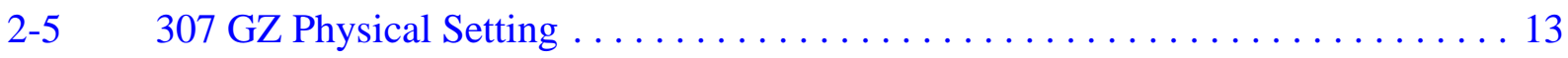

2-6 1999 Aerial Photograph of GMX Site.......................... 18

2-7 Photograph of Able Detonation on April 1, $1952 \ldots \ldots \ldots \ldots \ldots \ldots$

2-8 Americium-241 Isopleths and RIDP In Situ Measurement Locations at GMX ........................... 24

2-9 1994 Aerial Radiological Survey Results and RIDP In Situ Measurement Locations at Able . . . . . . . . . . . . . . . . . . . 29

2-10 1994 Aerial Radiological Survey Americium-241 Results and RIDP In Situ Measurement Locations at Hamilton. . . . . . . . . . . . . . . . 31

3-1 Conceptual Pathways to Receptors .......................... 34

3-2 Conceptual Site Model for GMX, 306 GZ, and 307 GZ (top)

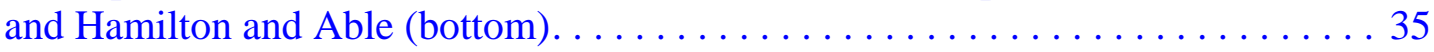

3-3 Risk-Based Corrective Action Decision Process $\ldots \ldots \ldots \ldots \ldots \ldots \ldots . \ldots 4$

A.2-1 Conceptual Pathways to Receptors ........................ A-7

A.2-2 Conceptual Site Model $\ldots \ldots \ldots \ldots \ldots \ldots \ldots \ldots \ldots \ldots \ldots \ldots \ldots$ A-8 


\section{List of Figures (Continued)}

Number

Title

Page

A.8-1 Example Decision I Sample Location at Able

A.8-2 Example Decision I and Decision II Sample Plot Locations at Hamilton

A-38

A.8-3 Example Decision I and Decision II Sample Plot Locations at GMX

A.8-4 Example Probabilistic Sampling Scheme at a Sample Plot. .

A-40

A.8-5 Judgmental Sampling at Drainages . . . . . . . . . . . . A-47

A.8-6 Hamilton Debris Pile . . . . . . . . . . . . . . . . . . . . A-49

A.8-7 Example Probabilistic Sampling Scheme for Surface Releases at $306 \mathrm{GZ}$ and $307 \mathrm{GZ}$.

A.8-8 Example Probabilistic Sampling Scheme for URMAs at $306 \mathrm{GZ}$ and $307 \mathrm{GZ}$ 


\section{List of Tables}

Number

Title

Page

2-1 Rainfall and PET Information for Frenchman Flat. . . . . . . . . . . . 14

2-2 RIDP Surface Soil Inventory for GMX $\ldots \ldots \ldots \ldots \ldots \ldots \ldots \ldots \ldots \ldots \ldots \ldots \ldots$

3-1 Analytical Program................................... 40

3-2 COPCs Reported by Analytical Methods......................... 41

3-3 Analytical Requirements for Radionuclides for CAU $106 \ldots \ldots \ldots \ldots \ldots 47$

3-4 Analytical Requirements for Chemicals for CAU $106 \ldots \ldots \ldots \ldots \ldots \ldots . \ldots 9$

6-1 Laboratory and Analytical Performance Criteria for CAU 106 DQIs . . . . . . . . 63

A.2-1 Conceptual Site Model Description of Elements for

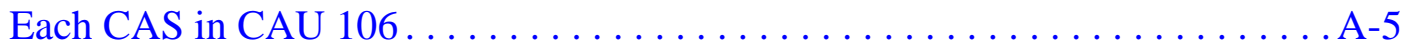

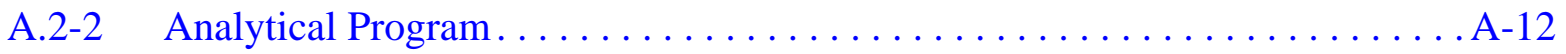

A.2-3 Land-Use and Exposure Scenarios . . . . . . . . . . . . . . . . . A-17

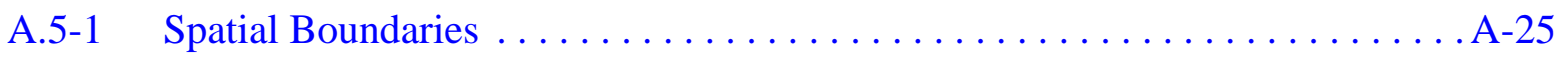




\section{List of Acronyms and Abbreviations}

${ }^{3} \mathrm{H}$

Ac

Am

ASTM

bgs

Ca

CA

CAA

CADD

CAI

CAIP

CAS

CAU

CERCLA

CFR

$\mathrm{Ci}$

$\mathrm{cm}$

Co

COC

COPC

cps

Cs

CSM

DCG

DoD
Tritium

Actinium

Americium

American Society for Testing and Materials

Below ground surface

Calcium

Contamination area

Corrective action alternative

Corrective action decision document

Corrective action investigation

Corrective action investigation plan

Corrective action site

Corrective action unit

Comprehensive Environmental Response, Compensation, and Liability Act

Code of Federal Regulations

Curie

Centimeter

Cobalt

Contaminant of concern

Contaminant of potential concern

Counts per second

Cesium

Conceptual site model

Derived Concentration Guideline

U.S. Department of Defense 


\section{List of Acronyms and Abbreviations (Continued)}

DOE U.S. Department of Energy

DOT U.S. Department of Transportation

DQI Data quality indicator

DQO Data quality objective

DRI Desert Research Institute

DU Depleted uranium

EPA U.S. Environmental Protection Agency

$\mathrm{Eu} \quad$ Europium

FAL Final action level

FFACO Federal Facility Agreement and Consent Order

FIDLER Field instrument for the detection of low-energy radiation

FSL Field-screening level

FSR Field-screening result

ft Foot

$\mathrm{ft}^{2} \quad$ Square foot

GPS Global Positioning System

GZ Ground zero

HCA High contamination area

HWAA Hazardous waste accumulation area

IDW Investigation-derived waste

in. Inch

K Potassium

$\mathrm{Kr} \quad$ Krypton

kt Kiloton

LCS Laboratory control sample

m Meter 


\section{List of Acronyms and Abbreviations (Continued)}

\begin{tabular}{|c|c|}
\hline $\mathrm{m}^{2}$ & Square meter \\
\hline MDC & Minimum detectable concentration \\
\hline $\mathrm{mi}$ & Mile \\
\hline $\mathrm{mi}^{2}$ & Square mile \\
\hline mrem/IA-yr & Millirem per Industrial Access year \\
\hline $\mathrm{mrem} / \mathrm{yr}$ & Millirem per year \\
\hline MS & Matrix spike \\
\hline MSD & Matrix spike duplicate \\
\hline NAC & Nevada Administrative Code \\
\hline NAD & North American Datum \\
\hline NAEG & Nevada Applied Ecology Group \\
\hline $\mathrm{Nb}$ & Niobium \\
\hline ND & Normalized difference \\
\hline NDEP & Nevada Division of Environmental Protection \\
\hline NEPA & National Environmental Policy Act \\
\hline NNES & Navarro Nevada Environmental Services, LLC \\
\hline NNSA/NSO & $\begin{array}{l}\text { U.S. Department of Energy, National Nuclear Security Administration } \\
\text { Nevada Site Office }\end{array}$ \\
\hline $\mathrm{Np}$ & Neptunium \\
\hline NTS & Nevada Test Site \\
\hline NTSWAC & Nevada Test Site Waste Acceptance Criteria \\
\hline PAL & Preliminary action level \\
\hline $\mathrm{Pb}$ & Lead \\
\hline PCB & Polychlorinated biphenyl \\
\hline $\mathrm{pCi} / \mathrm{g}$ & Picocuries per gram \\
\hline PET & Potential evapotranspiration \\
\hline
\end{tabular}




\section{List of Acronyms and Abbreviations (Continued)}

\begin{tabular}{|c|c|}
\hline PPE & Personal protective equipment \\
\hline PSM & Potential source material \\
\hline $\mathrm{Pu}$ & Plutonium \\
\hline PuCS & Plutonium-contaminated soils \\
\hline QA & Quality assurance \\
\hline QAPP & Quality Assurance Project Plan \\
\hline $\mathrm{QC}$ & Quality control \\
\hline RBCA & Risk-based corrective action \\
\hline RBSL & Risk-based screening level \\
\hline RCL & Remote Sensing Laboratory \\
\hline RCRA & Resource Conservation and Recovery Act \\
\hline REOP & Real Estate/Operations Permit \\
\hline RESRAD & Residual Radioactive \\
\hline RIDP & Radionuclide and Distribution Program \\
\hline $\mathrm{RI} / \mathrm{FS}$ & Remedial Investigation and Feasibility Study \\
\hline RL & Reporting limit \\
\hline RMA & Radioactive material area \\
\hline RNMS & Radionuclide Migration Study \\
\hline RPD & Relative percent difference \\
\hline RWMS & Radioactive waste management site \\
\hline $\mathrm{Sm}$ & Samarium \\
\hline $\mathrm{Sr}$ & Strontium \\
\hline SSTL & Site-specific target level \\
\hline SVOC & Semivolatile organic compound \\
\hline TED & Total effective dose \\
\hline Th & Thorium \\
\hline
\end{tabular}




\section{List of Acronyms and Abbreviations (Continued)}

$\mathrm{Tl}$

TLD

$\mathrm{TPH}$

$\mathrm{U}$

UCL

URMA

UTM

VOC

VSP

$\mathrm{yd}^{2}$

$\mu \mathrm{R} / \mathrm{hr}$

$\% R$
Thallium

Thermoluminescent dosimeter

Total petroleum hydrocarbons

Uranium

Upper confidence limit

Underground radioactive material area

Universal Transverse Mercator

Volatile organic compound

Visual Sample Plan

Square yard

Microroentgens per hour

Percent recovery 


\section{Executive Summary}

Corrective Action Unit (CAU) 106 is located in Area 5 of the Nevada Test Site, which is approximately 65 miles northwest of Las Vegas, Nevada. Corrective Action Unit 106 comprises the five corrective action sites (CASs) listed below:

- 05-23-02, GMX Alpha Contaminated Area

- 05-23-05, Atmospheric Test Site - Able

- 05-45-01, Atmospheric Test Site - Hamilton

- 05-45-04, 306 GZ Rad Contaminated Area

- 05-45-05, 307 GZ Rad Contaminated Area

These sites are being investigated because existing information on the nature and extent of potential contamination is insufficient to evaluate and recommend corrective action alternatives (CAAs). Additional information will be obtained by conducting a corrective action investigation before evaluating CAAs and selecting the appropriate corrective action for each CAS. The results of the field investigation will support a defensible evaluation of viable CAAs that will be presented in the Corrective Action Decision Document.

The sites will be investigated based on the data quality objectives (DQOs) developed on January 19, 2010, by representatives of the Nevada Division of Environmental Protection and the U.S. Department of Energy (DOE), National Nuclear Security Administration Nevada Site Office. The DQO process was used to identify and define the type, amount, and quality of data needed to develop and evaluate appropriate corrective actions for CAU 106.

The presence and nature of contamination at CAU 106 will be evaluated based on information collected from a field investigation. The CAU includes land areas impacted by the release of radionuclides from a weapons-effect tower test (CAS 05-45-01), a weapons-related airdrop test (CAS 05-23-05), “equation of state” experiments (CAS 05-23-02), and unknown support activities at two sites (CAS 05-45-04 and CAS 05-45-05).

Surface-deposited radiological contamination will be evaluated based on a comparison of the total effective dose (TED) at sample plot locations to the dose-based final action level. The TED will be calculated as the total of separate estimates of internal and external doses. Results from the analysis of soil samples collected from sample plots will be used to calculate internal radiological dose. 
Thermoluminescent dosimeters placed at the center of each sample plot will be used to measure external radiological dose. The presence and nature of contamination from other types of releases (such as migration and excavation as well as any potential releases discovered during the investigation) will be evaluated using soil samples collected from the locations most likely containing contamination, if present.

Appendix A provides a detailed discussion of the DQO methodology and the DQOs specific to each CAS.

The scope of the corrective action investigation for CAU 106 includes the following activities:

- Conduct radiological surveys.

- Collect and submit environmental samples for laboratory analysis to determine internal dose rates and the presence of contaminants of concern.

- If contaminants of concern are present, collect additional samples to define the extent of the contamination and determine the area where TED at the site exceeds final action levels (i.e., corrective action boundary).

- Collect samples of investigation-derived waste, as needed, for waste management purposes.

This Corrective Action Investigation Plan has been developed in accordance with the Federal Facility Agreement and Consent Order that was agreed to by the State of Nevada;

DOE, Environmental Management; U.S. Department of Defense; and DOE, Legacy Management. Under the Federal Facility Agreement and Consent Order, this Corrective Action Investigation Plan will be submitted to the Nevada Division of Environmental Protection for approval. Fieldwork will be conducted following approval of the plan. 


\subsection{Introduction}

This Corrective Action Investigation Plan (CAIP) contains project-specific information, including facility descriptions, environmental sample collection objectives, and criteria for conducting site investigation activities at Corrective Action Unit (CAU) 106: Areas 5, 11 Frenchman Flat Atmospheric Sites, Nevada Test Site (NTS), Nevada. It should be noted that this CAU originally included corrective action sites (CASs) located in Area 11 that have since been moved into another CAU.

This CAIP has been developed in accordance with the Federal Facility Agreement and Consent Order (FFACO) that was agreed to by the State of Nevada; U.S. Department of Energy (DOE), Environmental Management; U.S. Department of Defense; and DOE, Legacy Management (FFACO, 1996; as amended March 2010).

Corrective Action Unit 106 is located in Area 5 of the NTS, which is approximately 65 miles (mi) northwest of Las Vegas, Nevada (Figure 1-1). Corrective Action Unit 106 comprises the five CASs shown on Figure 1-2 and listed below:

- 05-23-02, GMX Alpha Contaminated Area

- 05-23-05, Atmospheric Test Site - Able

- 05-45-01, Atmospheric Test Site - Hamilton

- 05-45-04, 306 GZ Rad Contaminated Area

- 05-45-05, 307 GZ Rad Contaminated Area

The Corrective Action Investigation (CAI) will include field inspections, radiological surveys, geophysical surveys, sampling of environmental media, analysis of samples, and assessment of investigation results. Data will be obtained to support corrective action alternative (CAA) evaluations and waste management decisions.

\subsection{Purpose}

The CASs in CAU 106 are being investigated because hazardous and/or radioactive contaminants may be present in concentrations that exceed risk-based corrective action (RBCA) levels. Existing information on the nature and extent of potential contamination is insufficient to evaluate and 


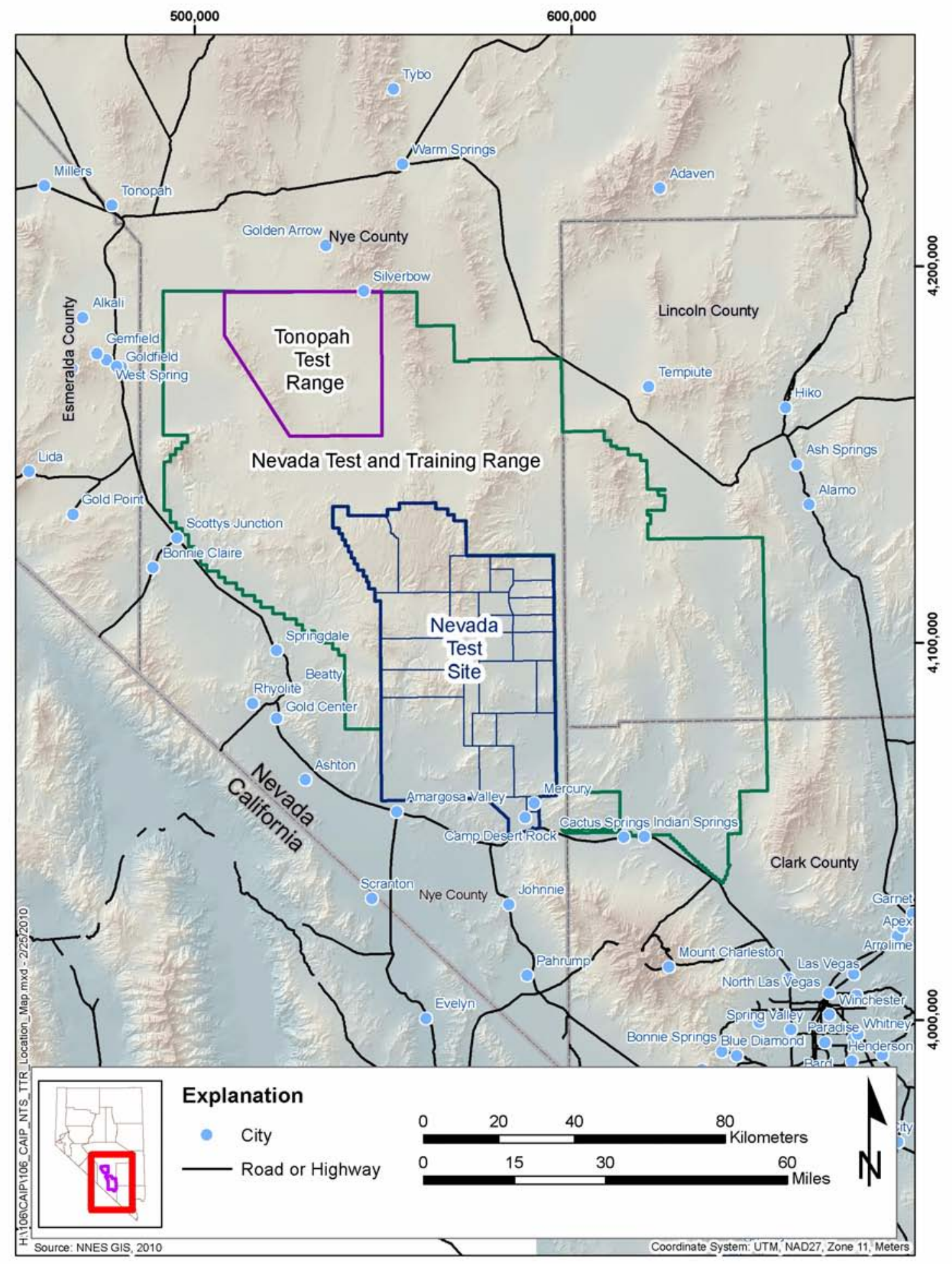

Figure 1-1

Nevada Test Site 


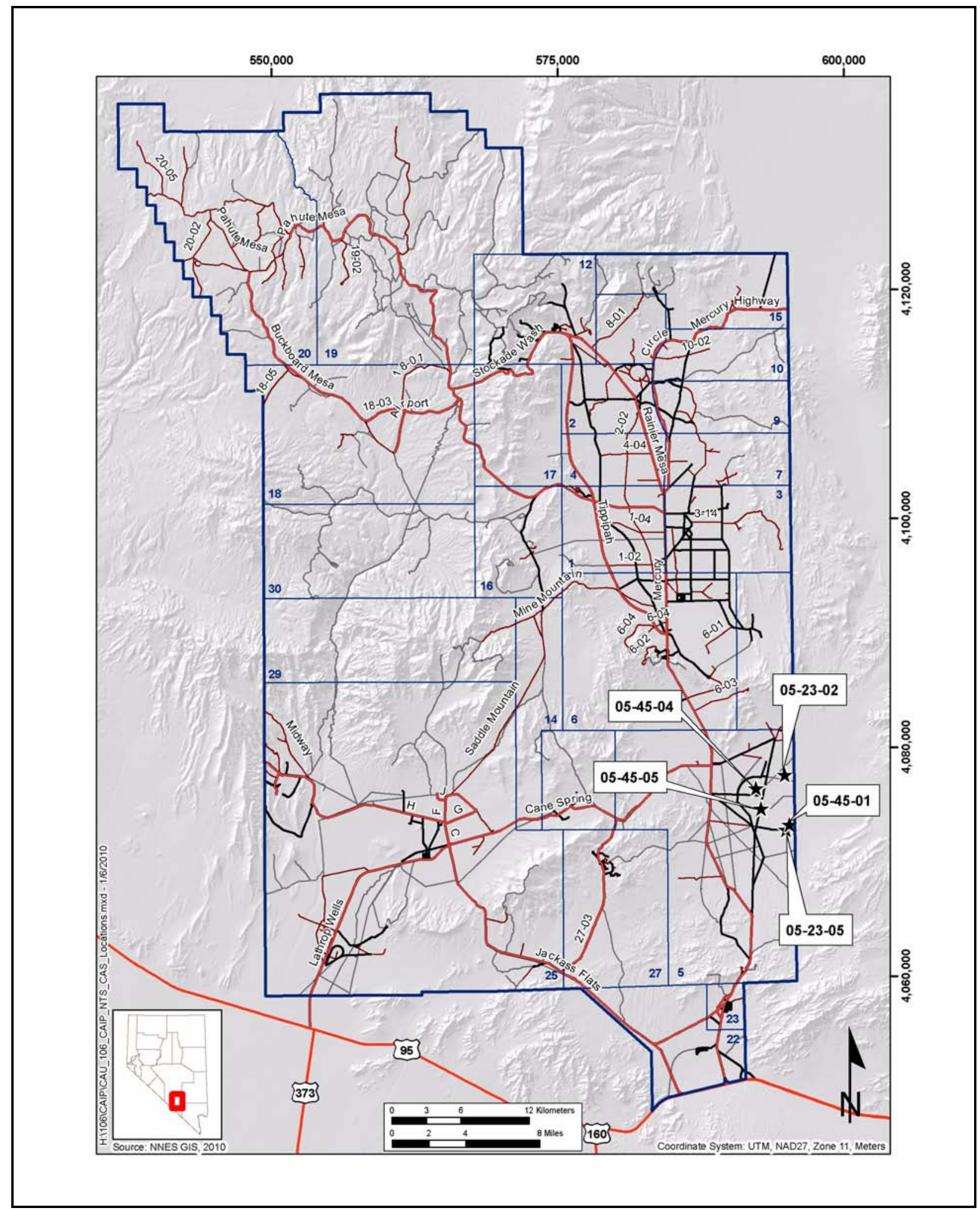

Figure 1-2

CAU 106, CAS Location Map 
recommend CAAs for the CASs. Additional information will be generated by conducting a CAI before evaluating and selecting CAAs.

\subsubsection{CAU 106 History and Description}

Corrective Action Unit 106 consists of five inactive CASs located in Area 5 on Frenchman Flat that will be herein referred to by their associated test and/or common names (GMX, Able, Hamilton, $306 \mathrm{GZ}$, and $307 \mathrm{GZ}$ ). These sites were used to support nuclear testing and other experiments conducted in the Frenchman Flat area, primarily during the 1950s. The CAU includes land areas impacted by the release of radionuclides from a weapons-effect tower test (Hamilton), a weapons-related airdrop test (Able), "equation of state" experiments (GMX), and unknown support activities at two sites (306 GZ and $307 \mathrm{GZ}$ ). Hazardous materials may have also been released at 306 GZ and 307 GZ. Operational histories for each CAU 106 CAS are detailed in Section 2.2.

\subsubsection{Data Quality Objective Summary}

The sites will be investigated based on data quality objectives (DQOs) developed by representatives of the Nevada Division of Environmental Protection (NDEP) and the DOE, National Nuclear Security Administration Nevada Site Office (NNSA/NSO). The DQOs are used to identify and define the type, amount, and quality of data needed to develop and evaluate appropriate corrective actions for CAU 106. This CAIP describes the investigative approach developed to collect the necessary data identified in the DQO process. Discussion of the DQO methodology and the DQOs specific to each CAS are presented in Appendix A. A summary of the DQO process is provided below.

The DQO problem statement for CAU 106 is: "Existing information on the nature and extent of potential contamination is insufficient to evaluate and recommend CAAs for the CASs in CAU 106." To address this problem, resolution of the following decision statements is required:

- Decision I: "Is any contaminant of concern (COC) associated with the CAS present in environmental media?” For judgmental sampling decisions, any contaminant of potential concern (COPC) associated with a CAS that is present at concentrations exceeding its corresponding final action level (FAL) will be defined as a COC. For probabilistic sampling decisions, any COPC for which the 95 percent upper confidence limit (UCL) of the mean exceeds its corresponding FAL will be defined as a COC. A COC may also be defined as 
a contaminant that, in combination with other like contaminants, is determined to jointly pose an unacceptable risk based on a multiple constituent analysis (NNSA/NSO, 2006).

- Decision II: “Is sufficient information available to evaluate potential CAAs?” Sufficient information is defined to include:

- The lateral and vertical extent of COC contamination

- The information needed to predict potential remediation waste types and volumes

- Any other information needed to evaluate the feasibility of remediation alternatives

A corrective action will be determined for any site containing a COC. The evaluation of the need for corrective action will include the potential for wastes that are present at the site to cause the future contamination of site environmental media if the wastes were to be released (see Section 3.4).

The informational inputs and data needs to resolve the problem statement and the decision statements were generated as part of the DQO process for this CAU and are documented in Appendix A. The information necessary to resolve the DQO decisions will be generated for each CAU 106 CAS by collecting and analyzing samples generated during a field investigation. The presence of a COC will be determined by collecting and analyzing samples following these two criteria:

- To make a judgmental sampling decision, samples must be collected in areas most likely to contain a COC.

- To make a probabilistic sampling decision, samples must be collected from random locations that represent contamination within the sampling unit (see Section A.5.4).

The DQOs for CAU 106 defined the following two release scenarios to appropriately address the different types of releases that may be present at the CASs:

- The test release is defined as the initial atmospheric deposition of radiological contaminants from nuclear tests. The initial test release is generally observed as an annular geometric pattern of contamination from soil particle activation and initial fallout that generally decreases in intensity with distance from the source.

- A non-test release is defined as the subsequent movement of radiological contaminants from test releases (either migration or mechanical displacement) and other potential releases of contaminants from site operations (e.g., spills and abandoned materials). 


\subsection{Scope}

To generate information needed to resolve the decision statements identified in the DQO process, the scope of the CAI for CAU 106 includes the following activities:

- Perform radiological surveys and field screening.

- Move surface debris and/or materials, as needed, to facilitate sampling and surveys.

- Measure in situ external dose rates using thermoluminescent dosimeters (TLDs) or other dose-measurement devices.

- Collect and submit environmental samples for laboratory analysis to determine internal dose rates.

- Collect samples of source material, if present, to determine the potential for a release to result in contamination exceeding FALs.

- Collect samples of potential remediation wastes, if present.

- Collect quality control (QC) samples.

- Collect and submit environmental samples for laboratory analysis to determine the presence and, if present, the nature and extent of COCs.

Contamination of environmental media originating from activities not identified in the conceptual site model (CSM) of any CAS will not be considered as part of this CAU unless the CSM and the DQOs are modified to include the release. If not included in the CSM, contamination originating from these sources will not be considered for sample location selection and/or will not be considered COCs. If such contamination is present, the contamination will be identified as part of another CAS (either new or existing).

\subsection{Corrective Action Investigation Plan Contents}

Section 1.0 presents the purpose and scope of this CAIP, while Section 2.0 provides background information about CAU 106. Objectives of the investigation, including the CSM, are presented in Section 3.0. Field investigation and sampling activities are discussed in Section 4.0, and waste management issues for this project are discussed in Section 5.0. General field and laboratory quality assurance (QA) (including collection of QA samples) is presented in Section 6.0 and in the Industrial 
Sites Quality Assurance Project Plan (QAPP) (NNSA/NV, 2002a). The project schedule and records availability are discussed in Section 7.0. Section 8.0 provides a list of references.

Appendix A provides a detailed discussion of the DQO methodology and the DQOs specific to each CAS, while Appendix B contains information on the project organization. Appendix C contains NDEP comments on the draft version of this document. 


\subsection{Facility Description}

Corrective Action Unit 106 comprises five CASs that were grouped together based on the geographical location of the sites, technical similarities, and the agency responsible for closure. All CASs are located in Area 5 on Frenchman Flat (see Figures 2-1 through 2-5). The Hamilton (CAS 05-45-01) and Able (CAS 05-23-05) sites are located on the Frenchman Lake dry lake bed and the remaining GMX (CAS 05-23-02), 306 GZ (CAS 05-45-04), and 307 GZ (CAS 05-45-05) sites are located nearby to the north.

\section{$2.1 \quad$ Physical Setting}

This section describes the general physical settings of Frenchman Flat in Area 5, including general background information pertaining to topography, geology, hydrogeology, and climatology. The following subsections are CAS-specific current conditions that pertain to the investigation and CSMs.

All five CASs in CAU 106 are located within the Frenchman Flat Hydrographic Area, which is a 110-square-mile $\left(\mathrm{mi}^{2}\right)$ closed basin surrounded by low-lying mountains that separate this area from the Mercury Valley Hydrographic Area to the south and from the Yucca Flat Hydrographic Area to the north (USGS, 1996). Erosion of the surrounding mountains has resulted in the accumulation of more than 1,000 feet (ft) of alluvial deposits in some areas of Frenchman Flat (DOE/NV, 1996). The 306 GZ, 307 GZ, and GMX sites are located on the alluvial deposits and unconsolidated gravels of Frenchman Flat, and the Hamilton and Able sites are located on the ephemeral Frenchman Lake (dry lake bed) that measures approximately $4.5 \mathrm{mi}^{2}$ (DRI, 2000). During the dry season, the ground surface consists of a rough hard-packed silt with a well-defined mud-crack pattern, which is a classic dessication structure of the dry lake environment. During the rainy season, the lake bed may fill with shallow water, especially during wet years.

The principal drainage into the dry lake bed is Nye Canyon from the north, with lesser drainages from the west, including Cane Spring Wash and Barren Wash. Elevations range from 3,080 ft around the lake bed to 4,000 ft around the surrounding hills and mountains.

Groundwater flow beneath the Frenchman Flat area occurs primarily within the carbonate-rock aquifer that flows generally from the northeast to southwest. Within the overlying alluvial and 


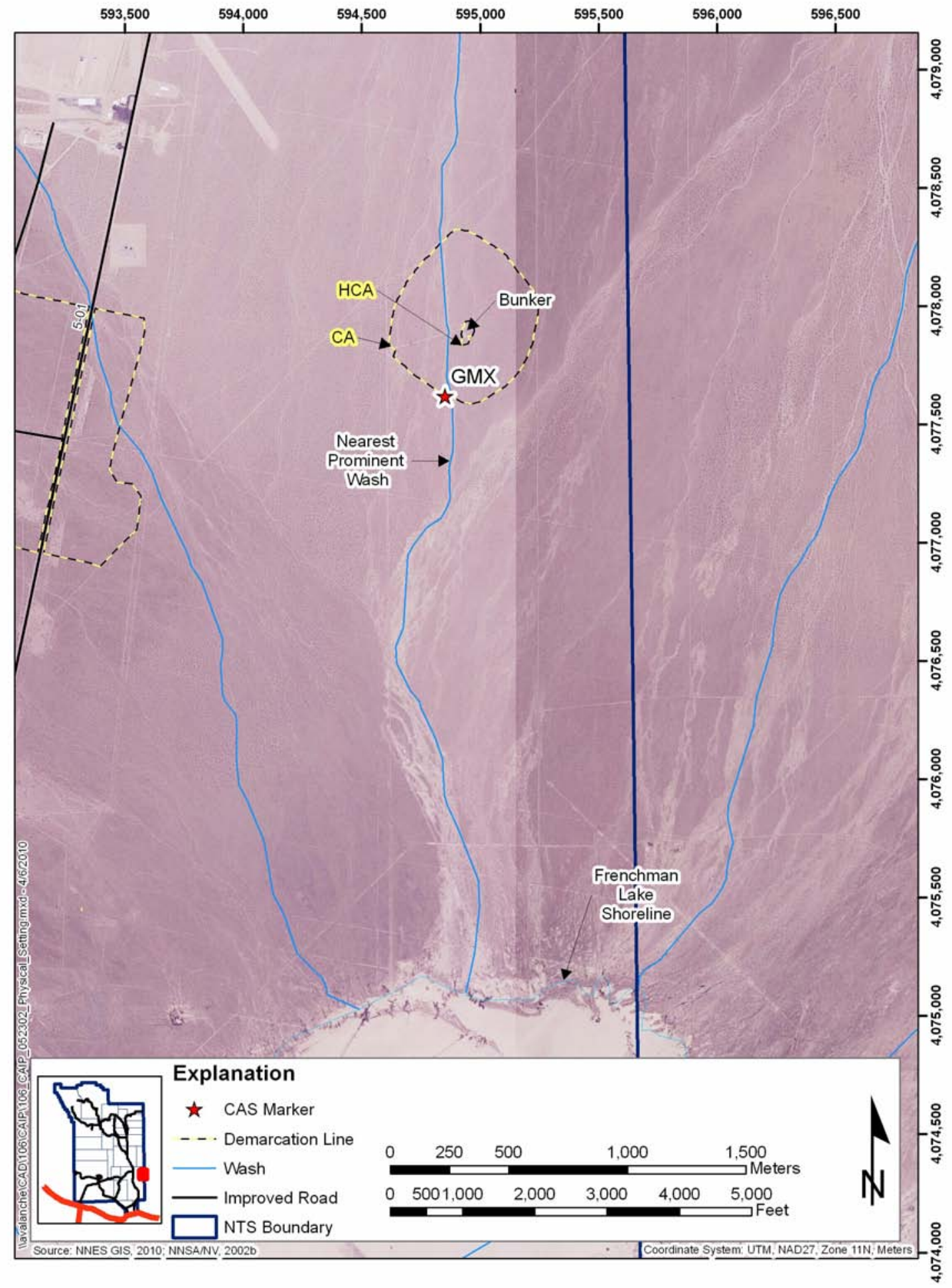

Figure 2-1

GMX Physical Setting 


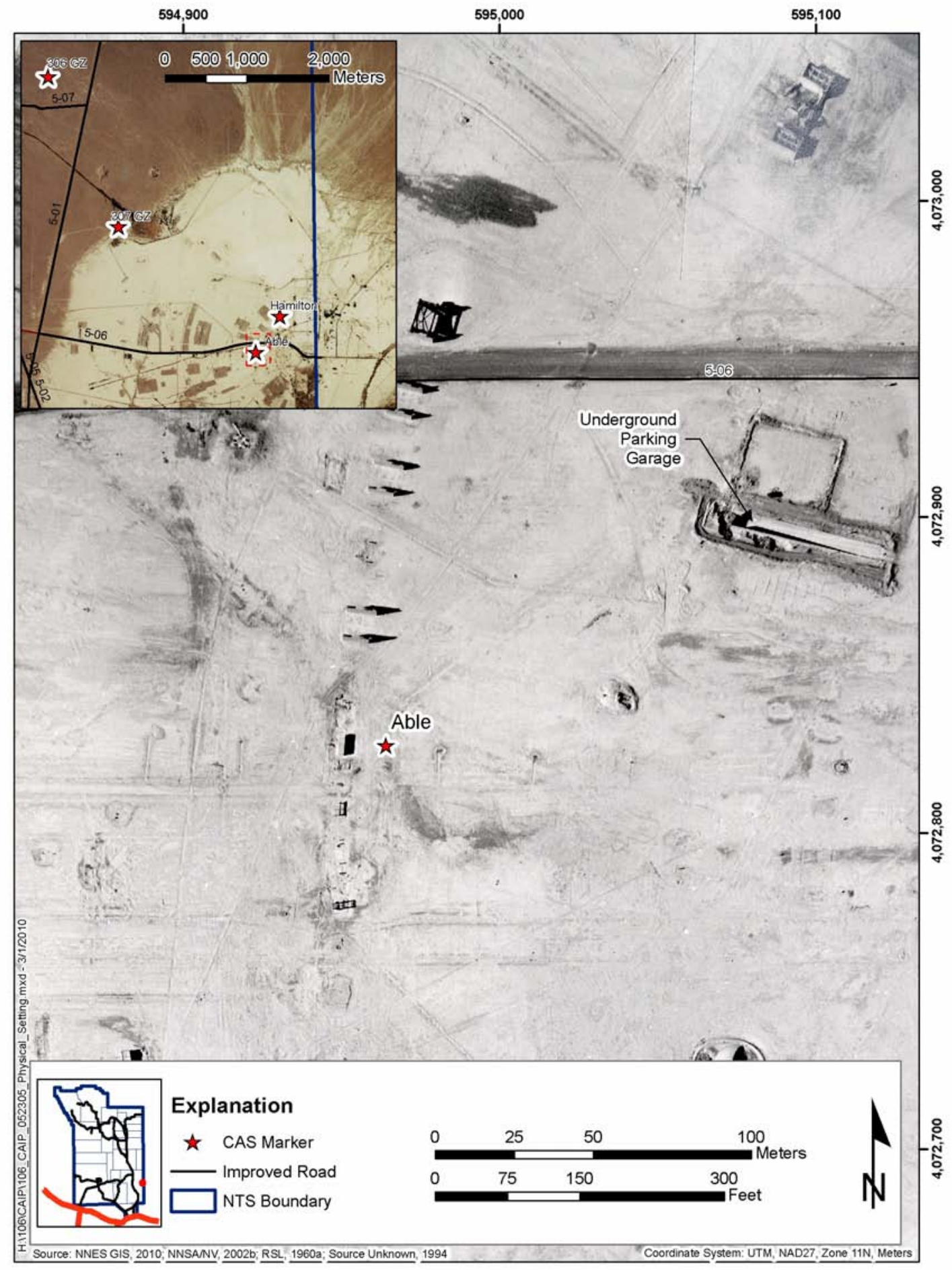

Figure 2-2

Able Physical Setting 


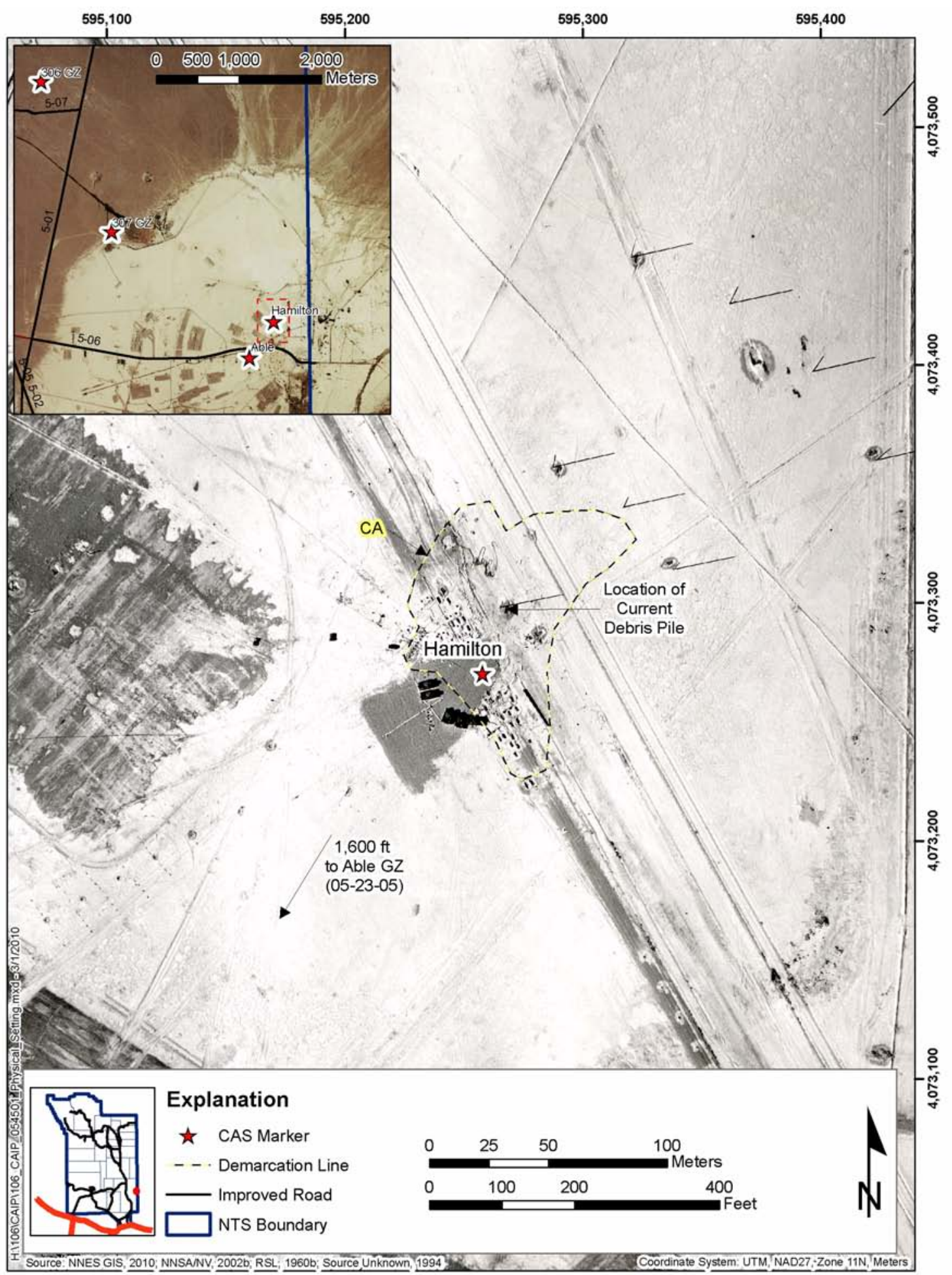

Figure 2-3

Hamilton Physical Setting 


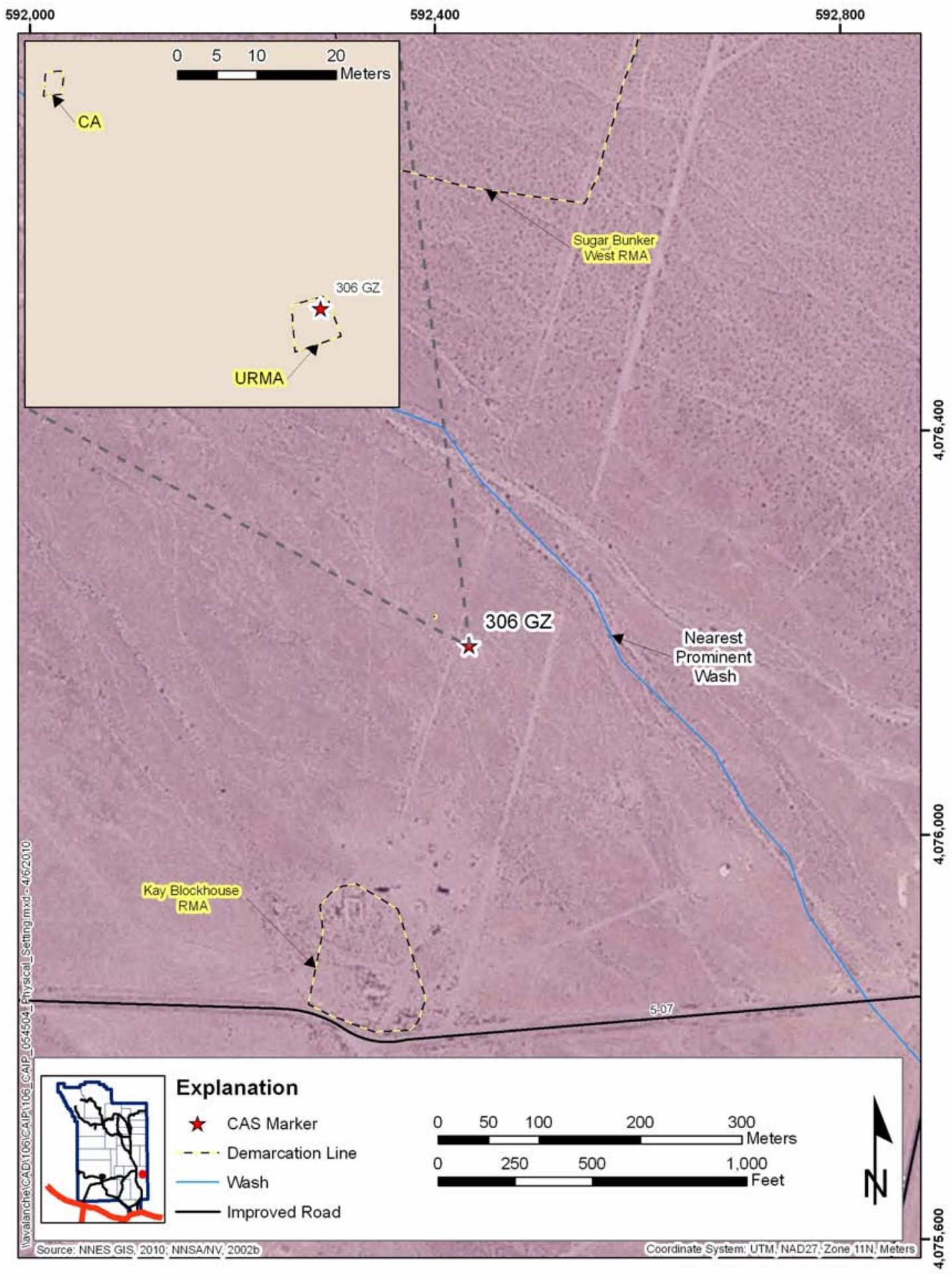

Figure 2-4

306 GZ Physical Setting 


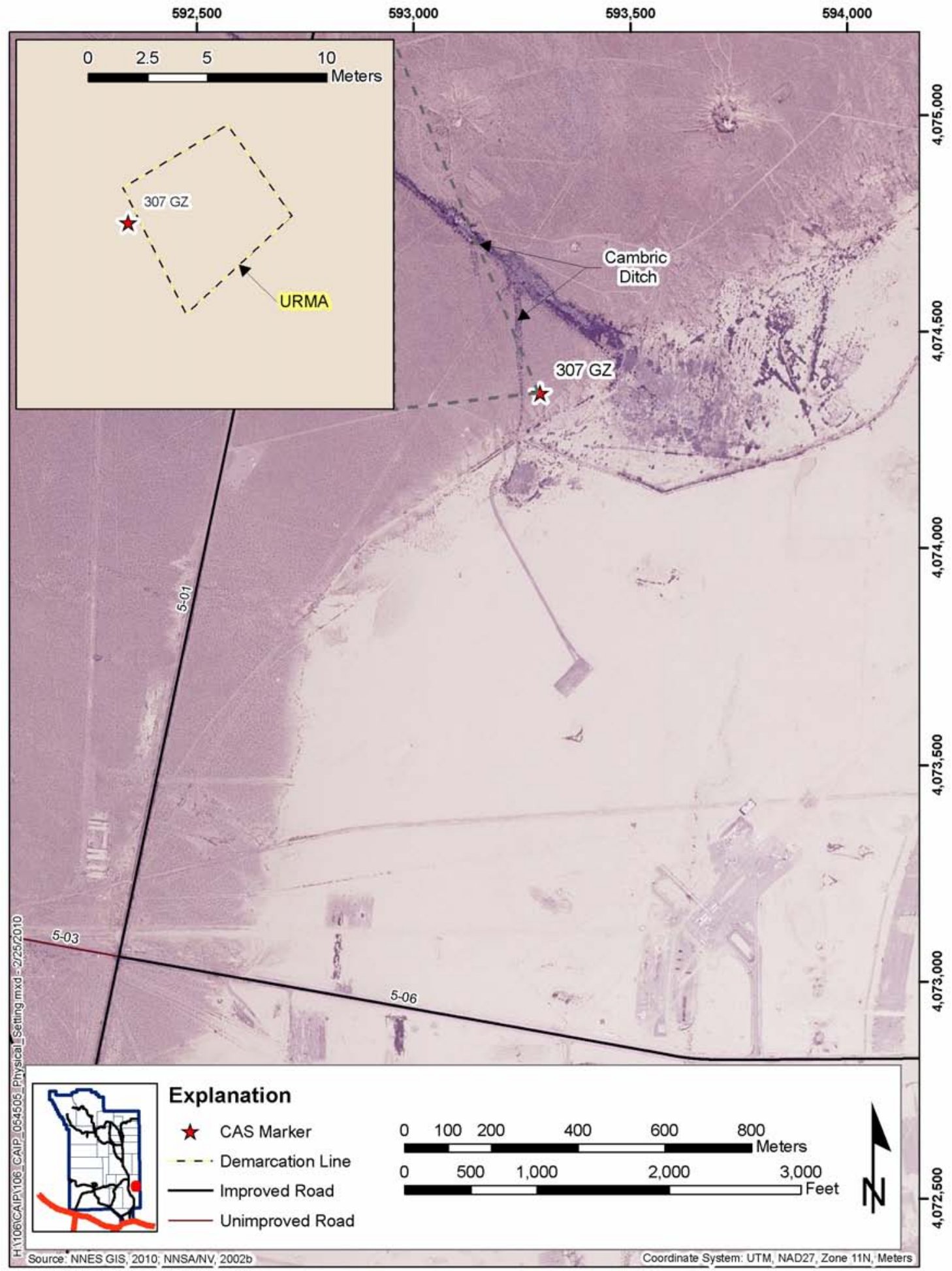

Figure 2-5

307 GZ Physical Setting 
volcanic aquifers, lateral groundwater flow occurs from the margins to the center of the basin, and downward into the carbonate-rock aquifer. The hydraulic gradient in most areas of the alluvial aquifer in Frenchman Flat is relatively flat (less than $1 \mathrm{ft}$ per mile) except near active water wells and/or test wells (USGS, 2003). The nearest wells to the CASs in CAU 106 are UE-5 PW-1, UE-5n, and ER-5-4. The most recent recorded depth to the water table ranges between approximately $700 \mathrm{ft}$ and $775 \mathrm{ft}$ below ground surface (bgs) at these wells (USGS and DOE, 2009).

The average annual precipitation at station Well 5 B, which is located near Frenchman Flat, is 4.51 inches (in.) (ARL/SORD, 2009). Additional rainfall and potential evapotranspiration (PET) information is presented in Table 2-1 (Yucel, 2009).

Table 2-1

Rainfall and PET Information for Frenchman Flat

\begin{tabular}{|c|c|c|}
\hline & $\begin{array}{l}\text { PET } \\
\text { (in.) }\end{array}$ & $\begin{array}{c}\text { Frenchman Flat } \\
\text { Precipitation } \\
\text { (in.) }\end{array}$ \\
\hline \hline Minimum & 62.3 & 1.14 \\
\hline Maximum & 64.8 & 9.67 \\
\hline Mean & 63.5 & 4.51 \\
\hline
\end{tabular}

\subsubsection{GMX}

The GMX site is located on the gentle slopes of Frenchman Flat approximately $1.5 \mathrm{mi}$ north of Frenchman Lake and $0.8 \mathrm{mi}$ east of 5-01 Road (Figure 2-1). This release site is identified by a large oval-shaped posted contamination area (CA) that is fenced with an attached "GMX" sign. The CA encloses an approximately 80-acre area, and an inner high contamination area (HCA) encloses an approximately 1-acre area. An earth-covered bunker with an open entry is located within the fenced HCA. Miscellaneous debris associated with testing activities is expected to be present at the site, such as scrap metal and wood. It is currently unknown whether debris or other materials have been abandoned in the bunker. The soil in this area consists of coarse alluvium and unconsolidated gravels. There are numerous small intermittent washes throughout the site that drain south to Frenchman Lake and one prominent wash located $185 \mathrm{ft}$ west of the HCA. 
The Able site is centrally located on Frenchman Lake (Figure 2-2), approximately $375 \mathrm{ft}$ south of 5-06 Road and $400 \mathrm{ft}$ southwest of the historic Underground Parking Garage associated with the Priscilla test. Ground zero for the Able test is currently marked by a t-post and metal tag with the markings “Able GZ.” There are no radiological or other postings associated with Able and no debris or vegetation present. The soil of the dry lake bed consists of hard-packed silt. There are many historic structures in the immediate area related to the Frenchman Flat Historic District (DRI, 2000); however, they do not impact the Able site.

\subsubsection{Hamilton}

The Hamilton site is centrally located on Frenchman Lake, approximately 1,000 ft north of 5-06 Road and 1,600 ft northeast of the Able site. The Hamilton test area is identified by a posted CA that measures approximately 7,000 square yards $\left(\mathrm{yd}^{2}\right)$ (Figure 2-3). Within the CA are the ground zero area and a large debris pile that consists of mounded soil, wood, concrete, and potentially other items. It is speculated that this pile may consist of the originally contaminated surface soils and materials that were subsequently moved into a debris pile. Because of the large number of instrumentation stations and foxholes that were used in support of the Hamilton test, there may be a significant amount of debris remaining at the site. The soil of the dry lake bed consists of hard-packed silt.

\subsection{4 $306 \mathrm{GZ}$}

The 306 GZ site is located on the gentle slopes of Frenchman Flat approximately 1.25 mi north of Frenchman Lake and 1,200 ft north of 5-07 Road just north of the Kay Blockhouse (CAU 204) (Figure 2-4). The site contains a 20-by-20 ft posted underground radioactive material area (URMA) that is bordered with partially burned wood planks. On the south side of the posted URMA are a group of partially buried cables that appear to extend in the shallow subsurface in the general direction of Kay Blockhouse. However, no association between the two sites has been identified. An adjacent 10-by-10-ft posted CA is located $130 \mathrm{ft}$ to the northwest. Surface debris present includes depleted uranium (DU) and previously melted metal fragments both inside and outside the posted URMA and CA. The soil in this area consists of coarse alluvium and unconsolidated gravels. The 
nearest prominent wash that drains south to Frenchman Lake is located approximately $500 \mathrm{ft}$ to the east.

\subsection{5 $307 \mathrm{GZ}$}

The 307 GZ site is located just off of the northwest shore of Frenchman Lake. The access road to the site is off the east side of 5-01 Road, $0.7 \mathrm{mi}$ past the intersection with 5-06 Road. (Figure 2-5). The site contains a 20-by-20-ft posted URMA located behind a Controlled Area posting. Metal and DU debris items are present. The site is also located $150 \mathrm{ft}$ east of an extension of Cambric Ditch that was excavated to support long-term pumping of Well RNM-2S in an effort to understand migration of radionuclides from the Cambric underground test as part of the Radionuclide Migration Study (RNMS).

\subsection{Operational History}

The following subsections provide a description of the use and history of each CAS in CAU 106 that may have resulted in releases of contaminants to the environment. The CAS-specific summaries are designed to describe the current definition of each CAS and document all significant, known activities.

\subsubsection{GMX}

This CAS consists of the potential releases to the environment from a series of 29 "equation of state" experiments conducted at the site between December 1954 and February 1956 (Malik, 1982). Two of the 29 tests are listed as type "U-238," indicating the potential presence of DU at the site. Of the remaining 27 tests, 24 are listed as type "Pu" and 3 are listed as type "non-active" (Malik, 1982). The experiments were conducted to measure the effects of plutonium (Pu) dispersal from the use of conventional explosives. According to a Remedial Investigation and Feasibility Study (RI/FS) Work Plan that included the GMX site (see Section 2.5.1), relatively small quantities of $\mathrm{Pu}$ were used, and the experiments were conducted on or very near one location resulting in $\mathrm{Pu}$ contamination over a 30-acre area (DOE/NV, 1992). Based on observations from an aerial photograph, the only disturbed areas of the site appear to be the access road leading to the bunker and the area within the HCA in and surrounding the bunker (Figure 2-6). The experiments were observed through a periscope by cameras in the bunker (Malik, 1982). Additional uses of the bunker are 
unknown. According to the RI/FS, decontamination of the test area began in 1956, consisting of shallow burial of Pu-contaminated clothing, scrap metals, and scrap wood near ground zero (DOE/NV, 1992). The specific burial location is not stated, and no additional references were provided for this information.

\subsubsection{Able}

This CAS consists of the potential releases to the environment from the Able atmospheric test conducted on April 1, 1952, on Frenchman Lake as part of Operation Tumbler-Snapper (DOE/NV, 2000). Able was a weapons-effect airdrop test (sponsored by Los Alamos National Laboratory and U.S. Department of Defense [DoD]) with the height of burst at $800 \mathrm{ft}$ and a yield of 1 kiloton (kt). The purpose of the Able test was to determine the effects of terrain on air-blast pressure and to check the validity of air-blast gauges used at the earlier tests of Operation Buster-Jangle (DRI, 2000). The test photograph shown in Figure 2-7 suggests that the fireball did not contact the ground. Therefore, trinity glass would not have formed, and a majority of the fission products and unburned fuel would have been carried away in the fission cloud by the wind. The photograph also indicates some ground disturbance due to the shock wave at the ground zero area.

\subsubsection{Hamilton}

This CAS consists of the potential releases to the environment from the Hamilton atmospheric test conducted on October 15, 1958, on Frenchman Lake as part of Operation Hardtack II. Hamilton was a weapons-related tower test (sponsored by Lawrence Livermore National Laboratory and DoD) that had a height of 15.2 meters (m) and a yield of 1.2 tons (DOE/NV, 2000). The main purpose of the Hamilton test was to evaluate the immediate lethality of the weapon and to measure the effects and damage to jeeps, tanks, armored personnel carriers, and animals (pigs and mice) placed in foxholes and pens (DRI, 2000). Before the detonation, personnel set up instrumentation for 11 DoD) Effects Test Group projects (DTRA, 2007). On October 31, 1958, a memo was issued stating that the area surrounding Hamilton ground zero within a 200-ft radius was contaminated with alpha and beta-gamma contamination (Wilcox, 1958). It is speculated that the contaminated surface soil may have been scraped together and relocated to a large debris pile that is presently located within the posted CA that surrounds ground zero. A second station (Station T-Fb) was originally planned to be a 


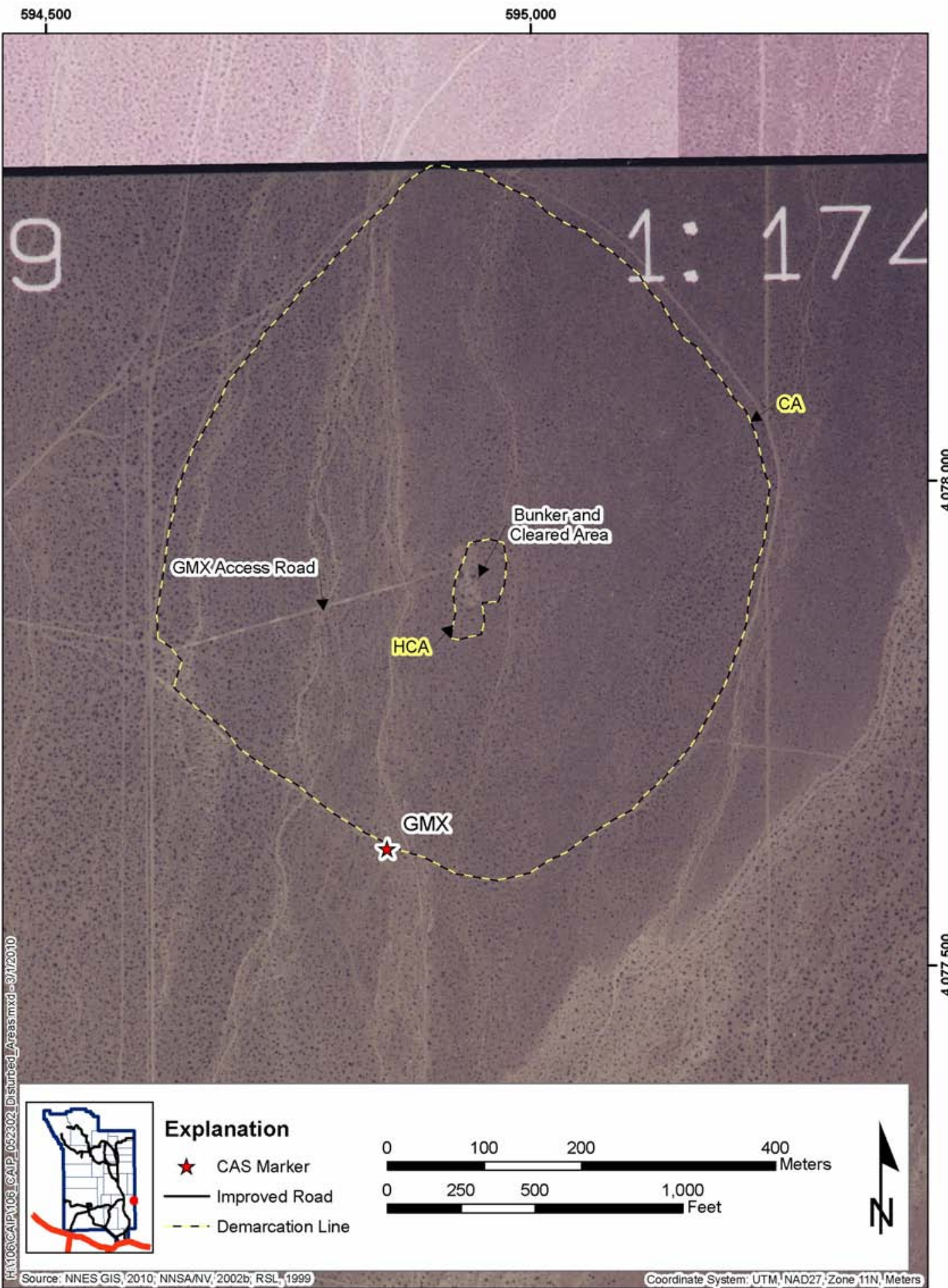

Figure 2-6

1999 Aerial Photograph of GMX Site 


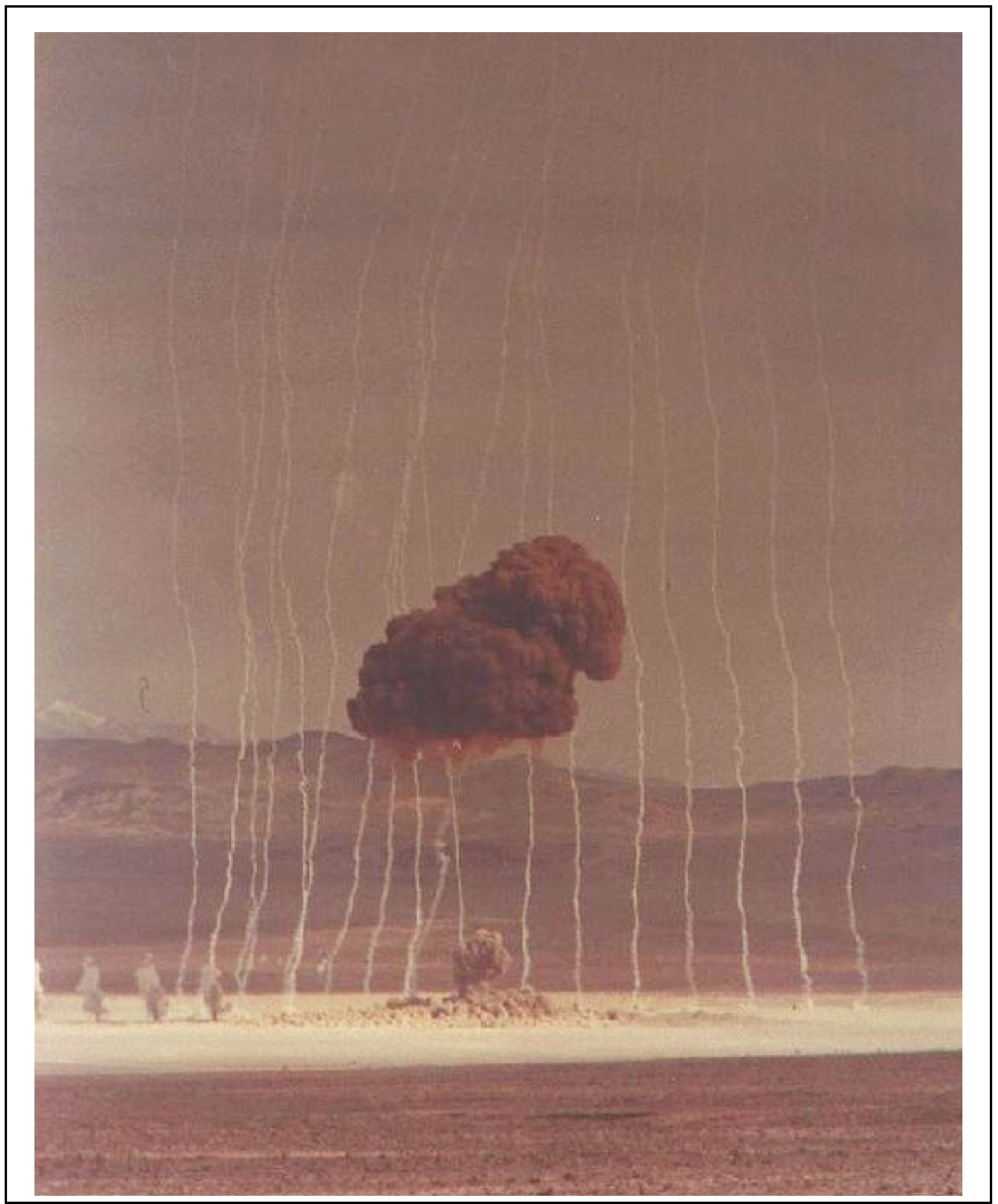

Figure 2-7

Photograph of Able Detonation on April 1, 1952

Source: NWA, 2002 
duplicate of the station for the Hamilton test (Station T-Fi); however, the plan changed during construction, and the tower was dismantled and stored (Holmes \& Narver, 1959). Figure 2-3 shows a post-test aerial photograph of the site layout. It is the opinion of Remote Sensing Laboratory (RSL) film-processing experts that the print may be black and white infrared, which is designed to accentuate disturbed earth, trails, roadways, vegetation, and so forth. These potentially disturbed areas appear as dark features on the photo.

\subsection{4 $306 \mathrm{GZ}$}

This CAS consists of the potential surface and subsurface releases to the environment from past activities associated with a posted URMA and an adjacent CA. Releases from debris will be included based on process knowledge of the materials and evidence of a release. The site was first identified in the Contaminated Land Areas Report (DOE/NV, 2000) as “306 GZ”; however, no information has yet been obtained regarding the activities that occurred there. Information about the specific type, number, and dates of experiment or test activities is unknown. Furthermore, it is unknown if anything has been buried within the posted URMA. It should not be assumed that the name "GZ" refers to "ground zero" because it is not believed that large-scale tests occurred at this site. According to interviewees, this site may have been the location of small-scale "test bed" experiments in support of other tests such as GMX.

\subsection{5 $307 \mathrm{GZ}$}

This CAS consists of the potential surface and subsurface releases to the environment from past activities associated with a posted URMA. The site was first identified in the Contaminated Land Areas Report (DOE/NV, 2000) as “307 GZ”; however, no information has yet been obtained regarding the activities that occurred there, including whether any wastes have been buried as is indicated by the URMA postings. Similar to $306 \mathrm{GZ}$, it should not be assumed that the name "GZ" refers to "ground zero" because it is not believed that large-scale tests occurred at this site.

\section{$2.3 \quad$ Waste Inventory}

Available documentation, interviews with former site employees, process knowledge, and general historical NTS practices were used to identify wastes that may be present. The potential wastes specific to each CAS are listed in the following subsections. 


\subsubsection{GMX}

Solid waste items identified at GMX include scrap metal. Additional wastes (e.g., DU) may be identified within and surrounding the bunker located in the HCA as well as in the surrounding CA. According to the RI/FS, items often buried at Pu-contaminated sites include clothing, scrap metals, and scrap wood. These materials may have been buried near ground zero (DOE/NV, 1992). Investigation-derived waste (IDW) streams including soil, personal protective equipment (PPE), and decontamination rinsate may be generated during the CAI. Potential waste types include industrial waste, Resource Conservation and Recovery Act (RCRA) hazardous waste, low-level radioactive waste, and mixed waste.

\subsubsection{Able}

No solid waste items have been identified at Able. Miscellaneous debris and structures are present in the surrounding area, but are not associated with this CAS. Investigation-derived waste streams including soil, PPE, and decontamination rinsate may be generated during the CAI. Potential waste types include industrial waste and low-level radioactive waste.

\subsubsection{Hamilton}

Solid waste items identified at Hamilton include miscellaneous metal, wood, plastic, and other test-related construction materials such as cables, rope, concrete, and fencing. A large debris pile (100 cubic yards) is present within the posted CA. This debris pile has the potential to contain scraped-together contaminated materials and soils produced after the Hamilton test was concluded. Additional wastes and debris piles may be present at the site. Investigation-derived waste streams including soil, PPE, and decontamination rinsate may be generated during the CAI. Potential waste types include industrial waste, hydrocarbon waste, RCRA hazardous waste, low-level radioactive waste, and mixed waste.

\subsection{4 $306 \mathrm{GZ}$}

Solid waste items identified at 306 GZ include DU, unknown molten metal pieces, and burnt wood. Investigation-derived waste streams including soil, PPE, and decontamination rinsate may be 
generated during the CAI. Potential waste types that may be identified during the CAI include industrial waste, RCRA hazardous waste, low-level radioactive waste, and mixed waste.

\subsection{5 $307 \mathrm{GZ}$}

Solid waste items identified at 307 GZ include DU. Investigation-derived waste streams including soil, PPE, and decontamination rinsate may be generated during the CAI. Potential waste types that may be identified during the CAI include industrial waste, RCRA hazardous waste, low-level radioactive waste, and mixed waste.

\subsection{Release Information}

The releases of contamination to the CASs are directly or indirectly associated with the Able and Hamilton nuclear weapons tests, the GMX “equation of state” experiments, and unknown activities at 306 GZ and 307 GZ. The investigation of specific releases will depend upon the nature of these releases. Therefore, the releases at CAU 106 have been categorized into either the test release scenario or the non-test release scenario as defined in Section 1.1.2.

The sources of contamination for the test release scenario at CAU 106 are the initial atmospheric deposition of radiological contaminants to surface soil from the Able and Hamilton nuclear weapons tests and the GMX “equation of state” experiments. The sources of contamination for the non-test release scenario at CAU 106 are either the subsequent movement of radiological contaminants released during the Hamilton test and the GMX experiments or surface and subsurface wastes (e.g., DU, miscellaneous chemicals and debris items) present at the GMX, Hamilton, 306 GZ, and 307 GZ sites.

Surface and shallow surface soils are the impacted media at all sites. Exposure routes to receptors include ingestion and inhalation of radionuclides in surface and shallow subsurface soil (internal exposure). Site workers may also be exposed to direct radiation by performing activities in proximity to radiologically contaminated materials (i.e., external dose).

The following subsections contain CAS-specific descriptions of known or suspected releases. 


\subsubsection{GMX}

Page 23 of 74

The test release source at GMX is the atmospheric deposition of radionuclides, primarily $\mathrm{Pu}$, to the surrounding surface soil from the 29 "equation of state" experiments conducted at the site. These experiments were conducted to measure the effects of $\mathrm{Pu}$ from conventional explosives. According to documentation, these experiments were conducted on or very near one location. It is speculated that this location was outside and adjacent to the bunker located within the posted HCA. The initial releases of radionuclides from the GMX experiments were distributed in an elongated annular pattern centered over the bunker and HCA as illustrated in a radiological flyover survey (see Figure 2-8).

The non-test release source includes radioactive surface and shallow subsurface sediments in the nearby washes that have resulted from the subsequent migration of initially deposited radioactivity from the test release scenario. Subsequent migration may occur as stormwater runoff causes sheet and gully erosion at numerous small washes and one prominent wash that are present at the site. Non-test release sources may also include DU and other abandoned wastes within and adjacent to the site bunker. Additional non-test release sources include any abandoned wastes at any other locations within the CAS boundary that have spilled, leaked, buried, or have the potential to release contaminants to the surface and shallow subsurface soil.

\subsubsection{Able}

The test release source at Able is the atmospheric deposition of radionuclides (e.g., fallout of fuel fragments and fission products, and neutron activation of soil) to the surface soil from the detonation of a weapons-effect test with a 1-kt yield at $800 \mathrm{ft}$ above the ground surface. Based on available information from radiological flyover surveys and soil studies, significant quantities of radionuclides were not released to the surface soil surrounding the Able ground zero. Therefore, soil contamination above FALs is not expected at this site. It is possible that the surface soil initially impacted by the Able test has subsequently been buried by lake sedimentation that occurs when the dry lake bed fills with shallow water. However, the initially impacted soil is expected to be near the surface (within the top 15 centimeters [cm] of soil) because of the low sedimentation rates on dry lake beds.

Non-test release sources have not been identified at Able; however, there is always a potential to identify a non-test release during the CAI. 


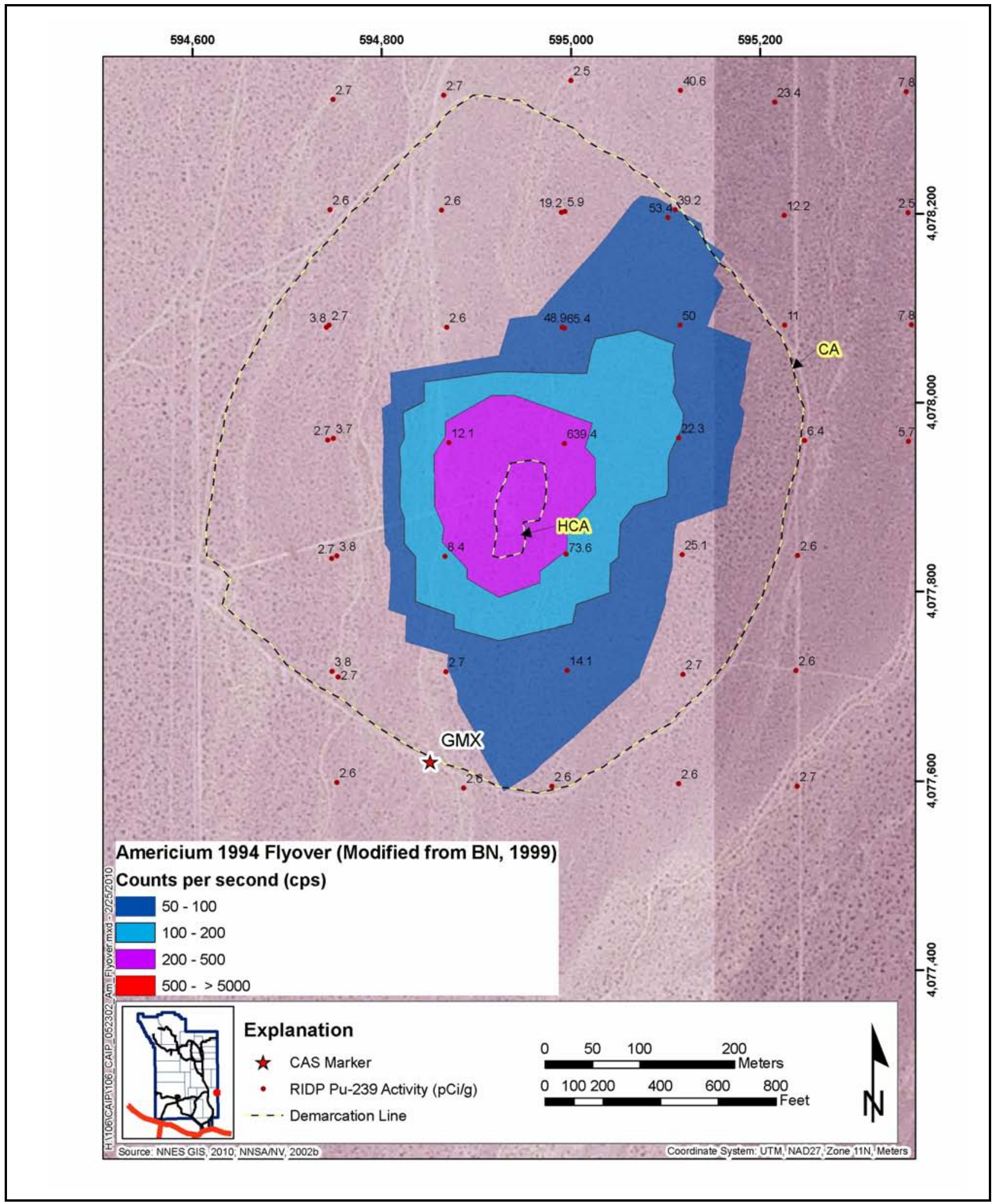

Figure 2-8

Americium-241 Isopleths and RIDP In Situ Measurement Locations at GMX 


\subsubsection{Hamilton}

The test release source at Hamilton is the atmospheric deposition of radionuclides (e.g., fallout of fuel fragments and fission products, and neutron activation of soil/debris or structures) to the surface soil from the detonation of a weapons-related test with a 1.2-ton yield from a 50-ft tower (no longer present). Based on the radiological flyover surveys, contamination is distributed in an annular pattern centered over ground zero and the posted CA. It is unknown whether this distribution pattern represents the initial surface contamination or contaminated surface soil and materials that may have been subsequently cleaned up and/or relocated to the large debris pile located within the CA. The debris pile will be addressed as a non-test release. It is also possible that the surface soil initially impacted by the Hamilton test has subsequently been buried by lake sedimentation that occurs when the dry lake bed fills with shallow water. However, the initially impacted soil is expected to be near the surface (within the top $15 \mathrm{~cm}$ of soil) because of the low sedimentation rates on dry lake beds.

Additional non-test release sources include any abandoned wastes within the CAS boundary that have spilled, leaked, or have the potential to release contaminants to the surface and shallow subsurface soil.

\subsection{4 $306 \mathrm{GZ}$}

The test release scenario, as defined in Section 1.1.2, does not apply to 306 GZ because there is no evidence of atmospheric deposition of radiological contaminants from a nuclear experiment.

The non-test release source of surface contamination includes abandoned wastes, particularly DU that may have released contaminants to the soil within and surrounding the posted URMA and CA. Other identified surface waste includes solid and molten metal fragments. Because information about the activities conducted at this site is scarce, radioactive and chemical contaminants that have not been identified may have been released to the surface soil. Non-test sources of subsurface contamination include any buried wastes within the boundary of the posted URMA. There is a potential for the subsequent migration of contaminants into nearby washes, although this is not anticipated because the nearest wash is $500 \mathrm{ft}$ to the east. 


\subsection{5 $307 \mathrm{GZ}$}

The test release scenario, as defined in Section 1.1.2, does not apply to 307 GZ because there is no evidence of atmospheric deposition of radiological contaminants from a nuclear experiment.

The non-test release source of surface contamination includes abandoned wastes, particularly DU that may have released contaminants to the soil within and surrounding the posted URMA. Because information about the activities conducted at this site is scarce, radioactive and chemical contaminants that have not been identified may have been released to the surface soil. Non-test sources of subsurface contamination include any buried wastes within the boundary of the posted URMA. The subsequent migration of contaminants into nearby washes is not anticipated at this site.

\subsection{Investigative Background}

The following subsections summarize the investigations conducted at the CAU 106 sites.

As part of an effort to assess the implications of contamination for future uses of the NTS, the Radionuclide Inventory and Distribution Program (RIDP) was established in 1981 to conduct a comprehensive survey of the important man-made radionuclides of NTS origin in the NTS surface soil (DRI, 1989). Data collected for the RIDP and by the Nevada Applied Ecology Group (NAEG) in the 1970s and 1980s allowed for estimates of surface soil inventories throughout the NTS. The RIDP estimated the inventory through in situ soil measurements by gamma spectroscopy and limited confirmatory soil sampling, and the NAEG utilized statistical designs and soil sample analyses to estimate radionuclide inventories for select areas of the NTS.

An aerial radiological survey flown in 1994 used radiological detection systems to identify gamma radiation (BN, 1999). From the data collected, the gross count rates, man-made radiation, and americium (Am)-241 count rates were published for areas of the NTS. The field detection of Pu contamination in surface soils can be achieved via the detection of low-energy gamma rays that are emitted from the Am-241 contaminant present in the Pu. The isotopes of Pu primarily emit alpha radiation, which is hard to detect in soils under field conditions. Special radiation detectors that are optimized to sense the low-energy gamma rays and to discriminate against other, higher-energy gamma rays must be used. The most common type is the field instrument for the detection of low-energy radiation (or “FIDLER”) detector. 


\subsubsection{GMX}

Previous investigations that produced data relevant to the CAI at GMX include the surface soil inventory studies by the RIDP and the NAEG, an aerial radiological survey, and an RI/FS.

Data collected for the RIDP and by NAEG allowed for estimates of surface soil inventories from the GMX area. The locations and Pu-239 activities (up to 639 picocuries per gram [pCi/g]) from RIDP in situ measurements are shown in Figure 2-8, and the reported inventory estimates for GMX are shown in Table 2-2 (DRI, 1989). In addition to the RIDP data, several studies were conducted by the NAEG between 1975 and 1985 (Essington et al., 1975; Gilbert 1977; Gilbert and Eberhardt, 1978; Essington, 1985a and b). These studies conclude that 95 percent of total inventory of Pu at GMX resides in the top $5 \mathrm{~cm}$ of the soil profile (Essington et al., 1975), and the highest concentrations of Pu-239/240 are found slightly northeast of ground zero (activities up to 3,500 pCi/g) (Gilbert et al., 1975).

Table 2-2

RIDP Surface Soil Inventory for GMX

\begin{tabular}{|c|c|}
\hline Radionuclide & Surface Soil Inventory (Ci) \\
\hline \hline Am-241 & 0.20 \\
\hline Pu-238 & 0.028 \\
\hline Pu-239/240 & 1.4 \\
\hline Cs-137 & 0.026 \\
\hline Sr-90 & 0.015 \\
\hline
\end{tabular}

$\mathrm{Ci}=$ Curie

$\mathrm{Cs}=$ Cesium

$\mathrm{Sr}=$ Strontium

Results from the 1994 aerial radiological survey show Am-241 count rates within the posted CA (and inner HCA) ranging from 50 to 500 counts per second (cps). The spatial distribution of the Am-241 data is depicted in Figure 2-8 as isopleths with an elongated pattern that may provide information regarding the radioactive contaminant plume. There was no distinguishable gamma gross count plume associated with GMX (BN, 1999).

In 1992, an RI/FS Work Plan for Plutonium-Contaminated Soils (PuCS) sites was prepared by DOE and The Earth Technology Corporation (DOE/NV, 1992). The RI/FS Work Plan established the 
objectives, procedures, tasks, and schedule for conducting an RI/FS at several PuCS sites, including the GMX site. Information regarding the physical setting and operational history of the GMX site is provided in Sections 2.1.1 and 2.2.1. The RI/FS Work Plan was written under the Comprehensive Environmental Response, Compensation, and Liability Act (CERCLA) regulatory framework prior to establishment of the FFACO in 1996, and the PuCS sites subsequently became CASs in the FFACO to be investigated under the corrective action process.

\subsubsection{Able}

Previous investigations that produced data relevant to the CAI at Able include the surface soil inventory studies by the RIDP and Desert Research Institute (DRI), and aerial radiological surveys.

The Frenchman Lake area was studied intensively as part of the RIDP because a total of 14 aboveground tests were conducted here (including Able and Hamilton). Figure 2-9 shows the locations of in situ measurements from Frenchman Lake in the vicinity of Able and indicates a low density of data points surrounding the Able site. Soil samples were collected from 29 of the in situ measurement locations from Frenchman Lake; however, none of these were collected at Able. The radionuclide inventory estimates for Frenchman Lake are reported (DRI, 1989); however, this information represents a reported 62.4-million-square-foot $\left(\mathrm{ft}^{2}\right)$ area, and therefore, does not provide value specific to the Able CAI.

In addition to the RIDP data, a radiological characterization study of the Frenchman Lake region was conducted as part of the NTS Radiological Assessment Project and included the Able and Hamilton sites (Barnes et al., 1980). Between April 1978 and June 1979, 68 samples were collected at the Able site and analyzed for americium (Am)-241, cesium (Cs)-137, europium (Eu)-155, cobalt (Co)-60, and plutonium (Pu)-239 activities (Barnes et al., 1980). The results are presented on contour maps showing only isopleths of activity for Am-241 (up to 2.5 pCi/g) and Pu-239 (up to 20 pCi/g), indicating that relatively low quantities are present for all analyzed constituents. The isopleths cover the region near Able; however, there are no distinct signatures directly associated with the Able site. Individual sample results are not reported.

The 1994 radiological flyover survey results show no distinguishable gross count or Am isopleths associated with Able (Figure 2-9). It should be noted that Able is located on the edge of the gross 


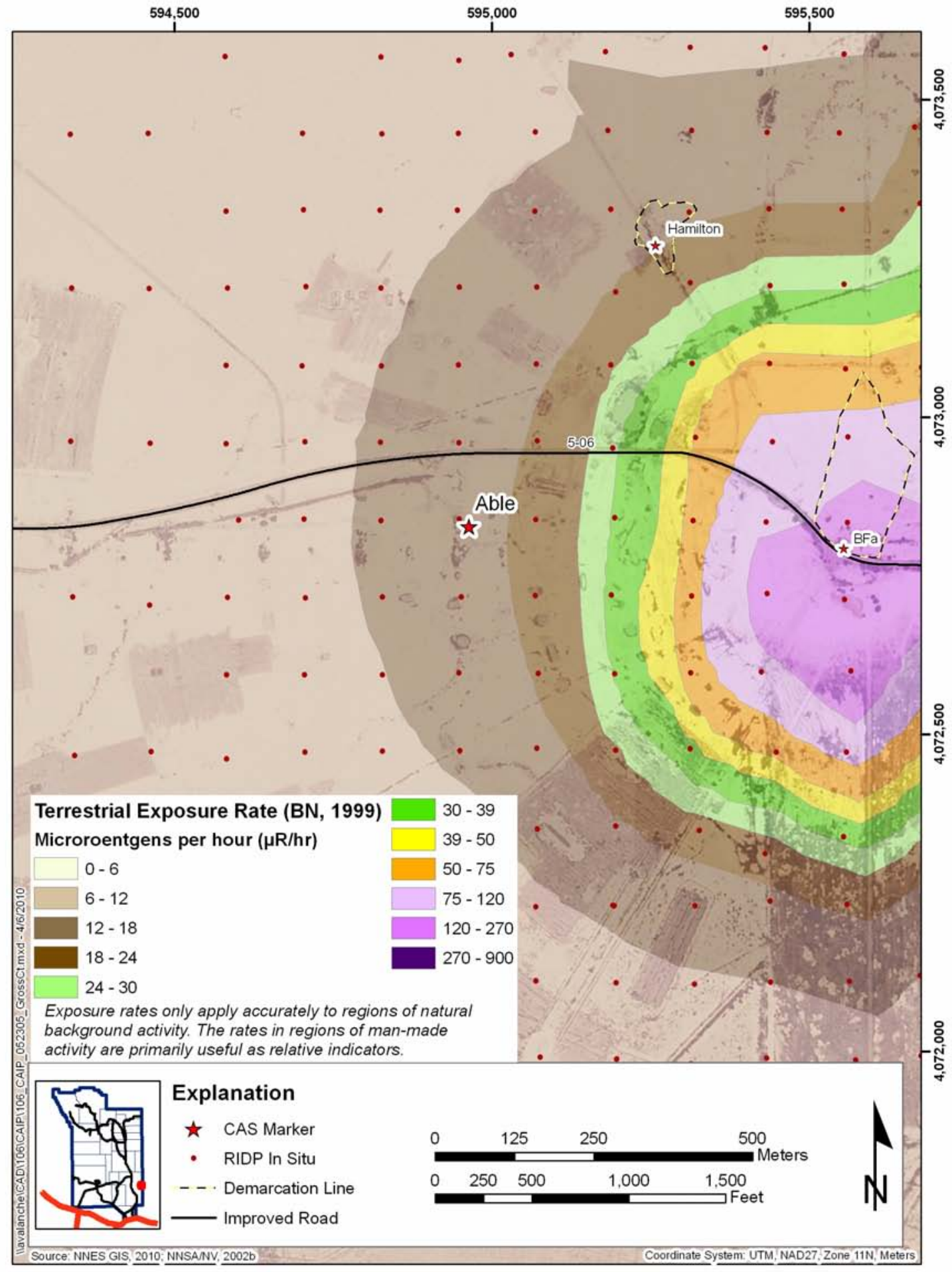

Figure 2-9 
gamma count plume (BN, 1999) associated with the BFa site (CAS 05-23-04), which is being addressed under CAU 541. The BFa site was the location of six tests conducted post-Able in 1953, 1955, and 1957.

\subsubsection{Hamilton}

Previous investigations that produced data relevant to the CAI at Hamilton include the surface soil inventory studies by the RIDP and DRI, and aerial radiological surveys.

The Hamilton site was also included in the collection of RIDP data for the Frenchman Lake region. Figure 2-10 shows the locations of in situ measurements from Frenchman Lake in the vicinity of Hamilton. Like Able, the density of data points is low. Two of the 29 sample locations collected from the Frenchman Lake region were located in the vicinity of the Hamilton ground zero. Sample location number " 54 " is located within the posted CA, and number " 52 " is located approximately $300 \mathrm{ft}$ southwest of ground zero. Radionuclide concentrations for Co-60, Cs-137, Eu-152, Eu-155, and Am-241 are reported in Appendix B of the RIDP report (DRI, 1989); however, no significant quantities were detected.

In addition to the RIDP data, a radiological characterization study of the Frenchman Lake region was conducted as part of the NTS Radiological Assessment Project and included the Hamilton site (Barnes et al., 1980). Between March 1978 and April 1979, 121 samples were collected at the Hamilton site, and the results are presented on contour maps showing isopleths of activity (pCi/g) for Am-241 and Pu-239. The maps show estimates of Am-241 activities up to $50 \mathrm{pCi} / \mathrm{g}$ and Pu-239 activities up to $400 \mathrm{pCi} / \mathrm{g}$, indicating that relatively low quantities are present (Barnes et al., 1980). Individual sample results are not reported.

The 1994 aerial radiological survey results show Am-241 count rates within and surrounding the posted CA up to 500 cps (BN, 1999). The spatial distribution of the Am-241 data is depicted in Figure 2-10 as isopleths centered about the ground zero and posted CA. This pattern may provide information regarding a surface soil radioactive contaminant plume surrounding the Hamilton ground zero, or it may be influenced by radioactivity from the large debris pile located within the CA. The pile may consist of the originally contaminated surface soils and materials that were collected into the pile following the Hamilton test. The radiological flyover survey results show no distinguishable 


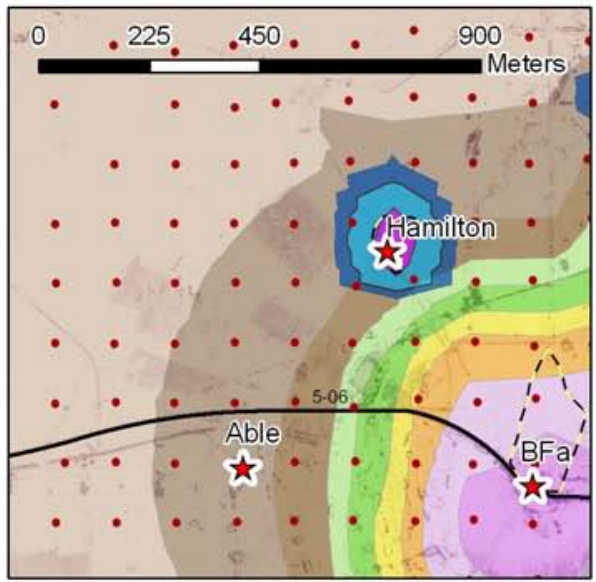

Terrestrial Exposure Rate (BN, 1999)

$30-39$

Microroentgens per hour ( $\mu \mathrm{R} / \mathrm{hr})$

$39-50$

$0-6$

$6-12$

$50-75$

$12-18$

$75-120$

$18-24$

$120-270$

$24-30$

Americium 1994 Flyover (Modified from BN, 1999)

Counts per second (cps)

$50-100$

$100-200$

$200-500$

Exposure rates only apply accurately to regions of

$500->5000$

Exptural background activity. The rates in regions of

man-made activity are primarily useful as

relative indicators.

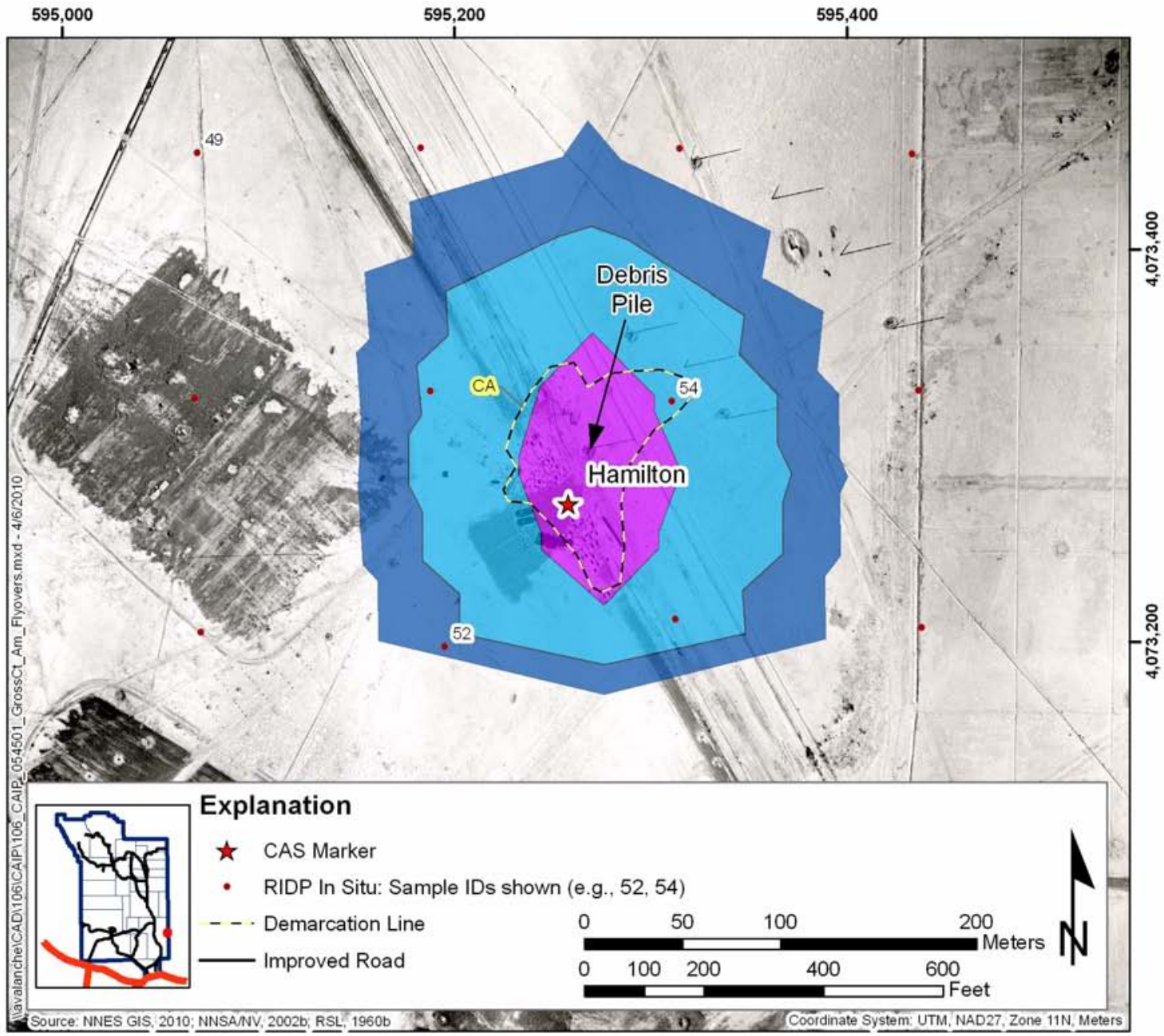

Figure 2-10

1994 Aerial Radiological Survey Americium-241 Results and RIDP In Situ Measurement Locations at Hamilton 
gross gamma count isopleths associated with Hamilton (Figure 2-10). Similar to Able, Hamilton is located on the edge of the gross gamma count plume (BN, 1999) associated with the BFa site (CAS 05-23-04 in CAU 541). The BFa tests were conducted prior to Hamilton in 1953, 1955, and 1957 (BN, 1999).

\subsection{4 $306 \mathrm{GZ}$}

After an extensive search of historical information regarding the $306 \mathrm{GZ}$, no previous investigations or historical analytical data have been identified. Furthermore, there is no coverage of RIDP data for this area, and there are no distinguishable gross count or Am-241 plumes associated with this site.

\subsection{5 $307 \mathrm{GZ}$}

After an extensive search of historical information regarding the $306 \mathrm{GZ}$, no previous investigations or historical analytical data have been identified. Furthermore, there is no coverage of RIDP data for this area, and there are no distinguishable gross count or Am-241 plumes associated with this site.

\subsubsection{National Environmental Policy Act}

The Final Environmental Impact Statement for the Nevada Test Site and Off-Site Locations in the State of Nevada (DOE/NV, 1996) includes site investigation activities such as those proposed for CAU 106.

In accordance with the NNSA/NSO National Environmental Policy Act (NEPA) Compliance Program, a NEPA checklist will be completed before beginning site investigation activities at CAU 106. This checklist requires NNSA/NSO project personnel to evaluate their proposed project activities against a list of potential impacts that include, but are not limited to, air quality, chemical use, waste generation, noise level, and land use. Completion of the checklist results in a determination of the appropriate level of NEPA documentation by the NNSA/NSO NEPA Compliance Officer. This will be accomplished before mobilization for the field investigation. 


\subsection{Objectives}

This section presents an overview of the DQOs for CAU 106 and formulation of the CSM. Also presented is a summary listing of the COPCs, the preliminary action levels (PALs), and the process used to establish FALs. Additional details and figures depicting the CSM are located in Appendix A.

\subsection{Conceptual Site Model}

The CSM describes the most probable scenario for current conditions at each site and defines the assumptions that are the basis for identifying the future land use, contaminant sources, release mechanisms, migration pathways, exposure points, and exposure routes. The CSM was used to develop appropriate sampling strategies and data collection methods. Site specific CSMs were developed for CAU 106 using information from the physical setting, potential contaminant sources, release information, historical background information, knowledge from similar sites, and physical and chemical properties of the potentially affected media and COPCs. Figure 3-1 depicts a representation of the conceptual pathways to receptors from CAU 106 sources. Figure 3.2 provides schematic representations of the CSMs. If evidence of contamination that is not consistent with the presented CSM is identified during investigation activities, the situation will be reviewed, the CSM will be revised, the DQOs will be reassessed, and a recommendation will be made as to how best to proceed. In such cases, decision-makers listed in Section A.2.1 will be notified and given the opportunity to comment on and/or concur with the recommendation.

The following sections discuss future land use and the identification of exposure pathways (i.e., combination of source, release, migration, exposure point, and receptor exposure route) for CAU 106.

\subsubsection{Land Use and Exposure Scenarios}

Land-use zones where the CAU 106 CASs are located dictate future land use, and restrict current and future land use to nonresidential (i.e., industrial) activities.

GMX and 306 GZ are located in the land-use zone described as "Reserved Zone.” This area includes land and facilities that provide widespread flexible support for diverse short-term testing and 


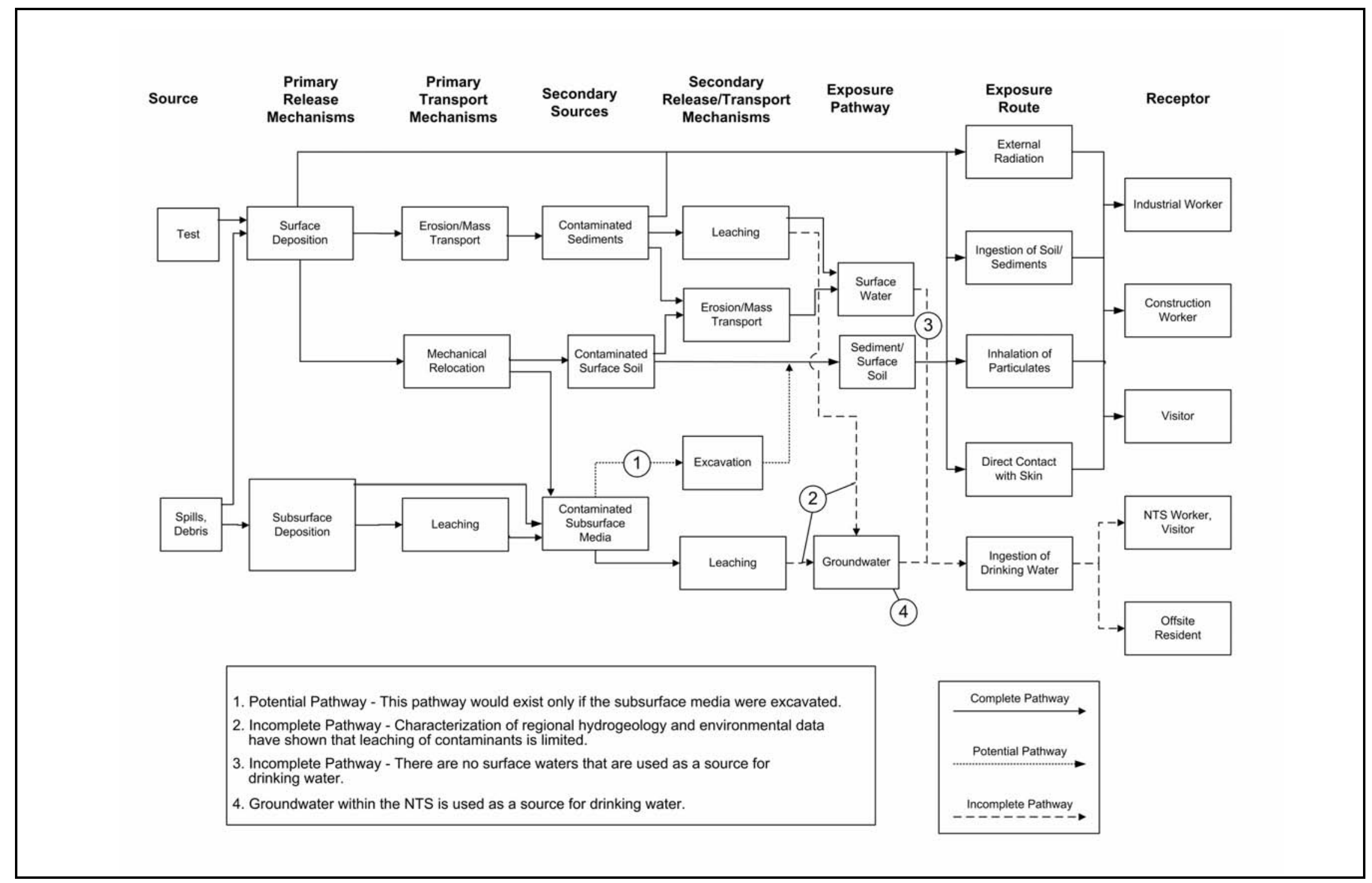

Figure 3-1

Conceptual Pathways to Receptors

UNCONTROLLED when Printed 


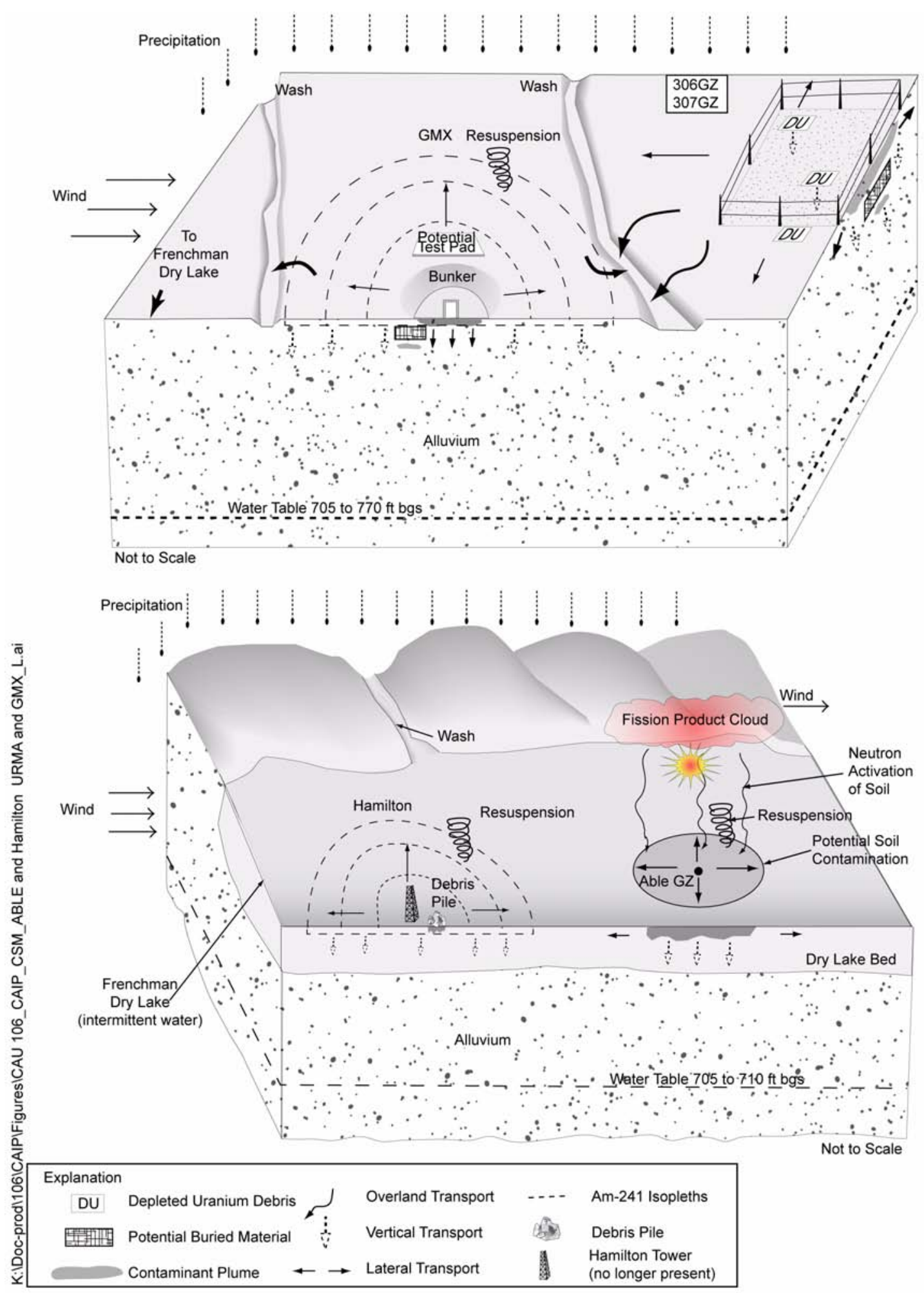

Figure 3-2

Conceptual Site Model for GMX, 306 GZ, and 307 GZ (top) and Hamilton and Able (bottom) 
experimentation. The reserved zone is also used for short-duration exercises and training, such as nuclear emergency response, Federal Radiological Monitoring and Assessment Center training, and DoD exercises and training (DOE/NV, 1998).

Able, Hamilton, and 307 GZ are located in the land-use zone described as "Research, Test, and Experiment Zone” within the NTS. This area is designated for small-scale research and development projects and demonstrations; pilot projects; outdoor tests; and experiments for the development, QA, or reliability of material and equipment under controlled conditions. This zone includes compatible research, development, and testing activities (DOE/NV, 1998).

The exposure scenario for CAU 106 is an Occasional Use Area, based on current and projected future land uses. This exposure scenario assumes exposure to industrial workers who are not assigned to the area as a regular work location but may occasionally use the area for intermittent or short-term activities. Site workers under this scenario are assumed to be on the site for an equivalent of 8 hours per day, 10 days per year, for 5 years.

These exposure scenarios are used in the calculation of Tier 2 and Tier 3 action levels as described in Section 3.3. Although Tier 2 and Tier 3 FALs may be established on the actual current and projected future land use scenarios, a more conservative land use scenario may also be used. For example, the FAL for a particular CAS categorized as an Occasional Use Area may be based on the Occasional Use Area scenario, or either the Remote Work Area scenario or the Industrial Area scenario may be used for conservatism.

\subsubsection{Contaminant Sources}

As discussed in Section 2.4, the test release sources at CAU 106 are the initial atmospheric deposition of radiological contaminants to surface soil from the Hamilton and Able tests and the GMX experiments. Contamination on the soil surface may be the source for future migration.

The non-test release sources at CAU 106 are spills or releases from surface and subsurface wastes (e.g., DU, miscellaneous chemicals and debris items) present at the GMX, Hamilton, 306 GZ, and $307 \mathrm{GZ}$ sites or the subsequent movement of radiological contaminants released during the Hamilton test and the GMX experiments. 
See Table A.2-1 for CAS-specific listing of potential contaminant sources.

\subsubsection{Release Mechanisms}

Test-related release mechanisms include release of fission products and neutron activation of soil and structural components at Hamilton and Able as well as release of unfissioned nuclear fuel at Hamilton, Able, and GMX. The atmospheric detonation at Hamilton and Able may have irradiated the surrounding soil with neutrons, causing the activation of some elements in the soil. However, the absence of gross count and Am-241 activities as shown by radiological flyover surveys and the minimal ground disturbance from the air burst at Able as shown by the test photograph (Figure 2-7) suggest that the test release of radionuclides to the surface soil was minor. Available data suggest that fission fragments and potential unfissioned fuel have been released in an annular pattern (as indicated by radiological flyover data at Hamilton and GMX) with a potential bias toward the prevailing wind direction at GMX (elongated to the north and south). Radionuclides with a low melting point (e.g., iodine) may have traveled significant distances before condensing and falling out of the plume, while those with higher melting points (e.g., cesium) would have condensed earlier and been deposited closer to ground zero. The nuclear fuel that did not fission (e.g., Pu-239) has a very high melting point and is generally found closer to ground zero.

Non-test release mechanisms for the CSM at all CASs include spills and leaks from abandoned surface waste onto surface soils. Additional non-test release mechanisms include the potential for subsurface releases from wastes at GMX, 306 GZ, and 307 GZ. There is a potential for subsequent migration of contaminants into nearby washes at GMX and 306 GZ, and mechanical displacement of contaminants to a debris pile at Hamilton.

\subsubsection{Migration Pathways}

Surface migration pathways include the lateral migration of potential contaminants across surface soils into washes transecting the sites since the original deposition. The washes entering and leaving these areas are generally dry but are subject to infrequent stormwater flows. These stormwater flow events provide an intermittent mechanism for both vertical (infiltration) and horizontal transport of contaminants. Contaminated sediments entrained by these stormwater events would be carried by the streamflow to locations where the flowing water loses energy and the sediments drop out. These 
locations are readily identified as sedimentation areas. This migration pathway applies to GMX, where numerous small washes and one prominent wash that drain to Frenchman Lake are present within the CAS boundary. There is also a wash approximately $500 \mathrm{ft}$ east of $306 \mathrm{GZ}$ that drains to Frenchman Lake; however, migration of contaminants is not expected because of the distance of the wash from the source. Other surface migration pathways include resuspension of contaminants by wind and relocation of contaminants through mechanical disturbance caused by cleanup or other activities (e.g., construction). At Hamilton, those activities may include removing surface contamination by scraping or grading and relocating it to a debris pile.

Infiltration and percolation of precipitation serve as a driving force for the potential downward migration of contaminants. However, because of high potential evapotranspiration (annual potential evapotranspiration at the Area 5 Radiological Waste Management Site has been estimated at 63.5 in. [Yucel, 2009]) and limited precipitation for this region (4.85 in. per year [ARL/SORD, 2009]), percolation of infiltrated precipitation at the NTS does not provide a significant mechanism for vertical migration of contaminants to groundwater (DOE/NV, 1992). Although there may be standing water at times on Frenchman Lake, accumulation of fine materials on the lake bed has decreased the hydraulic conductivity of the lake bed to the point where infiltration is not significant (i.e., most of the accumulated water evaporates before it infiltrates the lake bed surface). Reported recharge rates for the Frenchman Flat area range from below 0.1 to 2 millimeters per year (SNJV, 2004).

Subsurface migration pathways at all CASs are expected to be predominately vertical, although spills or leaks at the ground surface may also have limited lateral migration before infiltration. The depth of infiltration (shape of the subsurface contaminant plume) will be dependent upon the type, volume, and duration of the discharge as well as the presence of relatively impermeable layers that could modify vertical or horizontal transport pathways, both on the ground surface (e.g., concrete) and in the subsurface (e.g., caliche layers).

Migration is influenced by physical and chemical characteristics of the contaminants and media. Contaminant characteristics include, but are not limited to, solubility, density, and adsorption potential. Media characteristics include permeability, porosity, water holding capacity, sorting, chemical composition, and organic content. In general, contaminants with low solubility, high affinity for media, and high density can be expected to be found relatively close to release points. 
Contaminants with high solubility, low affinity for media, and low density can be expected to be found further from release points. These factors affect the migration pathways and potential exposure points for the contaminants in the various media under consideration.

\subsubsection{Exposure Points}

Exposure points for the CSM are expected to be areas of surface contamination where visitors and site workers may come in contact with contaminated surface soil. At Hamilton and Able, the initially contaminated surface may have been covered because of subsequent sedimentation on Frenchman Lake; however, the contaminated horizon is expected to be within the top $15 \mathrm{~cm}$ of the soil profile. Subsurface exposure points may exist if construction workers come in contact with contaminated media during future excavation activities.

\subsubsection{Exposure Routes}

Exposure routes to site workers include ingestion and inhalation from disturbance of, or direct contact with, contaminated media. Site workers may also be exposed to direct ionizing radiation by performing activities in proximity to radioactive materials.

\subsubsection{Additional Information}

Information concerning topography, geology, climatic conditions, hydrogeology, and infrastructure at the CAU 106 CASs is presented in Section 2.1 as it pertains to the investigation. This information has been addressed in the CSM and will be considered during the evaluation of CAAs, as applicable. Climatic and physical site conditions will be recorded during the CAI.

\subsection{Contaminants of Potential Concern}

Based on the suspected contaminants identified in Section 2.4, the COPCs for CAU 106 are defined as the list of analytes represented by the analytical methods identified in Table 3-1 for Decision I environmental samples taken at each of the CASs. The analytes reported for each analysis are listed in Table 3-2. 
Table 3-1

Analytical Program ${ }^{a}$

\begin{tabular}{|c|c|c|c|c|c|}
\hline Analyses & GMX & Able & Hamilton & $306 \mathrm{GZ}$ & $307 \mathrm{GZ}$ \\
\hline \multicolumn{6}{|c|}{ Organic COPCs } \\
\hline PCBs & -- & -- & -- & $\mathrm{X}$ & $\mathrm{X}$ \\
\hline SVOCs & -- & -- & -- & $\mathrm{X}$ & $\mathrm{X}$ \\
\hline VOCs & -- & -- & -- & $x$ & $x$ \\
\hline \multicolumn{6}{|c|}{ Inorganic COPCs } \\
\hline RCRA Metals & -- & -- & -- & $\mathrm{X}$ & $\mathrm{X}$ \\
\hline Total Beryllium & $x$ & & $x$ & $x$ & $x$ \\
\hline \multicolumn{6}{|c|}{ Radionuclide COPCs } \\
\hline Gamma Spectroscopy $^{b}$ & $\mathrm{x}$ & $\mathrm{x}$ & $\mathrm{x}$ & $x$ & $x$ \\
\hline Isotopic U & $x$ & $x$ & $x$ & $\mathrm{X}$ & $\mathrm{X}$ \\
\hline Isotopic $\mathrm{Pu}$ & $x$ & $x$ & $x$ & $x$ & $x$ \\
\hline Isotopic Am & $x$ & -- & $x$ & -- & -- \\
\hline Pu-241 & $x$ & -- & -- & -- & -- \\
\hline Sr-90 & $x$ & $x$ & $x$ & $x$ & $x$ \\
\hline
\end{tabular}

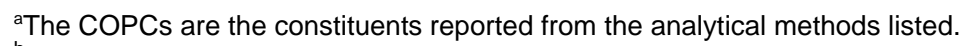

${ }^{b}$ Results of gamma analysis will be used to determine whether further isotopic analysis is warranted.

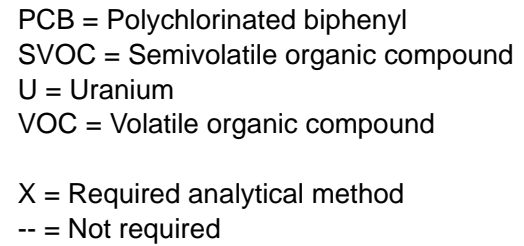

The list of COPCs is intended to encompass all contaminants that could potentially be present at each CAS. These COPCs were identified during the planning process through the review of site history, process knowledge, personal interviews, past investigation efforts (where available), and inferred activities associated with the CASs and other non-test releases (including those that may be discovered during the investigation). Specific COPCs will be determined for discovered potential releases based on the nature of the potential release (e.g., hydrocarbon stain, DU, lead bricks). 
Table 3-2

COPCs Reported by Analytical Methods

\begin{tabular}{|c|c|c|c|c|c|c|}
\hline \multicolumn{2}{|c|}{ VOCs } & \multicolumn{2}{|c|}{ SVOCs } & \begin{tabular}{|c|} 
PCBS \\
Aroclor 1016 \\
Aroclor 1221 \\
Aroclor 1232 \\
Aroclor 1242 \\
Aroclor 1248 \\
Aroclor 1254 \\
Aroclor 1260 \\
Aroclor 1268 \\
\end{tabular} & \begin{tabular}{l}
\multicolumn{1}{c|}{ Metals } \\
Arsenic \\
Barium \\
Beryllium \\
Cadmium \\
Chromium \\
Lead \\
Mercury \\
Selenium \\
Silver
\end{tabular} & $\begin{array}{l}\text { Radionuclides } \\
\mathrm{Am}-241\end{array}$ \\
\hline $\begin{array}{l}\text { 1,1,1,2-Tetrachloroethane } \\
\text { 1,1,1-Trichloroethane } \\
\text { 1,1,2,2-Tetrachloroethane } \\
\text { 1,1,2-Trichloroethane } \\
\text { 1,1-Dichloroethane } \\
\text { 1,1-Dichloroethene } \\
\text { 1,2,4-Trichlorobenzene } \\
\text { 1,2,4-Trimethylbenzene } \\
\text { 1,2-Dibromo-3-chloropropane } \\
\text { 1,2-Dichlorobenzene } \\
\text { 1,2-Dichloroethane } \\
\text { 1,2-Dichloropropane } \\
\text { 1,3,5-Trimethylbenzene } \\
\text { 1,3-Dichlorobenzene } \\
\text { 1,4-Dichlorobenzene } \\
\text { 1,4-Dioxane } \\
\text { 2-Butanone } \\
\text { 2-Chlorotoluene } \\
\text { 2-Hexanone } \\
\text { 4-Isopropyltoluene } \\
\text { 4-Methyl-2-pentanone } \\
\text { Acetone } \\
\text { Acetonitrile } \\
\text { Allyl chloride } \\
\text { Benzene } \\
\text { Bromodichloromethane } \\
\text { Bromoform } \\
\text { Bromomethane } \\
\text { Carbon disulfide }\end{array}$ & $\begin{array}{l}\text { Carbon tetrachloride } \\
\text { Chlorobenzene } \\
\text { Chloroethane } \\
\text { Chloroform } \\
\text { Chloromethane } \\
\text { Chloroprene } \\
\text { cis-1,2-Dichloroethene } \\
\text { Dibromochloromethane } \\
\text { Dichlorodifluoromethane } \\
\text { Ethyl methacrylate } \\
\text { Ethylbenzene } \\
\text { Isobutyl alcohol } \\
\text { Isopropylbenzene } \\
\text { Methacrylonitrile } \\
\text { Methyl methacrylate } \\
\text { Methylene chloride } \\
\text { n-Butylbenzene } \\
\text { n-Propylbenzene } \\
\text { sec-Butylbenzene } \\
\text { Styrene } \\
\text { tert-Butylbenzene } \\
\text { Tetrachloroethene } \\
\text { Toluene } \\
\text { Total xylenes } \\
\text { Trichloroethene } \\
\text { Trichlorofluoromethane } \\
\text { Vinyl acetate } \\
\text { Vinyl chloride }\end{array}$ & $\begin{array}{l}\text { 2,3,4,6-Tetrachlorophenol } \\
\text { 2,4,5-Trichlorophenol } \\
\text { 2,4,6-Trichlorophenol } \\
\text { 2,4-Dimethylphenol } \\
\text { 2,4-Dinitrotoluene } \\
\text { 2-Chlorophenol } \\
\text { 2-Methylnaphthalene } \\
\text { 2-Methylphenol } \\
\text { 2-Nitrophenol } \\
\text { 3-Methylphenol }{ }^{\text {a }} \text { (m-cresol) } \\
\text { 4-Methylphenol }{ }^{\text {a }} \text { (p-cresol) } \\
\text { 4-Chloroaniline } \\
\text { 4-Nitrophenol } \\
\text { Acenaphthene } \\
\text { Acenaphthylene } \\
\text { Aniline } \\
\text { Anthracene } \\
\text { Benzo(a)anthracene } \\
\text { Benzo(a)pyrene } \\
\text { Benzo(b)fluoranthene } \\
\text { Benzo(g,h,i)perylene } \\
\text { Benzo(k)fluoranthene } \\
\text { Benzoic acid } \\
\text { Benzyl alcohol } \\
\text { Bis(2-ethylhexyl)phthalate } \\
\text { Butyl benzyl phthalate } \\
\text { Carbazole } \\
\text { Chrysene } \\
\text { Di-n-butyl phthalate }\end{array}$ & $\begin{array}{l}\text { Di-n-octyl phthalate } \\
\text { Dibenzo(a,h)anthracene } \\
\text { Dibenzofuran } \\
\text { Diethyl phthalate } \\
\text { Dimethyl phthalate } \\
\text { Fluoranthene } \\
\text { Fluorene } \\
\text { Hexachlorobenzene } \\
\text { Hexachlorobutadiene } \\
\text { Hexachloroethane } \\
\text { Indeno(1,2,3-cd)pyrene } \\
\text { n-Nitroso-di-n-propylamine } \\
\text { Naphthalene } \\
\text { Nitrobenzene } \\
\text { Pentachlorophenol } \\
\text { Phenanthrene } \\
\text { Phenol } \\
\text { Pyrene } \\
\text { Pyridine }\end{array}$ & $\begin{array}{l}\text { Aroclor } 1016 \\
\text { Aroclor } 1221 \\
\text { Aroclor } 1232 \\
\text { Aroclor } 1242 \\
\text { Aroclor } 1248 \\
\text { Aroclor } 1254 \\
\text { Aroclor } 1260 \\
\text { Aroclor } 1268\end{array}$ & $\begin{array}{l}\text { Arsenic } \\
\text { Barium } \\
\text { Beryllium } \\
\text { Cadmium } \\
\text { Chromium } \\
\text { Lead } \\
\text { Mercury } \\
\text { Selenium } \\
\text { Silver }\end{array}$ & $\begin{array}{l}\text { Am-241 } \\
\text { Pu-238 } \\
\text { Pu-239/240 } \\
\text { Sr-90 } \\
\text { U-234 } \\
\text { U-235 } \\
\text { U-238 } \\
\text { Gamma-Emitting } \\
\text { Ac-228 (Th-232) } \\
\text { Am-241 } \\
\text { Co-60 } \\
\text { Cs-137 } \\
\text { Eu-152 } \\
\text { Eu-154 } \\
\text { Eu-155 } \\
\text { Nb-94 } \\
\text { Pb-212 } \\
\text { Pb-214 } \\
\text { Tl-208 } \\
\text { Th-234 (U-238) } \\
\text { U-235 }\end{array}$ \\
\hline
\end{tabular}

${ }^{a}$ May be reported as 3,4-Methylphenol or m,p-cresol.

$\begin{array}{ll}\mathrm{Ac}=\text { Actinium } & \mathrm{Pb}=\text { Lead } \\ \mathrm{K}=\text { Potassium } & \mathrm{Th}=\text { Thorium } \\ \mathrm{Nb}=\text { Niobium } & \mathrm{Tl}=\text { Thallium }\end{array}$

\subsection{Preliminary Action Levels}

The PALs presented in this section are to be used for site screening purposes. They are not necessarily intended to be used as cleanup action levels or FALs. However, they are useful in screening out contaminants that are not present in sufficient concentrations to warrant further evaluation, therefore streamlining the consideration of remedial alternatives. The RBCA process used to establish FALs is described in the Industrial Sites Project Establishment of Final Action Levels (NNSA/NSO, 2006). This process conforms with Nevada Administrative Code (NAC) Section 445A.227, which lists the requirements for sites with soil contamination (NAC, 2008a). For the evaluation of corrective actions, NAC Section 445A.22705 (NAC, 2008b) requires the use of American Society for Testing and Materials (ASTM) Method E1739 (ASTM, 1995) to "conduct an 
evaluation of the site, based on the risk it poses to public health and the environment, to determine the necessary remediation standards (i.e., FALs) or to establish that corrective action is not necessary.”

This RBCA process, summarized in Figure 3-3, defines three tiers (or levels) of evaluation involving increasingly sophisticated analyses:

- Tier 1 evaluation - Sample results from source areas (highest concentrations) are compared to action levels based on generic (non-site-specific) conditions (i.e., the PALs established in the CAIP). The FALs may then be established as the Tier 1 action levels, or the FALs may be calculated using a Tier 2 evaluation.

- Tier 2 evaluation - Conducted by calculating Tier 2 site-specific target levels (SSTLs) using site-specific information as inputs to the same or similar methodology used to calculate Tier 1 action levels. The Tier 2 SSTLs are then compared to individual sample results from reasonable points of exposure (as opposed to the source areas as is done in Tier 1) on a point-by-point basis. Total petroleum hydrocarbons (TPH) concentrations will not be used for risk-based decisions under Tier 2 or Tier 3. Rather, the individual chemical constituents of diesel will be compared to the SSTLs.

- Tier 3 evaluation - Conducted by calculating Tier 3 SSTLs on the basis of more sophisticated risk analyses using methodologies described in Method E1739 that consider site-, pathway-, and receptor-specific parameters.

If a Tier 2 or Tier 3 FAL was calculated based on an exposure scenario other than the Industrial Area scenario, a corrective action of closure in place with an administrative use restriction will be required in addition to any other corrective action applied to the CAS to prevent future industrial use of the area. For this reason, contamination at all sites will be evaluated against industrial-exposure-scenario-based FALs, and if applicable, site-specific-exposure-scenario-based FALs. The FALs (along with the basis for their selection) will be proposed in the Corrective Action Decision Document (CADD), where they will be compared to laboratory results in the evaluation of potential corrective actions.

This RBCA process includes a provision for conducting an interim remedial action if necessary and appropriate. The decision to conduct an interim action may be made at any time during the investigation and at any level (tier) of analysis. Concurrence of the decision-makers listed in Section A.2.1 will be obtained before any interim action is implemented. Evaluation of DQO 


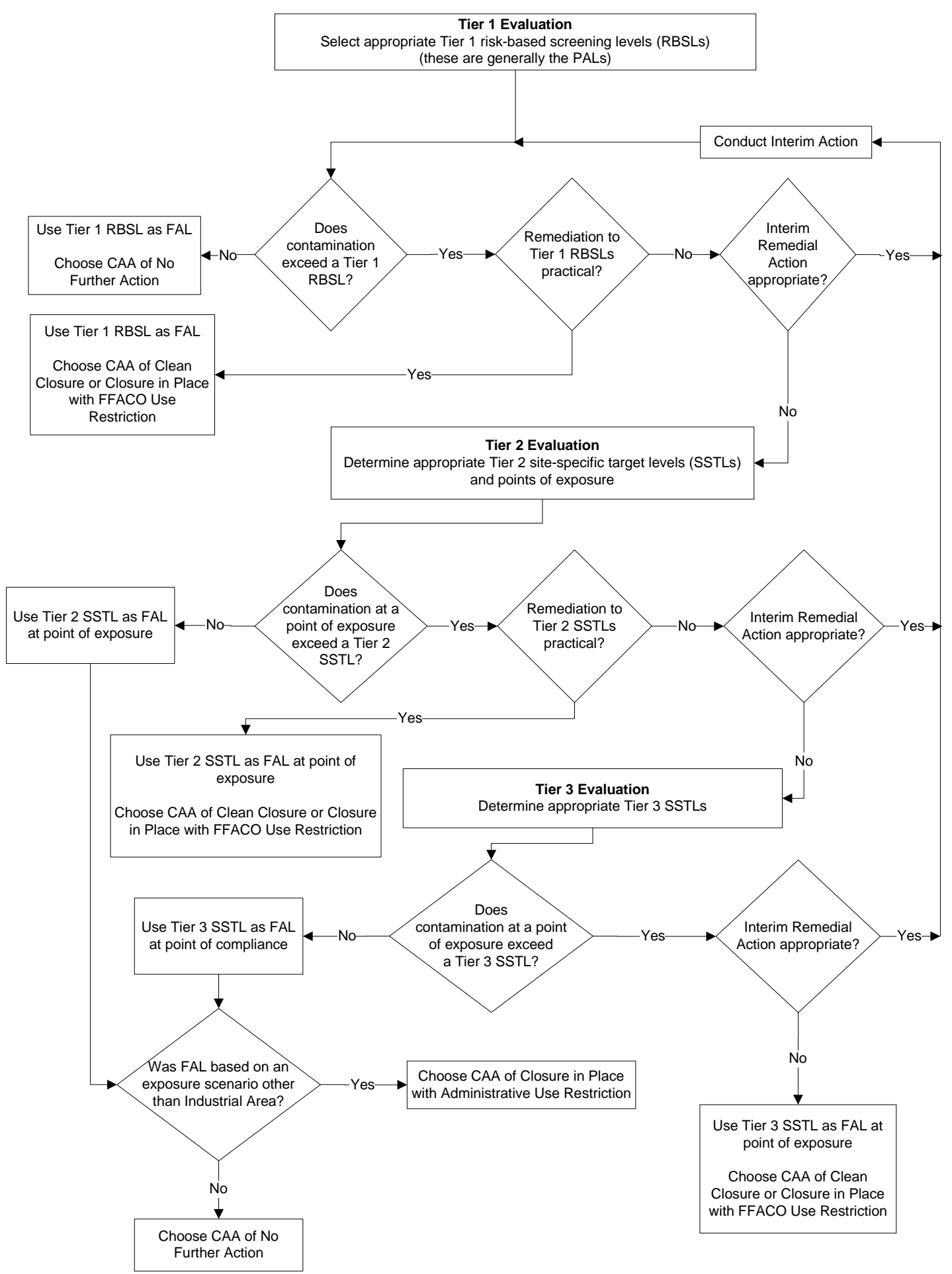

(ASTM, 1995)

Figure 3-3

Risk-Based Corrective Action Decision Process 
decisions will be based on conditions at the site following completion of any interim actions. Any interim actions conducted will be reported in the CADD.

\subsubsection{Chemical PALs}

Except as noted herein, the chemical PALs are defined as the U.S. Environmental Protection Agency (EPA) Region 9: Superfund, Preliminary Remediation Goals, Screening Levels for Chemical Contaminants in industrial soils (EPA, 2009). Background concentrations for RCRA metals will be used instead of screening levels when natural background concentrations exceed the screening level, as is often the case with arsenic on the NTS. Background is considered the mean plus two standard deviations of the mean for sediment samples collected by the Nevada Bureau of Mines and Geology throughout the Nevada Test and Training Range (formerly the Nellis Air Force Range)

(NBMG, 1998; Moore, 1999). For detected chemical COPCs without established screening levels, the protocol used by the EPA Region 9 in establishing screening levels (or similar) will be used to establish PALs. If used, this process will be documented in the CADD.

\subsubsection{Radionuclide PALs}

The PAL for radioactive contaminants is 25-millirem-per-year (mrem/yr) total effective dose (TED), based upon the Industrial Area exposure scenario. The Industrial Area exposure scenario is described in Industrial Sites Project Establishment of Final Action Levels (NNSA/NSO, 2006). That document establishes the default exposure conditions and Residual Radioactive (RESRAD) computer code input parameters to be used to calculate the potential radiation dose over a land area. Several input parameters are not specified so that site-specific information can be used.

For test releases, the Industrial Area scenario has been modified by pre-specifying values for several input parameters (such as an area of contamination of 1000 square meters $\left[\mathrm{m}^{2}\right]$ and a depth of contamination of $5 \mathrm{~cm}$ ). In addition, Derived Concentration Guideline (DCG) values for each individual radionuclide COPC were calculated. The DCG is the value, in pCi/g for surface soil, for a particular radionuclide, that would result in a dose of $25 \mathrm{mrem} / \mathrm{yr}$. Using DCGs in site evaluation facilitates the determination of a radiation dose estimate for each soil sample. 


\subsection{Data Quality Objective Process Discussion}

This section contains a summary of the DQO process that is presented in Appendix A. The DQO process is a strategic planning approach based on the scientific method that is designed to ensure that the data collected will provide sufficient and reliable information to identify, evaluate, and technically defend the recommendation of viable corrective actions (e.g., no further action, clean closure, or closure in place).

As presented in Section 1.1.2, the DQOs address two types of potential contaminant release scenarios:

- Test releases of contaminants are defined as the initial release of radionuclides from the nuclear test detonations.

- Non-test releases of contamination include the translocation of contamination deposited under the test release scenario (e.g., migration in stormwater runoff, excavated soil) and other potential releases (e.g., spills, lead-containing items, and potential source material [PSM]).

The test releases will be investigated through a combination of probabilistic and judgmental sampling, and the non-test releases will be investigated through judgmental sampling. Therefore, discussions related to these two release scenarios are presented separately.

The DQO strategy for CAU 106 was developed at a meeting on January 19, 2010. The DQOs were developed to identify data needs, clearly define the intended use of the environmental data, and to design a data collection program that will satisfy these purposes. During the DQO discussions for this CAU, the informational inputs or data needs to resolve problem statements and decision statements were documented.

The problem statement for CAU 106 is: "Existing information on the nature and extent of potential contamination is insufficient to evaluate and recommend CAAs for the CASs in CAU 106.” To address this problem statement, resolution of the following decision statements is required:

- Decision I: “Is any COC present in environmental media within the CAS?” If a COC is detected, then Decision II must be resolved. 
- Decision II: "If a COC is present, is sufficient information available to evaluate potential CAAs?" Sufficient information is defined to include:

- The lateral and vertical extent of COC contamination

- The information needed to determine potential remediation waste types

- The information needed to evaluate the feasibility of remediation alternatives

The presence of a COC would require a corrective action. A corrective action may also be necessary if there is a potential for wastes (i.e., PSM) that are present at a site to result in the introduction of COCs into site environmental media. To evaluate the potential for wastes to result in the introduction of a COC to the surrounding environmental media, the following conservative assumptions were made:

- Any containment of waste (e.g., fuel/oil reservoirs, pipe, concrete vaults and walls, drums) would fail at some point, and the waste would be released to the surrounding soil.

- A waste, regardless of concentration or configuration, may be assumed to be PSM and handled under a corrective action.

- Based on process knowledge and/or professional judgment, some waste may be assumed to not be PSM if it is clear that it could not result in soil contamination exceeding a FAL.

- If assumptions about the waste cannot be made, then the waste material will be sampled, and the results will be compared to FALs based on the following criteria:

- For non-liquid wastes, the concentration of any chemical contaminant in soil (following degradation of the waste and release of contaminants into soil) would be equal to the mass of the contaminant in the waste divided by the mass of the waste.

- For non-liquid wastes, the dose resulting from radioactive contaminants in soil (following degradation of the waste and release of contaminants into soil) would be calculated using the activity of the contaminant in the waste divided by the mass of the waste (for each radioactive contaminant) and calculating the combined resulting dose using the RESRAD code (Murphy, 2004).

- For liquid wastes, the resulting concentration of contaminants in the surrounding soil would be calculated based on the concentration of contaminants in the wastes and the liquid-holding capacity of the soil.

For the test and non-test release scenarios, Decision I will be resolved by submitting Decision I samples to analytical laboratories to determine the presence of COCs. CAS-specific samples will be submitted for the analyses listed in Table 3-1. The specific analyses for samples from non-test 
releases identified during the CAI will be selected dependent upon the type and nature of the identified release. Decision II samples for both release scenarios will be submitted as necessary to define the extent of unbounded COCs. In addition, samples will be submitted for analyses, as needed, to support waste management or health and safety decisions.

For the laboratory data, the data quality indicators (DQIs) of precision, accuracy, representativeness, completeness, comparability, and sensitivity needed to satisfy DQO requirements are discussed in Section 6.2. Laboratory data will be assessed in the CADD to confirm or refute the CSM. Analytical methods and target minimum detectable concentrations (MDCs) for each CAU 106 COPC are provided in Tables 3-3 and 3-4. The criteria for precision and accuracy listed in Tables 3-3 and 3-4 may vary from information in the QAPP as a result of the laboratory used or updated/new methods (NNSA/NV, 2002a).

Table 3-3

Analytical Requirements for Radionuclides for CAU 106

(Page 1 of 2)

\begin{tabular}{|c|c|c|c|c|c|}
\hline Analysis $^{a}$ & $\begin{array}{l}\text { Medium or } \\
\text { Matrix }\end{array}$ & $\begin{array}{l}\text { Analytical } \\
\text { Method }\end{array}$ & $M^{\prime} C^{b}$ & $\begin{array}{l}\text { Laboratory } \\
\text { Precision }\end{array}$ & $\begin{array}{c}\text { Laboratory } \\
\text { Accuracy }\end{array}$ \\
\hline \multicolumn{6}{|c|}{ Gamma-Emitting Radionuclides } \\
\hline \multirow[b]{2}{*}{$\begin{array}{c}\text { Gamma } \\
\text { Spectroscopy }\end{array}$} & $\overline{\overline{\text { Aqueous }}}$ & $\overline{\text { EPA 901.1 }}$ & \multirow[b]{2}{*}{$1 / 10 D C G s^{d}$} & \multirow{2}{*}{$\begin{array}{c}\text { RPD } \\
35 \% \text { (non-aqueous) }^{\mathrm{e}} \\
20 \% \text { (aqueous) }^{\mathrm{e}} \\
\mathrm{ND} \\
-2<\mathrm{N}<\mathrm{T}^{\mathrm{f}}\end{array}$} & \multirow[b]{2}{*}{$\begin{array}{c}\text { LCS Recovery } \\
(\% \mathrm{R}) \\
80-120^{\mathrm{g}}\end{array}$} \\
\hline & Non-aqueous & GA-01-R & & & \\
\hline \multicolumn{6}{|c|}{ Other Radionuclides } \\
\hline Isotopic U & All & $\overline{U-02-R C^{n}}$ & \multirow{7}{*}{$1 / 10 D_{C G s^{d}}$} & \multirow{4}{*}{$\begin{array}{c}\text { RPD } \\
35 \% \text { (non-aqueous) }^{\mathrm{e}} \\
20 \% \text { (aqueous) }^{\mathrm{e}}\end{array}$} & \multirow{4}{*}{$\begin{array}{c}\text { Chemical Yield } \\
\text { Recovery (\%R) } \\
\text { 30-105 }\end{array}$} \\
\hline \multirow{2}{*}{ Isotopic Pu } & Aqueous & Pu-10-RC & & & \\
\hline & Non-aqueous & $P u-02-R C^{h}$ & & & \\
\hline \multirow{2}{*}{ Isotopic Am } & Aqueous & $A m-03-R C^{h}$ & & & \\
\hline & Non-aqueous & $A m-01-R C^{h}$ & & \multirow{3}{*}{$\begin{array}{c}N D \\
-2<N D<2^{f}\end{array}$} & \multirow{3}{*}{$\begin{array}{c}\text { LCS Recovery } \\
(\% \mathrm{R}) \\
80-120^{\mathrm{i}}\end{array}$} \\
\hline \multirow{2}{*}{ Sr-90 } & Aqueous & EPA 905.0 & & & \\
\hline & Non-aqueous & Sr-02-RC & & & \\
\hline
\end{tabular}


Table 3-3

Analytical Requirements for Radionuclides for CAU 106 (Page 2 of 2)

\begin{tabular}{|c|c|c|c|c|c|}
\hline Analysis $^{a}$ & $\begin{array}{l}\text { Medium or } \\
\text { Matrix }\end{array}$ & $\begin{array}{c}\text { Analytical } \\
\text { Method }\end{array}$ & $M^{\prime b} C^{b}$ & $\begin{array}{l}\text { Laboratory } \\
\text { Precision }\end{array}$ & $\begin{array}{l}\text { Laboratory } \\
\text { Accuracy }\end{array}$ \\
\hline \multirow{2}{*}{ Gross Alpha/Beta } & Aqueous & EPA $900.0^{c}$ & \multirow{4}{*}{$1 / 10 D C G s^{d}$} & \multirow{4}{*}{$\begin{array}{c}\text { RPD } \\
35 \% \text { (non-aqueous) }^{\mathrm{e}} \\
20 \% \text { (aqueous) }^{\mathrm{e}}\end{array}$} & \multirow{4}{*}{$\begin{array}{c}\text { MS Recovery } \\
(\% R) \\
\text { Lab-specific } \\
\text { LCS Recovery } \\
(\% \mathrm{R}) \\
80-120^{\mathrm{i}}\end{array}$} \\
\hline & Non-aqueous & SM $7110 B^{k}$ & & & \\
\hline \multirow[b]{2}{*}{ Tritium } & Aqueous & EPA 906.0 & & & \\
\hline & Non-aqueous & $\begin{array}{l}\text { Laboratory } \\
\text { Procedure }\end{array}$ & & & \\
\hline
\end{tabular}

${ }^{\mathrm{a} A}$ list of constituents reported for each method is provided in Table 3-2.

${ }^{\mathrm{b}} \mathrm{The} \mathrm{MDC}$ is the minimum concentration of a constituent that can be measured and reported with $95 \%$ confidence (Standard Methods) ${ }^{\mathrm{k}}$.

${ }^{\mathrm{c}}$ Prescribed Procedures for Measurement of Radioactivity in Drinking Water (EPA, 1980).

${ }^{\mathrm{d}}$ The DCG is the value, in pCi/g of surface soil, for a particular radionuclide that would result in a dose of $25 \mathrm{mrem} / \mathrm{IA}-\mathrm{yr}$ (e.g., the PAL).

'Sampling and Analysis Plan Guidance and Template (EPA, 2000).

${ }^{\mathrm{f}}$ Evaluation of Radiochemical Data Usability (Paar and Porterfield, 1997).

${ }^{9}$ Test Methods for Evaluating Solid Waste, Physical/Chemical Methods (EPA, 2008).

${ }^{\mathrm{h}}$ The Procedures Manual of the Environmental Measurements Laboratory (DOE, 1997).

'Professional judgment and other industry acceptance criteria are used.

'Accuracy criteria are developed in-house using approved laboratory standard operating procedures in accordance with industry standards and the NNES Statement of Work requirements.

kStandard Methods for the Examination of Water and Wastewater (Clesceri et al., 1998).

'Laboratory standard operating procedures in accordance with industry standards and the NNES Statement of Work requirements (NNES, 2009).

LCS = Laboratory control sample

mrem/IA-yr = Millirem per Industrial Access year

MS = Matrix spike

$\mathrm{ND}=$ Normalized difference
NNES = Navarro Nevada Environmental Services, LLC

RPD $=$ Relative percent difference

$\% \mathrm{R}=$ Percent recovery 
Table 3-4

Analytical Requirements for Chemicals for CAU 106

\begin{tabular}{|c|c|c|c|c|c|}
\hline Analysis $^{a}$ & $\begin{array}{l}\text { Medium or } \\
\text { Matrix }\end{array}$ & $\begin{array}{c}\text { Analytical } \\
\text { Method }\end{array}$ & $\mathrm{MDC}^{\mathbf{b}}$ & $\begin{array}{l}\text { Laboratory } \\
\text { Precision }\end{array}$ & $\begin{array}{c}\text { Laboratory } \\
\text { Accuracy }\end{array}$ \\
\hline \multicolumn{6}{|c|}{ Organics } \\
\hline VOCs & All & $8260^{c}$ & \multirow{3}{*}{$<$ FALs } & \multirow{3}{*}{ Lab-specific $^{d}$} & \multirow{3}{*}{ Lab-specific $^{d}$} \\
\hline SVOCs & All & $8270^{c}$ & & & \\
\hline PCBs & All & $8082^{c}$ & & & \\
\hline \multicolumn{6}{|c|}{ Inorganics } \\
\hline Metals & All & $6010 / 6020^{c}$ & \multirow{3}{*}{$<$ FALs } & \multirow{3}{*}{$\begin{array}{c}\text { RPD } \\
35 \% \text { (non-aqueous) }^{2} \\
20 \% \text { (aqueous) }^{\mathrm{e}} \\
\\
\text { Absolute Difference } \\
\pm 2 \times \text { RL (non-aqueous) } \\
\pm 1 \times \text { RL (aqueous) }\end{array}$} & \multirow{3}{*}{$\begin{array}{c}\text { MS Recovery } \\
(\% \mathrm{R}) \\
75-125^{\mathrm{c}} \\
\\
\text { LCS Recovery } \\
(\% \mathrm{R}) \\
80-120^{\mathrm{c}}\end{array}$} \\
\hline \multirow[b]{2}{*}{ Mercury } & Aqueous & $7470^{c}$ & & & \\
\hline & Non-aqueous & $7471^{\mathrm{c}}$ & & & \\
\hline
\end{tabular}

${ }^{\mathrm{a}} \mathrm{A}$ list of constituents reported for each method is provided in Table 3-2.

${ }^{\mathrm{b}} \mathrm{The}$ MDC is the minimum concentration of a constituent that can be measured and reported with 99\% confidence (EPA, 2008).

${ }^{\mathrm{C}}$ Test Methods for Evaluating Solid Waste, Physical/Chemical Methods (EPA, 2008).

${ }^{\mathrm{d}}$ Precision and accuracy criteria are developed in-house using approved laboratory standard operating procedures in accordance with industry standards and the NNES Statement of Work requirements (NNES, 2009).

eSampling and Analysis Plan Guidance and Template (EPA, 2000).

${ }^{\ddagger}$ Contract Laboratory Program National Functional Guidelines for Inorganic Data Review (EPA, 2004).

$\mathrm{RL}=$ Reporting limit 


\subsection{Field Investigation}

This section contains a description of the activities to be conducted to gather and document information from the CAU 106 field investigation.

\subsection{Technical Approach}

The information necessary to satisfy the DQO data needs will be generated for CAU 106 by collecting and analyzing samples generated during a field investigation. The investigation will generate information required to evaluate the potential CAAs of no further action, clean closure, and closure in place.

The presence and nature of contamination for the test release scenario will be evaluated using a combination of judgmental and probabilistic approaches. Sample plots will be selected and evaluated judgmentally, and the samples collected within the sample plots will be collected and evaluated probablistically. However, a sample plot will not be established at Able. Available information indicates that soil contamination above FALs at this site is not expected. Therefore, only individual judgmental samples will be collected for the purpose of confirming that COCs are not present. All non-test releases (e.g., 306 GZ and 307 GZ) will be located, and the associated samples will be analyzed based on judgmental criteria. If it is determined that a COC is present at any CAS, that CAS will be further addressed by determining the extent of contamination before evaluating CAAs.

The TED will be determined by summing internal and external dose measurements. Sample results for individual radionuclides will be used to calculate internal dose using RESRAD computer code (Yu et al., 2001). External dose will be determined by collecting in situ measurements using a TLD. The TLD will be installed at the approximate center of the sample plot at a height of $1 \mathrm{~m}$ and be left in place for approximately 2,250 hours (equivalent to an annual industrial worker exposure). Each TLD contains three elements from which external dose measurements will be reported. For sample plots, the 95 percent UCL of the average TED for each plot will be the sum of the 95 percent UCL of the three TLD element estimates of external dose and the 95 percent UCL of the four estimates of internal 
dose from the soil samples. At Able, individual sample locations will be established rather than a sample plot. Therefore, the measured TED will be compared directly to the FAL.

Modifications to the investigative strategy may be required should unexpected field conditions be encountered at any CAS. Significant modifications shall be justified and documented before implementation. If an unexpected condition indicates that conditions are significantly different than the CSM, the activity will be rescoped and the identified decision-makers will be notified.

\subsection{Field Activities}

Field activities at CAU 106 include site preparation, sample location selection, sample collection, and demobilization.

\subsubsection{Site Preparation Activities}

Site preparation activities to be conducted before the start of environmental sampling may include relocating or removing surface debris and equipment, constructing hazardous waste accumulation areas (HWAAs) and site exclusion zones, constructing decontamination facilities, and moving staged equipment.

Before mobilization for collecting investigation samples, the following preparatory activities will also be conducted:

- Perform radiological surveys at GMX, Able, and Hamilton, and potentially at 306 GZ and 307 GZ.

- Install project-specific environmental monitoring TLDs (see Section 4.2.3 for additional information).

- Perform geophysical surveys at 306 GZ, 307 GZ, and GMX.

- Perform visual surveys at all CASs within CAU 106 to identify staining or soil discoloration, disturbance of native soils, wastes that may be PSM, or any other indication of potential contamination.

\subsubsection{Sample Location Selection}

Rationale for selecting areas for sampling is discussed in the following sections. 


\subsubsection{Test Releases}

Decision I will be evaluated by measuring TED either (1) within a sample plot (at Hamilton and GMX) established within the area of the highest Am-241 activities as determined from the 1994 flyover survey (BN, 1999) or a radiological survey conducted with a handheld instrument, or (2) at a single judgemental sample location (Able) determined based on radiological survey values. This will be done in an effort to find the location where the internal dose contributes the greatest amount to TED. At Hamilton and GMX, the highest Am activities may be an indicator of the greatest concentration of $\mathrm{Pu}$.

At Hamilton, if the 95 percent UCL of the TED at the Decision I sample plot exceeds 25 millirem per Industrial Access year (mrem/IA-yr), then at least two Decision II sample plot locations will be judgmentally established along each of three vectors with the Decision I plot central to all vectors. The Decision II sample plot locations must meet the criterion that at least one sample plot on each vector will be located outside the 25-mrem/IA-yr boundary. The same will apply at GMX, except that at least four Decision II sample plot locations will be established along each of three vectors with the Decision I plot being included in one of the vectors.

All soil samples collected at each sample plot and all TLDs placed at each sample plot will be sampled as described in Section 4.2.3.

\subsubsection{Non-test Releases}

For non-test releases at CAU 106, a judgmental sampling approach will be used to investigate the likelihood of the soil containing a COC. For the investigation of drainages, sample locations will be at locations determined from radiological survey results, or at the center of the two nearest sediment accumulation areas down gradient and outside the initial corrective action boundary. For the other non-test releases, biasing factors, such as stains, geophysical anomalies, radiological survey results, and wastes suspected of containing hazardous or radiological components, will be used to select the most appropriate samples from a particular location for collection and analysis. Biasing factors to be used for selection of sample locations are listed in Section A.8.4. As biasing factors are identified and used for selection of sampling locations, they will be documented in the appropriate field documents. 
If a COC is present at any non-test release scenario sample location, Decision II sampling will be conducted to define the extent of contamination. Extent (Decision II) sampling locations at each CAS will be selected based on the CSM, biasing factors, field-survey results, existing data, and the outer boundary sample locations where COCs are detected. In general, extent sample locations will be arranged in a triangular pattern around areas containing a COC at distances based on site conditions, COC concentrations, process knowledge, and biasing factors. If COCs extend beyond extent locations, additional Decision II samples will be collected from locations farther from the source. If a spatial boundary is reached, the CSM is shown to be inadequate, or the Site Supervisor determines that extent sampling needs to be re-evaluated, then work will be temporarily suspended, NDEP will be notified, and the investigation strategy will be re-evaluated. A minimum of one analytical result less than the action level from each lateral and vertical direction will be required to define the extent of COC contamination. The lateral and vertical extent of COCs will only be established based on validated laboratory analytical results (i.e., not field screening).

The sampling strategy and the estimated (or example) locations of biased samples are presented in Appendix A. The Task Manager or Site Supervisor may modify the number, location, and spacing of step-out samples as warranted by site conditions to achieve DQO criteria stipulated in Appendix A. Where sampling locations are modified, the justification for these modifications will be documented in the CADD.

\subsubsection{Sample Collection}

The CAU 106 sampling program will consist of the following activities:

- $\quad$ Collect and analyze samples from locations as described in Section 4.2.2.

- Collect required QC samples.

- Collect waste management samples as necessary.

- Collect external dose measurements by hanging TLDs at the sample plots, or collect instrument dose readings at extent locations.

- Collect soil samples from locations outside the influence of releases from the CAS, if necessary. 
- Perform radiological characterization surveys of construction materials and debris as necessary for disposal purposes.

- Record Global Positioning System (GPS) coordinates for each environmental sample location, as is feasible.

For the test release scenario at sites where Decision I and Decision II sample plots will be judgmentally established (i.e., Hamilton and GMX), a probabilistic sampling approach will be implemented for determining the internal dose by collecting composite samples within each 10-by-10-m plot. Each composite sample will consist of soil collected from nine random locations within the plot. For each composite sample, the first location will be selected randomly, and the remaining eight subsample locations will be established on a systematic triangular grid (see Section A.8.0). External dose will be determined by collecting in situ measurements using a TLD. The TLD will be installed at the approximate center of the sample plot at a height of $1 \mathrm{~m}$ and be left in place for approximately 2,250 hours (equivalent to an annual industrial worker exposure). At Able, a minimum of one sample location will be established rather than a sample plot. At this location, soil samples will be collected and field screened from various depth intervals (e.g., 0 to $5 \mathrm{~cm}, 5$ to $10 \mathrm{~cm}, 10$ to $15 \mathrm{~cm}$ bgs) to determine whether buried contamination exists. Samples collected at sample plots will be from the surface (0 to $5 \mathrm{~cm}$ bgs) unless it is determined that buried contamination exists. The process for determining whether buried contamination exists at Able and Hamilton is described in Section A.8.1.3.

For the non-test release scenario, Decision I samples (0 to $15 \mathrm{~cm}$ bgs) will be collected from sediment accumulation areas in drainages and other biased locations as described in Sections A.8.4.1.1 through A.8.4.1.3. If biasing factors are present in soils below locations where Decision I samples were collected, subsurface soil samples will also be collected by augering, backhoe excavation, direct-push, or drilling techniques, as appropriate. Subsurface soil samples will be collected at depth intervals selected by the Site Supervisor based on biasing factors to a depth where the biasing factors are no longer present. Decision II sampling of other non-test releases will consist of further defining the extent of contamination where COCs have been confirmed. If a COC is present in a drainage sedimentation area, then additional sediment depth samples will be collected until two consecutive samples have analytical results less than FALs. Downstream accumulation areas also will be sampled until two consecutive areas have analytical results less than FALs. A minimum of one analytical 
result less than the action level from each lateral and vertical direction will be required to define the extent of COC contamination.

\subsubsection{Sample Management}

The laboratory requirements (i.e., MDCs, precision, and accuracy) to be used when analyzing the COPCs are presented in Tables 3-3 and 3-4. The analytical program is presented in Table 3-1. All sampling activities and QC requirements for field and laboratory environmental sampling will be conducted in compliance with the Industrial Sites QAPP (NNSA/NV, 2002a) and other applicable, approved procedures.

\subsection{Safety}

A site-specific health and safety document will be prepared and approved before the field effort. This document defines the requirements for protecting the health and safety of the workers and the public. The following safety issues will be taken into consideration when evaluating the hazards and associated control procedures for field activities:

- Potential hazards to site personnel and the public, including, but not limited to, radionuclides, chemicals (e.g., heavy metals, VOCs, SVOCs, and petroleum hydrocarbons), adverse and rapidly changing weather, remote location, and motor vehicle and heavy equipment operations.

- $\quad$ Proper training of all site personnel to recognize and mitigate the anticipated hazards.

- Work controls to reduce or eliminate the hazards, including engineering controls, substitution of less hazardous materials, and use of appropriate PPE.

- Occupational exposure monitoring to prevent overexposures to hazards, such as radionuclides, chemicals, and physical agents (e.g., heat, cold, and high wind).

- Radiological surveying for alpha/beta and gamma emitters to minimize and/or control personnel exposures, and use of the "as-low-as-reasonably-achievable” principle when addressing radiological hazards.

- Emergency and contingency planning to include medical care and evacuation, decontamination, spill control measures, and appropriate notification of project management. The same principles apply to emergency communications. 


\subsection{Site Restoration}

Upon completion of CAI and waste management activities, the following actions will be implemented before closure of the site Real Estate/Operations Permit (REOP):

- All equipment, wastes, debris, and materials associated with the CAI will be removed from the site.

- All CAI-related signage and fencing (unless part of a corrective action) will be removed from the site.

- Site will be inspected and certified that restoration activities have been completed. 


\subsection{Waste Management}

Management of the waste generated during the CAU 106 field investigation will be in accordance with all applicable DOE orders, U.S. Department of Transportation (DOT) regulations, state and federal waste regulations, and agreements and permits between DOE and NDEP. Wastes will be characterized based on these regulations using process knowledge, field-screening results (FSRs), and analytical results from investigation and waste samples. Waste types that may be generated during the CAI include industrial, low-level radioactive, hazardous, hydrocarbon, or mixed wastes.

Disposable sampling equipment, PPE, and rinsate are considered potentially contaminated waste only by virtue of contact with potentially contaminated media (e.g., soil) or potentially contaminated debris (e.g., metal and concrete). Therefore, these wastes may be characterized based on CAI sample results. Conservative estimates of total waste contaminant concentrations may be made based on the mass of the waste, the amount of contaminated media contained in the waste, and the maximum concentration of contamination found in the media.

The following sections discuss how the field investigation will be conducted to minimize the generation of waste, the waste streams that are expected to be generated, and the management of IDW.

\subsection{Waste Minimization}

The CAI will be conducted in a manner that will minimize the generation of wastes by using process knowledge, visual examination, and/or radiological survey and swipe results to avoid collecting uncontaminated media or characterizing uncontaminated IDW as other than industrial or sanitary waste. As appropriate, media and debris will be returned to their original location. To limit unnecessary generation of hazardous or mixed waste, hazardous materials will not be used during the CAI unless required. Other waste minimization practices will include, as appropriate, avoiding contact with contaminated materials, performing dry decontamination or wet decontamination over source locations, and carefully segregating waste streams. 


\subsection{Potential Waste Streams}

The expected waste streams to be generated during the CAU 106 field investigation include industrial and low-level radioactive wastes from the sampling activities. However, because it is uncertain what wastes are present within the CAS boundaries (e.g., lead debris, batteries, historic spills), the following waste streams have been included as potential waste streams that may require management and disposal:

- Disposable sampling equipment and/or PPE

- Environmental media (e.g., soil)

- $\quad$ Surface debris in investigation area (e.g., metal, concrete, batteries)

- Decontamination rinsate

\subsection{Investigation-Derived Waste Management}

The onsite management of IDW will be determined based on regulations associated with the particular waste type (e.g., industrial, low-level radioactive, RCRA hazardous, hydrocarbon, mixed), or the combination of waste types. The following subsections describe how specific waste types will be managed.

\subsubsection{Industrial Waste}

Industrial IDW, if generated, will be collected, managed, and disposed of in accordance with the industrial waste management regulations and the permits for operation of the NTS Waste Landfills.

\subsubsection{Hydrocarbon Waste}

Hydrocarbon wastes, if generated, will be managed on site in a drum or other appropriate container until fully characterized. Hydrocarbon waste may be disposed of at a designated hydrocarbon landfill, an appropriate hydrocarbon waste management facility (e.g., recycling facility) or other method in accordance with the State of Nevada regulations (NDEP, 1997).

\subsubsection{Low-Level Radioactive Waste}

Low-level radioactive wastes, if generated, will be managed in accordance with the contractor-specific waste certification program plan, DOE orders, and the requirements of the current 
version of the Nevada Test Site Waste Acceptance Criteria (NTSWAC) (NNSA/NSO, 2009). Potential radioactive waste drums containing soil, PPE, disposable sampling equipment, and/or rinsate may be staged and managed at a designated radioactive material area (RMA).

\subsubsection{Hazardous Waste}

Suspected RCRA hazardous wastes, if generated, will be placed in DOT-compliant containers. All containerized hazardous waste will be handled, inspected, and managed in accordance with Title 40 Code of Federal Regulations (CFR) 262.34 (CFR, 2009a).

\subsubsection{Mixed Low-Level Waste}

Mixed wastes, if generated, shall be managed according to the requirements for hazardous wastes and the requirements for low-level waste.

\subsubsection{Polychlorinated Biphenyls}

Polychlorinated biphenyl wastes, if generated, will be managed according to 40 CFR 761

(CFR, 2009b), State of Nevada requirements (NAC, 2008a), and DOE guidance. 


\subsection{Quality Assurance/Quality Control}

The overall objective of the characterization activities described in this CAIP is to collect accurate and defensible data to support the selection and implementation of a closure alternative for CASs in CAU 106. The data from the TLD measurements will also meet rigorous data quality requirements. The TLDs will be obtained from, and measured by, the Environmental Technical Services group at the NTS. This group is responsible for a routine environmental monitoring program at the NTS. The program includes a campaign of TLDs that are emplaced at pre-established locations across the NTS for the monitoring of external dose. The TLDs are replaced and read quarterly. Details of this campaign can be found in the Nevada Test Site Environmental Report 2006 (NNSA/NSO, 2007). The TLDs will be submitted to the Environmental Technical Services group for inclusion in their routine quarterly read of the NTS environmental monitoring TLDs. The TLDs will be analyzed using automated TLD readers that are calibrated and maintained by the National Security Technologies, LLC, Radiological Control Department in accordance with existing QC procedures for TLD processing. A summary of the routine environmental monitoring TLD QC efforts and results can be found in Section 5.2.1 of the Nevada Test Site Environmental Report 2006 (NNSA/NSO, 2007). Certification is maintained through the DOE Laboratory Accreditation Program for dosimetry.

It was decided that the determination of the external dose component of the TED by TLDs would be the most accurate method because of the following reasons:

1. The TLDs will be exposed at the sample plots for the 2,250 hours of exposure time used for the Industrial Area exposure scenario. This eliminates errors in reading dose-rate meter scale graduations and needle fluctuations that would be magnified when as-read meter values are multiplied from units of “per hour” to 2,250 hours.

2. The use of a TLD to determine an individual's external exposure is the standard in radiation safety and serves as the "legal dose of record" when other measurements are available. Specifically, 10 CFR 835.402 (CFR, 2009c) requires that personnel dosimeters shall be provided to monitor individual exposures and that the monitoring program that uses the dosimeters shall be accredited in accordance with the DOE Laboratory Accreditation Program for Personnel Dosimetry. 
Sections 6.1 and 6.2 discuss the collection of required QC samples in the field and QA requirements for soil samples.

\subsection{Quality Control Sampling Activities}

Field QC samples will be collected in accordance with established procedures. Field QC samples are collected and analyzed to aid in determining the validity of environmental sample results. The number of required QC samples depends on the types and number of environmental samples collected. As determined in the DQO process, the minimum frequency of collecting and analyzing QC samples for this investigation are:

- For radiological samples:

- Field duplicates (1 per 20 environmental samples or 1 per CAS per matrix, if less than 20 collected)

- Laboratory QC samples (1 per 20 environmental samples or 1 per CAS per matrix, if less than 20 collected)

- For chemical samples:

- Trip blanks (1 per sample cooler containing VOC environmental samples)

- Equipment rinsate blanks (1 per sampling event for each type of decontamination procedure)

- Source blanks (1 per lot of uncharacterized source material that contacts sampled media)

- Field duplicates (1 per 20 environmental samples or 1 per CAS per matrix, if less than 20 collected)

- Field blanks (1 per CAS)

- Full laboratory QC samples (1 per 20 environmental samples or 1 per CAS per matrix, if less than 20 collected)

Additional QC samples may be submitted based on site conditions at the discretion of the Task Manager or Site Supervisor. Field QC samples shall be analyzed using the same analytical procedures implemented for associated environmental samples. Additional details regarding field QC samples are available in the Industrial Sites QAPP (NNSA/NV, 2002a). 


\subsection{Laboratory/Analytical Quality Assurance}

As stated in the DQOs (Appendix A), and except where noted, laboratory analytical quality data will be used for making DQO decisions. Rigorous QA/QC will be implemented for all laboratory samples, including documentation, data verification and validation of analytical results, and an assessment of DQIs as they relate to laboratory analysis.

\subsubsection{Data Validation}

Data verification and validation will be performed in accordance with the Industrial Sites QAPP (NNSA/NV, 2002a), except where otherwise stipulated in this CAIP. All chemical and radiological laboratory data from samples that are collected and analyzed will be evaluated for data quality according to company-specific procedures. The data will be reviewed to ensure that all required samples were appropriately collected, analyzed, and the results met data validation criteria. Validated data, including estimated data (i.e., J-qualified), will be assessed to determine whether the data meet the DQO requirements of the investigation and the performance criteria for the DQIs. The results of this assessment will be documented in the CADD. If the DQOs were not met, corrective actions will be evaluated, selected, and implemented (e.g., refine CSM or resample to fill data gaps).

\subsubsection{Data Quality Indicators}

The DQIs are qualitative and quantitative descriptors used in interpreting the degree of acceptability or utility of data. Data quality indicators are used to evaluate the entire measurement system and laboratory measurement processes (i.e., analytical method performance) as well as to evaluate individual analytical results (i.e., parameter performance). The quality and usability of data used to make DQO decisions will be assessed based on the following DQIs:

- Precision

- Accuracy/bias

- Representativeness

- Completeness

- Comparability

- Sensitivity

Table 6-1 provides the established analytical method/measurement system performance criteria for each of the DQIs and the potential impacts to the decision if the criteria are not met. The TLDs will 
be analyzed using automated TLD readers that are calibrated and maintained in accordance with existing QC procedures for TLD processing (Section 6.0) by a laboratory that is certified through the DOE Laboratory Accreditation Program for Personnel Dosimetry. The data from this system meets rigorous data quality requirements and will be assessed for the listed DQIs before inclusion in the CAU 106 dataset. Therefore, a separate evaluation of the TLD dataset against the DQIs will not be conducted.

The following subsections discuss each of the DQIs that will be used to assess the quality of laboratory data. The criteria for precision and accuracy in Tables 3-3 and 3-4 may vary from corresponding information in the Industrial Sites QAPP as a result of changes in analytical methodology and laboratory contracts (NNSA/NV, 2002a).

Table 6-1

Laboratory and Analytical Performance Criteria for CAU 106 DQIs

\begin{tabular}{|c|c|c|}
\hline DQI & Performance Metric & $\begin{array}{l}\text { Potential Impact on Decision } \\
\text { If Performance Metric Not Met }\end{array}$ \\
\hline Precision & $\begin{array}{l}\text { At least } 80 \% \text { of the sample results for each } \\
\text { measured contaminant are not qualified for } \\
\text { precision based on the criteria for each analytical } \\
\text { method-specific and laboratory-specific criteria } \\
\text { presented in Section } 6.2 .3 \text {. }\end{array}$ & $\begin{array}{l}\text { The affected analytical results from each } \\
\text { affected CAS will be assessed to } \\
\text { determine whether there is sufficient } \\
\text { confidence in analytical results to use the } \\
\text { data in making DQO decisions. }\end{array}$ \\
\hline Accuracy & $\begin{array}{l}\text { At least } 80 \% \text { of the sample results for each } \\
\text { measured contaminant are not qualified for } \\
\text { accuracy based on the method-specific and } \\
\text { laboratory-specific criteria presented in } \\
\text { Section } 6.2 .4 \text {. }\end{array}$ & $\begin{array}{l}\text { The affected analytical results from each } \\
\text { affected CAS will be assessed to } \\
\text { determine whether there is sufficient } \\
\text { confidence in analytical results to use the } \\
\text { data in making DQO decisions. }\end{array}$ \\
\hline Representativeness & $\begin{array}{l}\text { Samples contain contaminants at concentrations } \\
\text { present in the environmental media from which they } \\
\text { were collected. }\end{array}$ & $\begin{array}{l}\text { Analytical results will not represent true } \\
\text { site conditions. Inability to make } \\
\text { appropriate DQO decisions. }\end{array}$ \\
\hline $\begin{array}{c}\text { Decision I } \\
\text { Completeness }\end{array}$ & $80 \%$ of the CAS-specific COPCs have valid results. & $\begin{array}{l}\text { Cannot support/defend decision on } \\
\text { whether COCs are present. }\end{array}$ \\
\hline $\begin{array}{c}\text { Decision II } \\
\text { Completeness }\end{array}$ & $\begin{array}{l}100 \% \text { of COCs used to define extent have valid } \\
\text { results. }\end{array}$ & $\begin{array}{l}\text { Extent of contamination cannot be } \\
\text { accurately determined. }\end{array}$ \\
\hline Comparability & $\begin{array}{l}\text { Sampling, handling, preparation, analysis, } \\
\text { reporting, and data validation are performed using } \\
\text { standard methods and procedures. }\end{array}$ & $\begin{array}{l}\text { Inability to combine data with data } \\
\text { obtained from other sources and/or } \\
\text { inability to compare data to regulatory } \\
\text { action levels. }\end{array}$ \\
\hline Sensitivity & $\begin{array}{l}\text { Minimum detectable concentrations are less than } \\
\text { or equal to respective FALs. }\end{array}$ & $\begin{array}{l}\text { Cannot determine whether COCs are } \\
\text { present or migrating at levels of concern. }\end{array}$ \\
\hline
\end{tabular}




\subsubsection{Precision}

Page 64 of 74

Precision is a measure of the repeatability of the analysis process from sample collection through analysis results and is used to assess the variability between two equal samples.

Determinations of precision will be made for field duplicate samples and laboratory duplicate samples. Field duplicate samples will be collected simultaneously with samples from the same source under similar conditions in separate containers. The duplicate sample will be treated independently of the original sample in order to assess field impacts and laboratory performance on precision through a comparison of results. Laboratory precision is evaluated as part of the required laboratory internal QC program to assess performance of analytical procedures. The laboratory sample duplicates are an aliquot, or subset, of a field sample generated in the laboratory. They are not a separate sample but a split, or portion, of an existing sample. Typically, laboratory duplicate QC samples may include matrix spike duplicate (MSD) and LCS duplicate samples for organic, inorganic, and radiological analyses.

Precision is a quantitative measure used to assess overall analytical method and field-sampling performance as well as to assess the need to "flag” (qualify) individual parameter results when corresponding QC sample results are not within established control limits.

The criteria used for the assessment of inorganic chemical precision when both results are greater than or equal to 5x reporting limit (RL) are 20 percent and 35 percent for aqueous and soil samples, respectively. When either result is less than $5 x \mathrm{RL}$, a control limit of $\pm 1 \mathrm{x} R \mathrm{R}$ and $\pm 2 \mathrm{x}$ RL for aqueous and soil samples, respectively, is applied to the absolute difference.

The criteria used for the assessment of organic chemical precision are based on professional judgment using laboratory-defined control limits. The criteria used for the assessment of radiological precision when both results are greater than or equal to 5x MDC are 20 percent and 35 percent for aqueous and soil samples, respectively. When either result is less than 5x MDC, the ND should be between -2 and +2 for aqueous and soil samples. The parameters to be used for assessment of precision for duplicates are listed in Table 3-4.

Any values outside the specified criteria do not necessarily result in the qualification of analytical data. It is only one factor in making an overall judgment about the quality of the reported analytical 
results. The performance metric for assessing the DQI of precision on DQO decisions (see Table 6-1) is that at least 80 percent of sample results for each measured contaminant are not qualified due to duplicates exceeding the criteria. If this performance is not met, an assessment will be conducted in the CADD on the impacts to DQO decisions specific to affected contaminants at specific CASs.

\subsubsection{Accuracy}

Accuracy is a measure of the closeness of an individual measurement to the true value. It is used to assess the performance of laboratory measurement processes.

Accuracy is determined by analyzing a reference material of known parameter concentration or by reanalyzing a sample to which a material of known concentration or amount of parameter has been added (spiked). Accuracy will be evaluated based on results from three types of spiked samples: MS, LCS, and surrogates (organics). The LCS sample is analyzed with the field samples using the same sample preparation, reagents, and analytical methods employed for the samples. One LCS will be prepared with each batch of samples for analysis by a specific measurement.

The criteria used for the assessment of inorganic chemical accuracy are 75 to 125 percent for MS recoveries and 80 to 120 percent for LCS recoveries. For organic chemical accuracy, MS and LCS laboratory-specific percent recovery criteria developed and generated in-house by the laboratory according to approved laboratory procedures are applied. The criteria used for the assessment of radiochemical accuracy are 80 to 120 percent for LCS and MS recoveries.

Any values outside the specified criteria do not necessarily result in the qualification of analytical data. It is only one factor in making an overall judgment about the quality of the reported analytical results. Factors beyond laboratory control, such as sample matrix effects, can cause the measured values to be outside the established criteria. Therefore, the entire sampling and analytical process may be evaluated when determining the usability of the affected data.

The performance metric for assessing the DQI of accuracy on DQO decisions (see Table 6-1) is that at least 80 percent of the sample results for each measured contaminant are not qualified for accuracy. If this performance is not met, an assessment will be conducted in the CADD on the impacts to DQO decisions specific to affected contaminants and CASs. 


\subsubsection{Representativeness}

Representativeness is the degree to which sample characteristics accurately and precisely represent characteristics of a population or an environmental condition (EPA, 2002). Representativeness is assured by carefully developing the CAI sampling strategy during the DQO process such that false negative and false positive decision errors are minimized. The criteria listed in DQO Step 6 (Specify Performance or Acceptance Criteria) are:

- For Decision I judgmental sampling, having a high degree of confidence that the sample locations selected will identify COCs if present anywhere within the CAS.

- For Decision I probabilistic sampling, having a high degree of confidence that the sample locations selected will represent contamination of the CAS.

- Having a high degree of confidence that analyses conducted will be sufficient to detect any COCs if present in the samples.

- For Decision II, having a high degree of confidence that the sample locations selected will identify the extent of COCs.

These are qualitative measures that will be used to assess measurement system performance for representativeness. The assessment of this qualitative criterion will be presented in the CADD.

\subsubsection{Completeness}

Completeness is defined as generating sufficient data of the appropriate quality to satisfy the data needs identified in the DQOs. For judgmental sampling, completeness will be evaluated using both a quantitative measure and a qualitative assessment. The quantitative measurement to be used to evaluate completeness is presented in Table 6-1 and is based on the percentage of measurements made that are judged to be valid.

For the judgmental sampling approach, the completeness goal is 80 percent. If this goal is not achieved, the dataset will be assessed for potential impacts on making DQO decisions. For the probabilistic sampling approach, the completeness goal is a calculated minimum sample size required to produce a valid statistical comparison of the sample mean to the FAL. 
The qualitative assessment of completeness is an evaluation of the sufficiency of information available to make DQO decisions. This assessment will be based on meeting the data needs identified in the DQOs and will be presented in the CADD. Additional information will be collected if it is determined that DQO decisions cannot be resolved with the available information.

\subsubsection{Comparability}

Comparability is a qualitative parameter expressing the confidence with which one dataset can be compared to another (EPA, 2002). The criteria for the evaluation of comparability will be that all sampling, handling, preparation, analysis, reporting, and data validation were performed and documented in accordance with approved procedures that are in conformance with standard industry practices. Analytical methods and procedures approved by DOE will be used to analyze, report, and validate the data. These methods and procedures are in conformance with applicable methods used in industry and government practices. An evaluation of comparability will be presented in the CADD.

\subsubsection{Sensitivity}

Sensitivity is the capability of a method or instrument to discriminate between measurement responses representing different levels of the variable of interest (EPA, 2002). The evaluation criterion for this parameter will be that measurement sensitivity (i.e., MDCs) will be less than or equal to the corresponding FALs. If this criterion is not achieved, the affected data will be assessed for usability and potential impacts on meeting site characterization objectives. This assessment will be presented in the CADD.

As presented in Section 3.4, the evaluation criterion for this parameter will be that the analytical methods must be sufficient to detect contamination that is present in the samples at concentrations less than or equal to the corresponding FALs. The target MDC for each COPC is provided in Tables 3-3 and 3-4. 


\subsection{Duration and Records Availability}

\subsection{Duration}

Field and analytical activities will require approximately 120 days to complete.

\subsection{Records Availability}

Historical information and documents referenced in this plan are retained in the DOE project files in Las Vegas, Nevada, and can be obtained through written request to the DOE Federal Sub-Project Director. This document is available in the DOE public reading rooms located in Las Vegas and Carson City, Nevada, or by contacting the appropriate DOE Federal Sub-Project Director. 


\subsection{References}

ARL/SORD, see Air Resources Laboratory/Special Operations and Research Division.

ASTM, see American Society for Testing and Materials.

Air Resources Laboratory/Special Operations and Research Division. 2009. "NTS Climatological

Rain Gauge Data.” As accessed at http://www.sord.nv.doe.gov/home_climate_rain.htm on 15 December.

American Society for Testing and Materials. 1995 (reapproved 2002). Standard Guide for Risk-Based Corrective Action Applied at Petroleum Release Sites, ASTM E1739 - 95(2002). Philadelphia, PA.

BN, see Bechtel Nevada.

Barnes, M.G., J.J. Giacomini, R.T. Reiman, and B. Elliot. 1980. NTS Radiological Assessment Project: Results for Frenchman Lake Region of Area 5, DOE/DP/01253-17. Prepared for U.S. Department of Energy, Nevada Operations Office. Reno, NV: Desert Research Institute, Water Resources Center.

Bechtel Nevada. 1999. An Aerial Radiological Survey of the Nevada Test Site, DOE/NV/11718--324. Prepared for U.S. Department of Energy, Nevada Operations Office. Las Vegas, NV: Remote Sensing Laboratory.

CFR, see Code of Federal Regulations.

Clesceri, L.S., A.E. Greenberg, and A.D. Eaton, eds. 1998. Standard Methods for the Examination of Water and Wastewater, 20th edition. Published by American Public Health Association, American Water Works Association, and Water Environmental Federation.

Code of Federal Regulations. 2009a. Title 40 CFR, Part 262, "Standards Applicable to Generators of Hazardous Waste,” Section 34, “Accumulation Time.” Washington, DC: U.S. Government Printing Office.

Code of Federal Regulations. 2009b. Title 40 CFR, Part 761, "Polychlorinated Biphenyls (PCBs) Manufacturing, Processing, Distribution in Commerce, and Use Prohibitions.” Washington, DC: U.S. Government Printing Office.

Code of Federal Regulations. 2009c. Title 10 CFR Part 835, “Occupational Radiation Protection,” Section 402, “Individual Monitoring.” Washington, DC: U.S. Government Printing Office.

DOE, see U.S. Department of Energy. 
DOE/NV, see U.S. Department of Energy, Nevada Operations Office.

DRI, see Desert Research Institute.

DTRA, see Defense Threat Reduction Agency.

Defense Threat Reduction Agency. 2007. Fact Sheet: Operation HARDTACK II. As accessed at http://www.dtra.mil/documents/ntpr/factsheets/Operation_HARDTACK_II.pdf on 1 March 2010.

Desert Research Institute. 1989. Nevada Test Site Radionuclide Inventory and Distribution Program: Report \#5, Areas 5, 11, 12, 15, 17, 18, 19, 25, 26, and 30, DOE/NV/10384-26. Prepared by R.D. McArthur and S.W. Mead. Las Vegas, NV.

Desert Research Institute. 2000. A Cold War Battlefield: Frenchman Flat Historic District, Nevada Test Site, Nye County, Nevada, DOE/NV/13609-01. Prepared by W.G. Johnson, B.A. Holz, and R. Jones. Las Vegas, NV.

EPA, see U.S. Environmental Protection Agency.

Essington, E.H. 1985a. "Soil Radionuclide Distribution Studies for the Nevada Applied Ecology Group-1981.” In The Dynamics of Transuranics and Other Radionuclides in Natural Environments, NVO-272. pp. 123-195. December. W.A. Howard and R.G. Fuller eds. Las Vegas, NV: U.S. Department of Energy, Nevada Operations Office.

Essington, E.H. 1985b. "Investigations for the Nevada Applied Ecology Group: A Historical Review and Current Status.” In The Dynamics of Transuranics and Other Radionuclides in Natural Environments, NVO-272. pp. 197-259. December. W.A. Howard and R.G. Fuller eds. Las Vegas, NV: U.S. Department of Energy, Nevada Operations Office.

Essington, E.H., R.O. Gilbert, L.L. Eberhardt, and E.B. Fowler. 1975. Plutonium, Americium and Uranium Concentrations in Nevada Test Site Soil Profiles, LA-UR-75-1770; IAEA-SM-199/76. Prepared for U.S. Energy Research and Development Administration. Los Alamos, NM: Los Alamos Scientific Laboratory.

FFACO, see Federal Facility Agreement and Consent Order.

Federal Facility Agreement and Consent Order. 1996 (as amended March 2010). Agreed to by the State of Nevada; U.S. Department of Energy, Environmental Management; U.S. Department of Defense; and U.S. Department of Energy, Legacy Management.

Gilbert, R.O. 1977. "Revised Total Amounts of ${ }^{239,240} \mathrm{Pu}$ in Surface Soil at Safety-Shot Sites.” In Transuranics in Desert Ecosystems, Nevada Applied Ecology Group, NVO-181. pp. 423-429. November. M.G. White, P.B. Dunaway, and D.L. Wireman eds. Las Vegas, NV: U.S. Department of Energy, Nevada Operations Office. 
Gilbert, R.O., and L.L. Eberhardt. 1978. "Statistical Design and Analysis for NAEG Studies: Current Status and a Review of Past Efforts.” In Selected Environmental Plutonium Research Reports of the NAEG, NVO-192. pp. 451-482. June. M.G. White and P.B. Dunaway eds. Las Vegas, NV: U.S. Department of Energy, Nevada Operations Office.

Gilbert, R.O., L.L. Eberhardt, E.B. Fowler, E.M. Romney, and E.H. Essington. 1975. “Statistical Design and Analysis of Environmental Studies for Plutonium and Other Transuranics at NAEG 'Safety-Shot' Sites." In Proceedings of IAEA International Symposium on Transuranic Nuclides in the Environment, CONF--751105--6. BNWL SA 5505. 17 November. San Francisco, CA.

Holmes \& Narver, see Holmes \& Narver, Inc.

Holmes \& Narver, Inc. 1959. Operation Hardtack, Phase II Completion Report. July. Prepared for the Atomic Energy Commission.

Malik, J., Los Alamos National Laboratory. 1982. Memorandum to R.V. Nutley (DOE/NV) regarding the GMX-6 equation-of-state experiments conducted in the 1954-1956 time frame, 9 September. Los Alamos, NM.

Moore, J., Science Applications International Corporation. 1999. Memorandum to M. Todd (SAIC) titled "Background Concentrations for NTS and TTR Soil Samples,” 3 February. Las Vegas, NV: IT Corporation.

Murphy, T., Bureau of Federal Facilities. 2004. Letter to R. Bangerter (NNSA/NSO) titled "Review of Industrial Sites Project Document Guidance for Calculating Industrial Sites Project Remediation Goals for Radionuclides in Soil Using the Residual Radiation (RESRAD) Computer Code,” 19 November. Las Vegas, NV.

NAC, see Nevada Administrative Code.

NBMG, see Nevada Bureau of Mines and Geology.

NDEP, see Nevada Division of Environmental Protection.

NNES, see Navarro Nevada Environmental Services, LLC.

NNES GIS, see Navarro Nevada Environmental Services Geographic Information Systems.

NNSA/NSO, see U.S. Department of Energy, National Nuclear Security Administration Nevada Site Office.

NNSA/NV, see U.S. Department of Energy, National Nuclear Security Administration Nevada Operations Office.

NWA, see Nuclear Weapon Archive. 
Navarro Nevada Environmental Services, LLC. 2009. Statement of Work for Analytical Laboratories, Section C. Las Vegas, NV.

Navarro Nevada Environmental Services Geographic Information Systems. 2010. ESRI ArcGIS Software.

Nevada Administrative Code. 2008a. NAC 445A.227, "Contamination of Soil: Order by Director for Corrective Action; Factors To Be Considered in Determining Whether Corrective Action Required.” Carson City, NV. As accessed at http://www.leg.state.nv.us/nac on 15 December 2009.

Nevada Administrative Code. 2008b. NAC 445A.22705, "Contamination of Soil: Evaluation of Site by Owner or Operator; Review of Evaluation by Division.” Carson City, NV. As accessed at http://www.leg.state.nv.us/nac on 15 December 2009.

Nevada Bureau of Mines and Geology. 1998. Mineral and Energy Resource Assessment of the Nellis Air Force Range, Open-File Report 98-1. Reno, NV.

Nevada Division of Environmental Protection. 1997 (as amended in 2006). Class III Solid Waste Disposal Site for Hydrocarbon Burdened Soils, Area 6 of the NTS, Permit SW 13-097-02, Rev. 7. Carson City, NV.

Nuclear Weapon Archive. 2002. Photograph “Tumbler Able.” Nuclear Weapon Archive website. As accessed at http://nuclearweaponarchive.org/Usa/Tests/Tumblers.html on 5 January, 2010.

Paar, J.G., and D.R. Porterfield. 1997. Evaluation of Radiochemical Data Usability, ES/ER/MS-5. April. Oak Ridge, TN: U.S. Department of Energy.

RSL, see Remote Sensing Laboratory.

Remote Sensing Laboratory. 1960a. Aerial Photograph "RSL_Area5_NTS-681-A_1-33_ABLE,” 16 April. Las Vegas, NV.

Remote Sensing Laboratory. 1960b. Aerial Photograph "RSL_Area5_NTS-681-A_1-9_HAMILTON," 16 April. Las Vegas, NV.

Remote Sensing Laboratory. 1999. Aerial Photograph “doe-rsl_997-13,” 14 March. Las Vegas, NV.

SNJV, see Stoller-Navarro Joint Venture.

Stoller-Navarro Joint Venture. 2004. Phase II Hydrologic Data for the Groundwater Flow and Contaminant Transport Model of Corrective Action Unit 98: Frenchman Flat, Nye County, Nevada, S-N/99205-032. Las Vegas, NV.

USGS, see U.S. Geological Survey. 
USGS and DOE, see U.S. Geological Survey and U.S. Department of Energy.

U.S. Department of Energy. 1997. The Procedures Manual of the Environmental Measurements Laboratory, HASL-300, 28th edition, Vol. I. February. New York, NY.

U.S. Department of Energy, National Nuclear Security Administration Nevada Operations Office. 2002a. Industrial Sites Quality Assurance Project Plan, Nevada Test Site, Nevada, Rev. 3, DOE/NV--372. Las Vegas, NV.

U.S. Department of Energy, National Nuclear Security Administration Nevada Site Office. 2002b. Nevada Test Site Orthophoto Site Atlas, DOE/NV/11718--604. Aerial photos acquired Summer 1998. Prepared by Bechtel Nevada. Las Vegas, NV.

U.S. Department of Energy, National Nuclear Security Administration Nevada Site Office. 2006. Industrial Sites Project Establishment of Final Action Levels, Rev. 0, DOE/NV--1107. Las Vegas, NV.

U.S. Department of Energy, National Nuclear Security Administration Nevada Site Office. 2007. Nevada Test Site Environmental Report 2006, DOE/NV 25946--259. Prepared by National Security Technologies, LLC.

U.S. Department of Energy, National Nuclear Security Administration Nevada Site Office. 2009. Nevada Test Site Waste Acceptance Criteria, DOE/NV-325-Rev. 7-01. Las Vegas, NV.

U.S. Department of Energy, Nevada Operations Office. 1992. Remedial Investigation and Feasibility Study for the Plutonium Contaminated Soils at Nevada Test Site, Nellis Air Force Range and Tonopah Test Range, April. Las Vegas, NV.

U.S. Department of Energy, Nevada Operations Office. 1996. Final Environmental Impact Statement for the Nevada Test Site and Off-Site Locations in the State of Nevada, DOE/EIS 0243. Las Vegas, NV.

U.S. Department of Energy, Nevada Operations Office. 1998. Nevada Test Site Resource Management Plan, DOE/NV--518. Las Vegas, NV.

U.S. Department of Energy, Nevada Operations Office. 2000. United States Nuclear Tests, July 1945 through September 1992, DOE/NV--209-REV 15. Las Vegas, NV.

U.S. Environmental Protection Agency. 1980. Prescribed Procedures for Measurement of Radioactivity in Drinking Water, EPA 600/4-80-032. Cincinnati, OH: Environmental Monitoring and Support Laboratory Office of Research and Development.

U.S. Environmental Protection Agency. 2000. Sampling and Analysis Plan Guidance and Template, R9QA/002.1. As accessed at http://www.epa.gov/region09/qa/projplans.html on 15 December 2009. 
U.S. Environmental Protection Agency. 2002. Guidance for Quality Assurance Project Plans, EPA QA/G5, EPA/240/R-02/009. Washington, DC.

U.S. Environmental Protection Agency. 2004. USEPA Contract Laboratory Program National Functional Guidelines for Inorganic Data Review, OSWER 9240.1-45/EPA 540-R-04-004. October. Washington, DC: Office of Superfund Remediation and Technology Innovation.

U.S. Environmental Protection Agency. 2008. SW-846 On-Line, Test Methods for Evaluating Solid Waste, Physical/Chemical Methods. As accessed at http://www.epa.gov/epaoswer/hazwaste/test/main.htm on 15 December 2009.

U.S. Environmental Protection Agency. 2009. Region 9: Superfund, Preliminary Remediation Goals, Screening Levels for Chemical Contaminants. As accessed at http://www.epa.gov/region09/waste/sfund/prg/index.html on 15 December. Prepared by EPA Office of Superfund and Oak Ridge National Laboratory.

U.S. Geological Survey. 1996. Summary of Hydrogeological Controls on Groundwater Flow at the Nevada Test Site, Nye County, Nevada, USGS Water-Resources Investigations Report 96-4109. Prepared by R.J. Laczniak, J.C. Cole, D.A. Sawyer, and D.A. Trudeau.

U.S. Geological Survey. 2003. Simulation of Net Infiltration and Potential Recharge Using a Distributed Parameter Watershed Model of the Death Valley Region, Nevada and California, U.S. Geological Survey Water-Resources Investigations Report 03-4090. Prepared by J.A.Hevesi, A.L. Flint, and L.E. Flint.

U.S. Geological Survey and U.S. Department of Energy. 2009. "USGS/DOE Cooperative Studies in Nevada; Water-Level Wells, Nevada Test Site.” As accessed at http://nevada.usgs.gov/doe_nv/ ntsmap.htm on 15 December.

Wilcox, F.W., Reynolds Electrical \& Engineering Co., Inc. 1958. Memorandum to Distribution titled "Rad-Safe Procedures for October 31, 1958,” 30 October.

Yu, C., A.J. Zielen, J.J. Cheng, D.J. LePoire, E. Gnanapragasam, S. Kamboj, J. Arnish, A. Wallo III, W.A. Williams, and H. Peterson. 2001. User's Manual for RESRAD Version 6, ANL/EAD-4. Argonne, IL: Argonne National Laboratory, Environmental Assessment Division. (Version 6.4 released in December 2007.)

Yucel, V., National Security Technologies, LLC. 2009. Memorandum to R.L. Kidman (SNJV) regarding PET data, 30 April. Las Vegas, NV. 


\section{Appendix A}

\section{Data Quality Objectives}


The DQO process described in this appendix is a seven-step strategic systematic planning method used to plan data collection activities and define performance criteria for the CAU 106, Areas 5, 11 Frenchman Flat Atmospheric Sites, field investigation. The DQOs are designed to ensure that the data collected will provide sufficient and reliable information to identify, evaluate, and technically defend recommended corrective actions (i.e., no further action, closure in place, or clean closure). Existing information about the nature and extent of contamination at the CASs in CAU 106 is insufficient to evaluate and select preferred corrective actions; therefore, a CAI will be conducted.

The CAU 106 CAI will be based on the DQOs presented in this appendix as developed by representatives of the NDEP and the NNSA/NSO. The seven steps of the DQO process presented in Sections A.2.0 through A.8.0 were developed in accordance with Guidance on Systematic Planning Using the Data Quality Objectives Process (EPA, 2006).

The DQO process presents a combination of probabilistic and judgmental sampling approaches. In general, the procedures used in the DQO process provide:

- A method to establish performance or acceptance criteria, which serve as the basis for designing a plan for collecting data of sufficient quality and quantity to support the goals of a study.

- Criteria that will be used to establish the final data collection design, such as:

- The nature of the problem that has initiated the study and a conceptual model of the environmental hazard to be investigated.

- The decisions or estimates that need to be made, and the order of priority for resolving them.

- $\quad$ The type of data needed.

- An analytic approach or decision rule that defines the logic for how the data will be used to draw conclusions from the study findings.

- Acceptable quantitative criteria on the quality and quantity of the data to be collected, relative to the ultimate use of the data. 
- A data collection design that will generate data meeting the quantitative and qualitative criteria specified. A data collection design specifies the type, number, location, and physical quantity of samples and data, as well as the QA and QC activities that will ensure that sampling design and measurement errors are managed sufficiently to meet the performance or acceptance criteria specified in the DQOs. 


\section{A.2.0 Step 1 - State the Problem}

Step 1 of the DQO process defines the problem that requires study, identifies the planning team, and develops a conceptual model of the environmental hazard to be investigated.

The problem statement for CAU 106 is: "Existing information on the nature and extent of potential contamination is insufficient to evaluate and recommend CAAs for the CASs in CAU 106."

\section{A.2.1 Planning Team Members}

The DQO planning team consists of representatives from NDEP and NNSA/NSO. The DQO planning team met on January 19, 2010, for the DQO meeting.

\section{A.2.2 Conceptual Site Model}

The CSM is used to organize and communicate information about site characteristics. It reflects the best interpretation of available information at a point in time. The CSM is a primary vehicle for communicating assumptions about release mechanisms, potential migration pathways, or specific constraints. It provides a summary of how and where contaminants are expected to move and what impacts such movement may have. It is the basis for assessing how contaminants could reach receptors both in the present and future. The CSM describes the most probable scenario for current conditions at each site and defines the assumptions that are the basis for identifying appropriate sampling strategy and data collection methods. An accurate CSM is important as it serves as the basis for all subsequent inputs and decisions throughout the DQO process.

The CSM was developed for CAU 106 using information from the physical setting, potential contaminant sources, release information, historical background information, knowledge from similar sites, and physical and chemical properties of the potentially affected media and COPCs.

The CSM consists of:

- Potential contaminant releases, including media subsequently affected.

- Release mechanisms (the conditions associated with the release). 
- Potential contaminant source characteristics, including contaminants suspected to be present and contaminant-specific properties.

- Site characteristics, including physical, topographical, and meteorological information.

- Migration pathways and transport mechanisms that describe the potential for migration and where the contamination may be transported.

- The locations of points of exposure where individuals or populations may come in contact with a COC associated with a CAS.

- Routes of exposure where contaminants may enter the receptor.

If additional elements are identified during the CAI that are outside the scope of the CSM, the situation will be reviewed and a recommendation will be made as to how to proceed. In such cases, NDEP will be notified and given the opportunity to comment on, or concur with, the recommendation.

The applicability of the CSM to each CAS is summarized in Table A.2-1, which provides information on CSM elements that will be used throughout the remaining steps of the DQO process. Figure A.2-1 depicts conceptual pathways to receptors from CAU 106 sources. Figure A.2-2 depicts a graphical representation of the CSM. 
Table A.2-1

Conceptual Site Model Description of Elements for Each CAS in CAU 106

(Page 1 of 2)

\begin{tabular}{|c|c|c|c|c|c|}
\hline CAS Identifier & $05-23-02$ & $05-23-05$ & $05-45-01$ & $05-45-04$ & $05-45-05$ \\
\hline CAS Description & $\begin{array}{c}\text { GMX Alpha } \\
\text { Contaminated Area }\end{array}$ & $\begin{array}{l}\text { Atmospheric Test } \\
\text { Site - Able }\end{array}$ & $\begin{array}{c}\text { Atmospheric Test } \\
\text { Site - Hamilton }\end{array}$ & $\begin{array}{c}306 \text { GZ Rad } \\
\text { Contaminated Area }\end{array}$ & $\begin{array}{c}307 \text { GZ Rad } \\
\text { Contaminated Area }\end{array}$ \\
\hline Site Status & \multicolumn{5}{|c|}{ Sites are inactive and/or abandoned } \\
\hline Exposure Scenario & \multicolumn{5}{|c|}{ Occasional } \\
\hline $\begin{array}{c}\text { Sources of } \\
\text { Potential Soil } \\
\text { Contamination }\end{array}$ & $\begin{array}{l}\text { Test Release: } \\
\text { atmospheric } \\
\text { deposition of } \\
\text { radionuclides, } \\
\text { primarily Pu } \\
\text { Non-Test Release: } \\
\text { contaminated } \\
\text { sediments in nearby } \\
\text { washes, abandoned } \\
\text { wastes (e.g., DU) }\end{array}$ & $\begin{array}{l}\text { Test Release: } \\
\text { atmospheric } \\
\text { deposition of } \\
\text { radionuclides from } \\
\text { airburst }\end{array}$ & $\begin{array}{l}\text { Test Release: } \\
\text { atmospheric } \\
\text { deposition of } \\
\text { radionuclides from } \\
\text { tower test } \\
\text { Non-Test Release: } \\
\text { wastes in debris pile, } \\
\text { or found at the site }\end{array}$ & $\begin{array}{l}\text { - Non-Test Release: a } \\
\text { (e.g., DU) or buried wa }\end{array}$ & $\begin{array}{l}\text { andoned surface } \\
\text { stes. }\end{array}$ \\
\hline $\begin{array}{l}\text { Location of } \\
\text { Contamination/ } \\
\text { Release Point }\end{array}$ & $\begin{array}{l}\text { - } \text { Soil in annular } \\
\text { pattern within posted } \\
\text { CA and HCA } \\
\text { - Soil within and } \\
\text { surrounding bunker } \\
\text { - Soil directly below } \\
\text { and adjacent to } \\
\text { debris } \\
\text { - Sediments in nearby } \\
\text { washes }\end{array}$ & $\begin{array}{l}\text { - Surface soil } \\
\text { surrounding ground } \\
\text { zero area } \\
\text { Contaminated soil is } \\
\text { potentially buried } \\
\text { under thin horizon of } \\
\text { accumulated lake } \\
\text { sediments }\end{array}$ & $\begin{array}{l}\text { - } \begin{array}{l}\text { Surface soil in } \\
\text { annular pattern } \\
\text { surrounding ground } \\
\text { zero area }\end{array} \\
\text { - Soil directly below } \\
\text { and adjacent to } \\
\text { debris pile } \\
\text { - Contaminated soil is } \\
\text { potentially buried } \\
\text { under thin horizon of } \\
\text { accumulated lake } \\
\text { sediments }\end{array}$ & $\begin{array}{ll}\text { - } & \text { Surface soil within and } \\
\text { URMAs and CA } \\
\text { - } \quad \text { Surface soil directly be } \\
\text { waste items } \\
\text { - Shallow subsurface so }\end{array}$ & $\begin{array}{l}\text { surrounding posted } \\
\text { ow and adjacent to } \\
\text { within URMA boundary }\end{array}$ \\
\hline
\end{tabular}


Table A.2-1

Conceptual Site Model Description of Elements for Each CAS in CAU 106

(Page 2 of 2)

\begin{tabular}{|c|c|c|c|c|c|}
\hline CAS Identifier & $05-23-02$ & 05-23-05 & $05-45-01$ & $05-45-04$ & $05-45-05$ \\
\hline CAS Description & $\begin{array}{c}\text { GMX Alpha } \\
\text { Contaminated Area }\end{array}$ & $\begin{array}{l}\text { Atmospheric Test } \\
\text { Site - Able }\end{array}$ & $\begin{array}{l}\text { Atmospheric Test } \\
\text { Site - Hamilton }\end{array}$ & $\begin{array}{c}306 \text { GZ Rad } \\
\text { Contaminated Area }\end{array}$ & $\begin{array}{c}307 \text { GZ Rad } \\
\text { Contaminated Area }\end{array}$ \\
\hline Amount Released & \multicolumn{5}{|c|}{ Unknown } \\
\hline Affected Media & $\begin{array}{l}\text { Surface and shallow } \\
\text { subsurface soil, wash } \\
\text { sediments }\end{array}$ & Surface soil & \multicolumn{3}{|c|}{ Surface and shallow subsurface soil } \\
\hline $\begin{array}{c}\text { Potential } \\
\text { Contaminants }\end{array}$ & $\begin{array}{l}\text { Isotopic } \mathrm{Pu} \text {, other } \\
\text { potential radionuclides }\end{array}$ & $\begin{array}{l}\text { Fission products, other } \\
\text { potential radionuclides }\end{array}$ & $\begin{array}{l}\text { Isotopic } \mathrm{Pu} \text {, fission } \\
\text { products, other potential } \\
\text { radionuclides }\end{array}$ & \multicolumn{2}{|c|}{$\begin{array}{l}\text { VOCs, SVOCs, RCRA metals, PCBs, isotopic } \\
\text { uranium, and other potential radionuclides }\end{array}$} \\
\hline $\begin{array}{l}\text { Transport } \\
\text { Mechanisms }\end{array}$ & \multicolumn{5}{|c|}{$\begin{array}{l}\text { Percolation of precipitation through subsurface media serves as the major driving force for migration of contaminants. Surface water } \\
\text { runoff may provide for the transportation of some contaminants within or outside the footprints of the CASs. Although there may be } \\
\text { standing water at times on Frenchman Lake, accumulation of fine materials on the lake bed has decreased the hydraulic conductivity } \\
\text { of the lake bed to the point where infiltration is not significant. Wind may cause resuspension and transport of windborne } \\
\text { contaminants; however, this is not a significant mechanism. }\end{array}$} \\
\hline Migration Pathways & \multicolumn{5}{|c|}{$\begin{array}{l}\text { Vertical transport expected to dominate over lateral transport due to small surface gradients. However, location of GMX, } 306 \mathrm{GZ} \text {, and } \\
307 \mathrm{GZ} \text { on alluvial fan that drains to Frenchman Lake provides potential for overland transport of contaminants. }\end{array}$} \\
\hline $\begin{array}{l}\text { Lateral and Vertical } \\
\text { Extent of } \\
\text { Contamination }\end{array}$ & \multicolumn{5}{|c|}{$\begin{array}{l}\text { Contamination, if present, is expected to be contiguous to the release points. Concentrations are expected to decrease with distance } \\
\text { and depth from the source. Groundwater contamination is not expected. Lateral and vertical extent of COC contamination is } \\
\text { assumed to be within the spatial boundaries. }\end{array}$} \\
\hline Exposure Pathways & \multicolumn{5}{|c|}{$\begin{array}{l}\text { The potential for contamination exposure is limited to industrial and construction workers, and military personnel conducting training. } \\
\text { These human receptors may be exposed to COPCs through oral ingestion, inhalation, and dermal contact (absorption) of soil and/or } \\
\text { debris due to inadvertent disturbance of these materials or direct radiation exposure from radioactive materials. }\end{array}$} \\
\hline
\end{tabular}




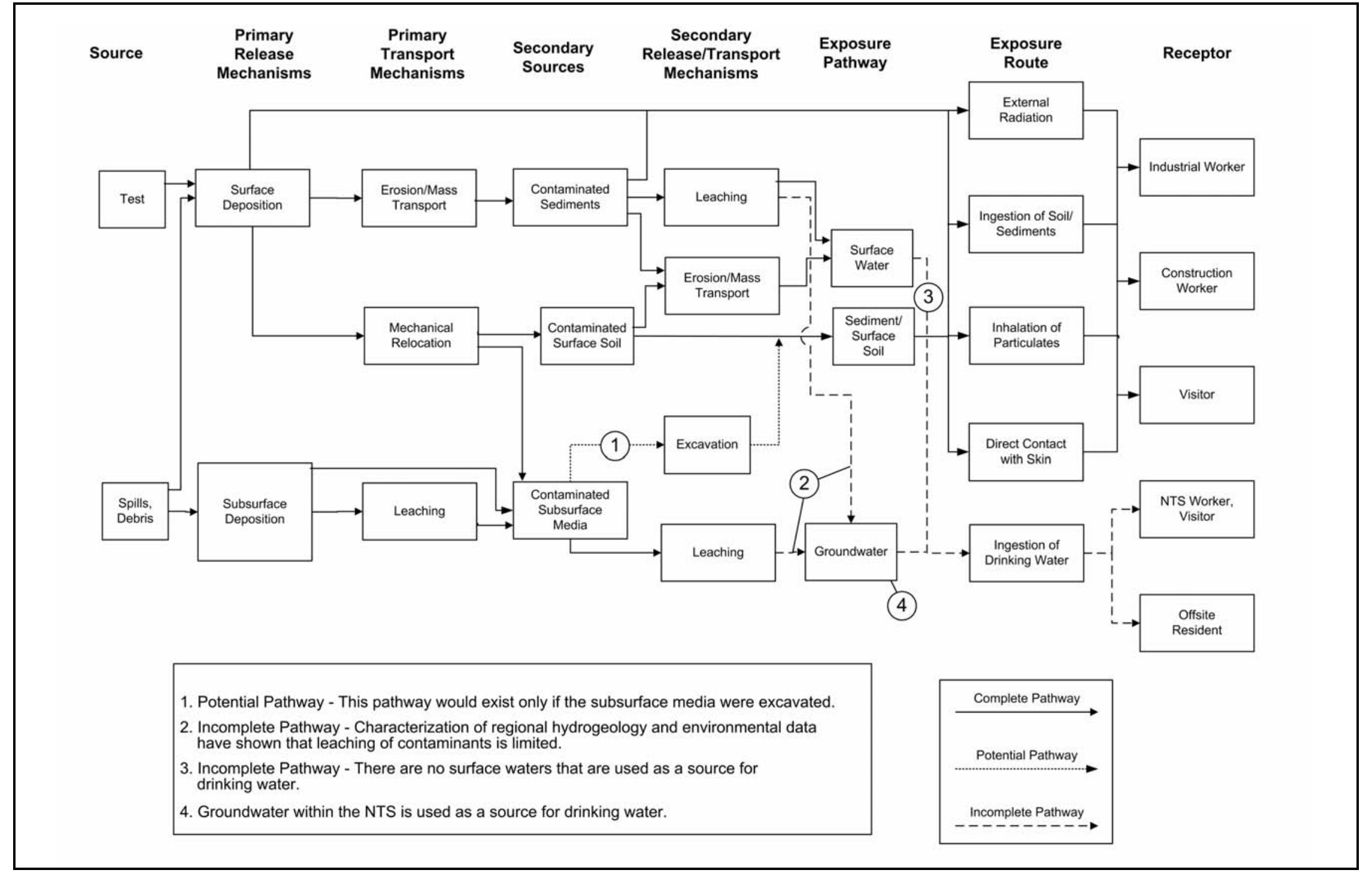

Figure A.2-1

Conceptual Pathways to Receptors

\section{UNCONTROLLED when Printed}




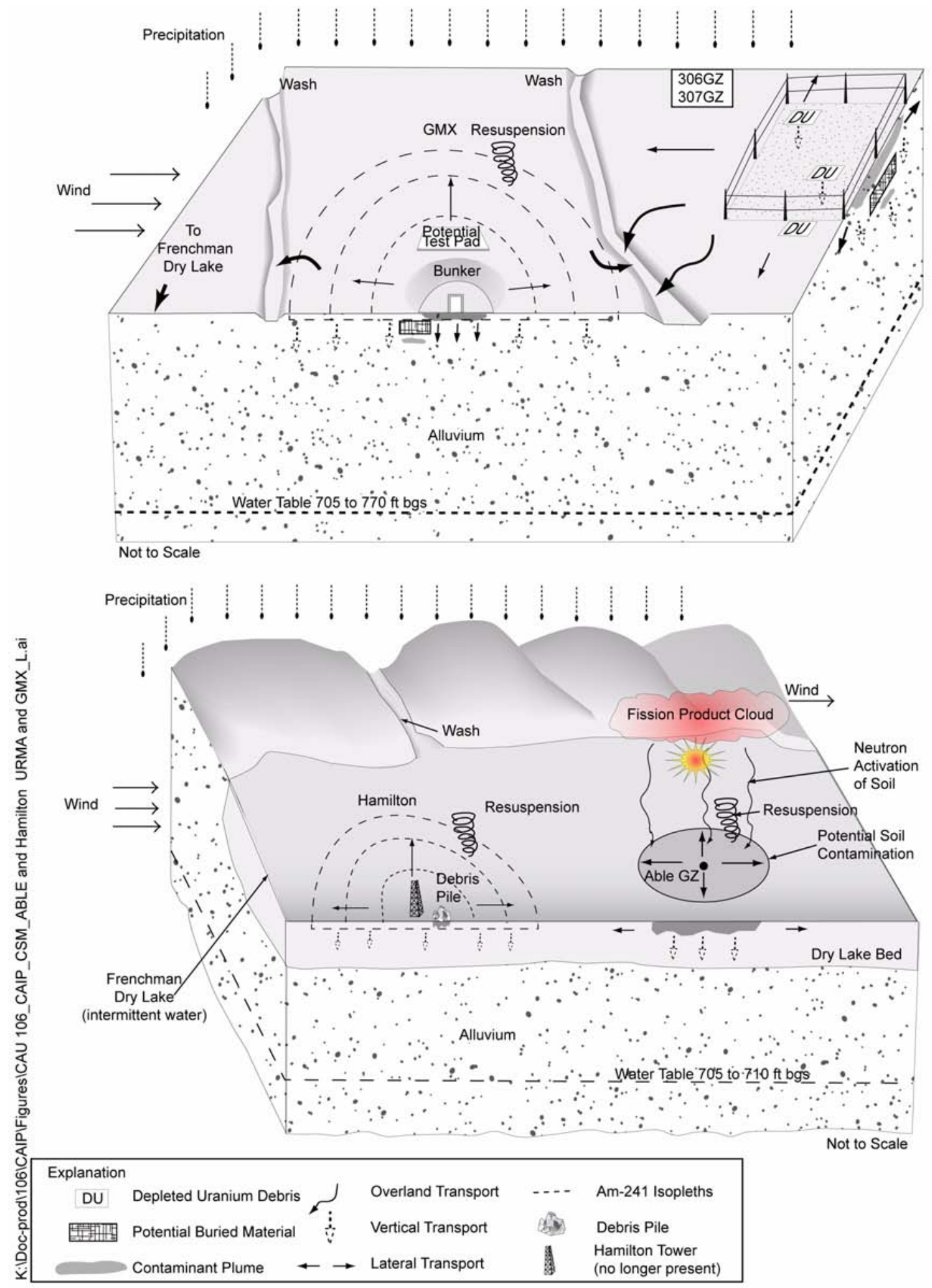

Figure A.2-2

Conceptual Site Model 


\section{A.2.2.1 Release Sources}

The following two release scenarios address the different types of releases that may be present at CAU 106. The test release is defined as the initial atmospheric deposition of radiological contaminants from nuclear tests. The initial test release is generally observed as an annular geometric pattern of contamination from soil particle activation and initial fallout that generally decreases in intensity with distance from the source. A non-test release is defined as the subsequent movement of radiological contaminants from test releases (either migration or mechanical displacement) and other potential releases of contaminants from site operations (e.g., spills and abandoned materials).

The sources of contamination for test releases at CAU 106 are the initial atmospheric deposition of radiological contaminants to surface soil from nuclear weapons-related (Hamilton) and weapons-effect (Able) tests, and “equation of state” experiments (GMX). Contamination on the soil surface may be the source for future migration. The sources of contamination for non-test releases at GMX, Hamilton, 306 GZ, and 307 GZ are those resulting from spills or wastes (e.g., DU, miscellaneous chemicals and debris items) found at the site, or the subsequent movement of contaminated materials that have migrated as a result of wind, water, excavation, or some other influence.

The most likely locations of the contamination and releases to the environment are the soils directly below or adjacent to the CSM's surface and subsurface components (i.e., soils impacted by fallout, wastes present, and other non-test releases). Contamination, if present, is expected to be contiguous to the release points, and concentrations are expected to decrease with horizontal and vertical distance from the source. See Sections A.2.2.1.1 through A.2.2.1.5 for CAS-specific sources of test and non-test releases.

\section{A.2.2.1.1 GMX}

The test release source at GMX is the atmospheric deposition of radionuclides, primarily $\mathrm{Pu}$, to the surrounding surface soil from the 29 "equation of state" experiments conducted at the site. These experiments were conducted to measure the effects of Pu from use of conventional explosives. According to documentation, these experiments were conducted on or very near one location. It is speculated that this location was outside and adjacent to the bunker located within the posted HCA. 
The initial release of radionuclides from the GMX experiments was distributed in an elongated annular pattern centered over the bunker and HCA as illustrated in a radiological flyover survey (Figure 2-6).

The non-test release source includes radioactive surface and shallow subsurface sediments in the nearby washes that have resulted from the subsequent migration of initially deposited radioactivity from the test release scenario. This may occur because of sheet and gully erosion from stormwater runoff as numerous small washes and one prominent wash are present within the CAS boundary. Non-test release sources may also include abandoned surface or buried wastes (e.g., DU, Pu-contaminated debris) within and adjacent to the site bunker or any other locations within the CAS boundary that have spilled, leaked, or have the potential to release contaminants to the surface and shallow subsurface soil.

\section{A.2.2.1.2 Able}

The test release source at Able is the atmospheric deposition of radionuclides (e.g., fallout of fuel fragments and fission products, and neutron activation of soil) to the surface soil from the detonation of a weapons-effect test with a 1-kt yield at $800 \mathrm{ft}$ above the ground surface. Based on available information from radiological flyover surveys and soil studies, significant quantities of radionuclides were not released to the surface soil surrounding the Able ground zero. Therefore, soil contamination above FALs is not expected at this site. It is possible that the surface soil initially impacted by the Able test has subsequently been buried by lake sedimentation that occurs when the dry lake bed fills with shallow water. However, the initially impacted soil is expected to be within the top $15 \mathrm{~cm}$ of soil because of the low sedimentation rates on dry lake beds.

Non-test release sources have not been identified at Able; however, there is always a potential to identify a non-test release during the CAI.

\section{A.2.2.1.3 Hamilton}

The test release source at Hamilton is the atmospheric deposition of radionuclides (e.g., fallout of fuel fragments and fission products) to the surface soil from the detonation of a weapons-related test with a 1.2-ton yield from a 50-ft tower (no longer present). Based on the radiological flyover surveys, 
contamination is distributed in an annular pattern centered over the ground zero and the posted CA. It is unknown whether this distribution pattern represents the initial surface contamination or whether the contaminated surface soil and materials were subsequently cleaned up and relocated to the large debris pile located within the CA. If the latter is true, then the debris pile could be the source of a potential non-test release of radioactivity to the underlying surface and shallow subsurface soil. It is also possible that the surface soil initially impacted by the Hamilton test has subsequently been buried by lake sedimentation that occurs when the dry lake bed fills with shallow water. However, the initially impacted soil is expected to be within the top $15 \mathrm{~cm}$ of soil because of the low sedimentation rates on dry lake beds.

Additional non-test release sources include any abandoned wastes within the CAS boundary that have spilled, leaked, or have the potential to release contaminants to the surface and shallow subsurface soil.

\section{A.2.2.1.4 $306 \mathrm{GZ}$}

The test release scenario, as defined in Section 1.1.2, does not apply to 306 GZ because there is no evidence of atmospheric deposition of radiological contaminants from a nuclear test.

The non-test release source of surface contamination includes abandoned wastes, particularly DU that may have released contaminants to the soil within and surrounding the posted URMA and CA. Other identified surface waste includes solid and previously melted metal fragments. Because information about the activities conducted at this site is limited, it is possible that unknown radioactive and chemical contaminants may have been released to the surface soil. Non-test sources of subsurface contamination include any buried wastes within the boundary of the posted URMA. The subsequent migration of contaminants into nearby washes is possible but not anticipated because the nearest wash is $500 \mathrm{ft}$ to the east.

\section{A.2.2.1.5 $307 \mathrm{GZ}$}

The test release scenario, as defined in Section 1.1.2, does not apply to 307 GZ because there is no evidence of atmospheric deposition of radiological contaminants from a nuclear test. 
The non-test release source of surface contamination includes abandoned wastes, particularly DU that may have released contaminants to the soil within and surrounding the posted URMA. Because information about the activities conducted at this site is scarce, unknown radioactive and chemical contaminants have potentially been released to the surface soil. Non-test sources of subsurface contamination include any buried wastes within the boundary of the posted URMA. The subsequent migration of contaminants into nearby washes is not anticipated at this site.

\section{A.2.2.2 Potential Contaminants}

The CAS-specific COPCs are based on a conservative evaluation of possible site activities considering the incomplete site histories of the CASs and considering contaminants found at similar NTS sites. The COPCs were identified during the planning process through the review of site history, process knowledge, personal interviews, past investigation efforts (where available), and inferred activities associated with the CASs. The list of COPCs is intended to encompass all of the significant contaminants that could potentially be present at each CAS. Significant contaminants are defined as contaminants that are present at concentrations exceeding the PAL. The COPCs applicable to Decision I environmental samples from each of the CASs of CAU 106 are defined as the analytes reported from the analytical methods stipulated in Table A.2-2. If previously unknown releases are identified during the CAI, the specific COPCs will be determined based on the nature of the potential release (e.g., hydrocarbon stain, lead bricks).

Table A.2-2

Analytical Program ${ }^{a}$

(Page 1 of 2)

\begin{tabular}{|c|c|c|c|c|c|}
\hline Analyses & GMX & Able & Hamilton & $306 \mathrm{GZ}$ & $307 \mathrm{GZ}$ \\
\hline \multicolumn{6}{|c|}{ Organic COPCs } \\
\hline PCBs & -- & -- & -- & $\bar{x}$ & $\bar{x}$ \\
\hline SVOCs & -- & -- & -- & $x$ & $x$ \\
\hline VOCs & -- & -- & -- & $x$ & $x$ \\
\hline \multicolumn{6}{|c|}{ Inorganic COPCs } \\
\hline RCRA Metals & -- & $\overline{--}$ & $\overline{--}$ & $\bar{x}$ & $\bar{x}$ \\
\hline Total Beryllium & $x$ & & $\mathrm{x}$ & $\mathrm{x}$ & $x$ \\
\hline
\end{tabular}


Table A.2-2

Analytical Program ${ }^{a}$

(Page 2 of 2)

\begin{tabular}{|c|c|c|c|c|c|}
\hline Analyses & GMX & Able & Hamilton & $306 \mathrm{GZ}$ & $307 \mathrm{GZ}$ \\
\hline \multicolumn{6}{|c|}{ Radionuclide COPCs } \\
\hline Gamma Spectroscopy $^{b}$ & $x$ & $\mathrm{x}$ & $\mathrm{x}$ & $\mathrm{X}$ & $x$ \\
\hline Isotopic U & $x$ & $x$ & $x$ & $x$ & $x$ \\
\hline Isotopic $\mathrm{Pu}$ & $x$ & $x$ & $x$ & $x$ & $x$ \\
\hline Isotopic Am & $x$ & -- & $x$ & -- & -- \\
\hline Pu-241 & $x$ & -- & -- & -- & -- \\
\hline Sr-90 & $x$ & $x$ & $x$ & $x$ & $x$ \\
\hline
\end{tabular}

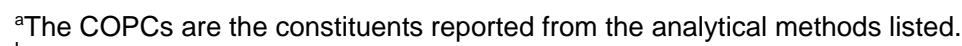

${ }^{\mathrm{b}}$ Results of gamma analysis will be used to determine whether further isotopic analysis is warranted.

$X=$ Required analytical method

$--=$ Not required

\section{A.2.2.3 Contaminant Characteristics}

Contaminant characteristics include, but are not limited to, solubility and adsorption potential. In general, contaminants with low solubility and high affinity for media can be expected to be found relatively close to release points. Contaminants with high solubility and low affinity for media are found farther from release points or in low areas where evaporation of ponding will concentrate dissolved contaminants.

As stated in Subsurface Nobel Gas Transport at the Nevada Test Site (Thompson et al., 1997), the Cambric event at the NTS was used to study long-term radionuclide migration from the underground detonation of a nuclear device. The Cambric test (with a yield of 750 tons) was conducted below the water table in Frenchman Flat in 1965. A well installed into the groundwater $91 \mathrm{~m}$ away from ground zero was continuously pumped from 1975 to 1991 to draw radionuclides from the detonation cavity. The extracted water was tested for radionuclides. None of the adsorbing radionuclides (Am-241, calcium [Ca]-41, Cs-137, Eu-154, Pu-241, samarium [Sm]-151, neptunium [Np]-237, and Sr-90) were detected in the pumped groundwater, attesting to their low solubility and affinity to adsorb to media. The radionuclides tritium $\left({ }^{3} \mathrm{H}\right)$ and krypton $(\mathrm{Kr})$ detected in the pumped groundwater are considered conservative tracers in groundwater (i.e., they do not interact with the geologic media 
through which the water moves). This test demonstrated the relative immobility of the adsorbing radionuclides under saturated conditions. These adsorbing radionuclides can be expected to be even less mobile in the vadose zone because the mass flow of water is the predominant driver in contaminant migration and water movement through the vadose zone is much less than in the saturated conditions of the aquifer.

Based on this evidence, the target radionuclide elements for GMX (Pu and U); Hamilton (Pu, Am, Cs, Eu, and Co); Able (Cs, Eu, and Co); 306 GZ (U); and 307 GZ (U) are classified as adsorbing radionuclides with low solubilities located in unsaturated media. Therefore, these contaminants are expected to be found relatively close to release points.

\section{A.2.2.4 Site Characteristics}

Site characteristics are defined by the interaction of physical, topographical, and meteorological attributes and properties. Topographical and meteorological properties and attributes include slope stability, precipitation frequency and amounts, precipitation runoff pathways, drainage channels and ephemeral streams, and evapotranspiration potential. Meteorological data are presented in Section 2.1.

All five CASs in CAU 106 are located within the Frenchman Flat Hydrographic Area. Erosion of the surrounding mountains has resulted in the accumulation of more than 1,000 $\mathrm{ft}$ of alluvial deposits in some areas of Frenchman Flat (DOE/NV, 1996). The 306 GZ, 307 GZ, and GMX sites are located on the alluvial deposits and unconsolidated gravels of Frenchman Flat, and the Hamilton and Able test sites are located on the ephemeral Frenchman Lake (dry lake bed). During the dry season, the ground surface consists of a rough hard-packed silt with a well-defined mud-crack pattern, which is a classic dessication structure of the dry lake environment. During the rainy season, the lake bed may fill with shallow water (especially during wet years), and this layer of water may be moved around by wind. The principal drainage into the dry lake bed is Nye Canyon from the north, with lesser drainages from the west, including Cane Spring Wash and Barren Wash. Depth to groundwater ranges between approximately $700 \mathrm{ft}$ and $775 \mathrm{ft}$ bgs (USGS and DOE, 2009).

Prominent washes are present at GMX and 306 GZ. At GMX, there are numerous small intermittent washes throughout the site that drain south to Frenchman Lake and one prominent wash located 
$185 \mathrm{ft}$ west of the HCA. The nearest prominent wash at $306 \mathrm{GZ}$ that drains to Frenchman Lake is located approximately $500 \mathrm{ft}$ to the east. It should be noted that $307 \mathrm{GZ}$ is located $150 \mathrm{ft}$ east of an extension of Cambric Ditch that was excavated to support long-term pumping of Well RNM-2S in an effort to understand migration of radionuclides from the Cambric underground test as part of the Radionuclide Migration Study (RNMS); however, this feature is not expected to impact 307 GZ.

\section{A.2.2.5 Migration Pathways and Transport Mechanisms}

Migration pathways include the lateral migration of potential contaminants across surface soils/sediments and vertical migration of potential contaminants through subsurface soils. Contaminants present in ephemeral washes are subject to much higher transport rates than contaminants present in other surface areas. These ephemeral washes, such as at GMX and 306 GZ, are generally dry, but are subject to infrequent stormwater flows. These stormwater flow events provide an intermittent mechanism for both vertical and horizontal transport of contaminants. Contaminated sediments entrained by these stormwater events would be carried by the streamflow to locations where the flowing water loses energy and the sediments drop out. These locations are readily identifiable as sedimentation areas. The drainages in the Frenchman Flat area ultimately drain to Frenchman Lake dry lake bed. The seasonal filling of Frenchman Lake may provide a hydraulic driver for percolation and migration of contaminants for the Hamilton and Able sites. Other migration pathways for contamination from the sites include transport of contaminated windborne materials and mechanical disturbance due to maintenance or construction activities at the site. Specifically at CAU 106, this can include activities such as decontamination and demolition of facilities, structures, equipment, or materials.

Migration is influenced by the chemical characteristics of the contaminants (presented in Section A.2.2.3) and the physical characteristics of the vadose media (presented in Section A.2.2.4). In general, the contaminants that are reasonably expected to be present at CAU 106 (i.e., $\mathrm{Pu}$ and $\mathrm{U}$ at GMX; Pu, Am, Cs, Eu, and Co at Hamilton; Cs, Eu, and Co at Able; and U at 306 GZ and 307 GZ) have low solubilities and high affinity for media. The physical characteristics of the vadose media generally include medium to high adsorptive capacities, low moisture contents (i.e., available water-holding capacity), and relatively long distances to groundwater (i.e., over $700 \mathrm{ft}$ bgs). Based 
on these physical and chemical factors, contamination is expected to be found relatively close to release points.

Infiltration and percolation of precipitation serve as a driving force for downward migration of contaminants. However, because of high PET (mean PET at the Area 5 Radioactive Waste Management Site (RWMS) has been estimated at 63.5 in. [Yucel, 2009]) and limited precipitation for this region (average annual precipitation at station Well $5 \mathrm{~B}$ is $4.51 \mathrm{in}$. [ARL/SORD, 2009]), percolation of infiltrated precipitation at the NTS does not provide a significant mechanism for vertical migration of contaminants to groundwater (DOE/NV, 1992). Although there may be standing water at times on the Frenchman Lake, accumulation of fine materials on the lake bed has decreased the hydraulic conductivity of the lake bed to the point where infiltration is not significant (i.e., most of the accumulated water evaporates before it infiltrates the lake bed surface) (SNJV, 2004).

Subsurface migration pathways at CAU 106 are expected to be predominately vertical, although spills or leaks at the ground surface may also have limited lateral migration before infiltration. The depth of infiltration (shape of the subsurface contaminant plume) will be dependent upon the type, volume, and duration of the discharge as well as the presence of relatively impermeable layers that could modify vertical or horizontal transport pathways, both on the ground surface (e.g., concrete) and in the subsurface (e.g., caliche layers).

\section{A.2.2.6 Exposure Scenarios}

Human receptors may be exposed to COPCs through oral ingestion, inhalation, dermal contact (absorption) of soil or debris due to inadvertent disturbance of these materials or external irradiation by radioactive materials. The land-use and exposure scenarios for the CAU 106 sites are listed in Table A.2-3. These are based on NTS current and future land use. All sites are at remote locations without any site improvements and where no regular work is performed; however, there is a potential for site workers to occupy these locations on an occasional and temporary basis, such as a military exercise in the future. Therefore, these sites are classified as occasional work areas. 
Table A.2-3

Land-Use and Exposure Scenarios

\begin{tabular}{|c|l|l|}
\hline Site & \multicolumn{1}{|c|}{ Record of Decision Land-Use Zone } & \multicolumn{1}{|c|}{ Exposure Scenario } \\
\hline \hline & $\begin{array}{l}\text { Reserved Zone } \\
\text { This area includes land and facilities that provide } \\
\text { widespread flexible support for diverse short-term } \\
\text { testing and experimentation. The reserved zone is also } \\
\text { used for short-duration exercises and training, such as } \\
\text { nuclear emergency response, Federal Radiological } \\
\text { Monitoring and Assessment Center training, and DoD } \\
\text { exercises and training. }\end{array}$ & $\begin{array}{l}\text { Occasional Use Area } \\
\text { Worker will be exposed to the site occasionally } \\
\text { (up to 80 hours per year for 5 years). Site } \\
\text { structures are not present for shelter and } \\
\text { comfort of the worker. }\end{array}$ \\
\hline Able, & $\begin{array}{l}\text { Research Test and Experiment Zone } \\
\text { This area is designated for small-scale research and } \\
\text { development projects and demonstrations; pilot } \\
\text { projects; outdoor tests; and experiments for the } \\
\text { development, QA, or reliability of material and } \\
\text { equipment under controlled conditions. This zone } \\
\text { includes compatible defense and nondefense research, } \\
\text { development, and testing projects and activities. }\end{array}$ & \\
\hline
\end{tabular}




\section{A.3.0 Step 2 - Identify the Goal of the Study}

Step 2 of the DQO process states how environmental data will be used in meeting objectives and solving the problem, identifies study questions or decision statement(s), and considers alternative outcomes or actions that can occur upon answering the question(s).

\section{A.3.1 Decision Statements}

The Decision I statement is: "Is any COC present in environmental media within the CAS?” For judgmental sampling design, any analytical result for a COPC above the FAL will result in that COPC being designated as a COC. For probability (random) sampling design, any COPC that has a 95 percent UCL of the average concentration above the FAL will result in that COPC being designated as a COC. A COC may also be defined as a contaminant that, in combination with other like contaminants, is determined to jointly pose an unacceptable risk based on a multiple contaminant analysis (NNSA/NSO, 2006). If a COC is detected, then Decision II must be resolved.

The Decision II statement is: "If a COC is present, is sufficient information available to evaluate potential CAAs?” Sufficient information is defined to include:

- The lateral and vertical extent of COC contamination

- The information needed to determine potential remediation waste types

- The information needed to evaluate the potential for COC migration

The presence of a COC would require a corrective action. A corrective action may also be necessary if there is a potential for wastes (i.e., PSM) that are present at a site to result in the introduction of COCs into site environmental media. To evaluate the potential for wastes to result in the introduction of a COC to the surrounding environmental media, the following conservative assumptions were made:

- Any containment of waste (e.g., fuel/oil reservoirs, pipe, concrete vaults and walls, drums) would fail at some point, and the waste would be released to the surrounding soil.

- A waste, regardless of concentration or configuration, may be assumed to be PSM and handled under a corrective action. 
- Based on process knowledge and/or professional judgment, some waste may be assumed to not be PSM if it is clear that it could not result in soil contamination exceeding a FAL.

- If assumptions about the waste cannot be made, then the waste material will be sampled, and the results will be compared to FALs based on the following criteria:

- For non-liquid wastes, the concentration of any chemical contaminant in soil (following degradation of the waste and release of contaminants into soil) would be equal to the mass of the contaminant in the waste divided by the mass of the waste.

- For non-liquid wastes, the dose resulting from radioactive contaminants in soil (following degradation of the waste and release of contaminants into soil) would be calculated using the activity of the contaminant in the waste divided by the mass of the waste (for each radioactive contaminant) and calculating the combined resulting dose using the RESRAD code (Murphy, 2004).

- For liquid wastes, the resulting concentration of contaminants in the surrounding soil would be calculated based on the concentration of contaminants in the wastes and the liquid-holding capacity of the soil.

For the test and non-test release scenarios, Decision I will be resolved by submitting Decision I samples to analytical laboratories to determine the presence of COCs. The specific analyses for samples from non-test releases identified during the CAI will be selected dependent upon the type and nature of the identified release. Decision II samples for both release scenarios will be submitted as necessary to define the extent of unbounded COCs.

If sufficient information is not available to evaluate potential CAAs, then site conditions will be re-evaluated and additional samples will be collected (as long as the scope of the investigation is not exceeded and any CSM assumption has not been shown to be incorrect).

\section{A.3.2 Alternative Actions to the Decisions}

This section identifies actions that may be taken to solve the problem depending on the possible outcomes of the investigation.

\section{A.3.2.1 Alternative Actions to Decision I}

If no COC associated with a release from the CAS is detected, then further assessment of the CAS is not required. If a COC associated with a release from the CAS is detected, then the extent of COC 
contamination will be determined, and additional information required to evaluate potential CAAs will be collected.

\section{A.3.2.2 Alternative Actions to Decision II}

If the lateral and vertical extent of COC contamination has not been defined by bounding sample results, then additional bounding samples will be collected. If sample analytical results are not sufficient to predict potential remediation waste types, then additional waste characterization samples will be collected. If available information is not sufficient to evaluate the potential for COC migration, additional information will be collected. If sufficient information is not available to evaluate potential CAAs, then additional samples will be collected. Otherwise, collection of additional information is not required. 


\section{A.4.0 Step 3 - Identify Information Inputs}

Step 3 of the DQO process identifies the information needed, determines sources for information, and identifies sampling and analysis methods that will allow reliable comparisons with FALs.

\section{A.4.1 Information Needs}

To resolve Decision I (determine whether a COC is present at a CAS), samples will be collected and analyzed following these two criteria:

- Samples must either (a) be collected in areas most likely to contain a COC (judgmental sampling) or (b) properly represent contamination at the CAS (probabilistic sampling).

- The analytical suite selected must be sufficient to identify any COCs present in the samples.

To resolve Decision II for test release contamination, samples need to be collected and analyzed to meet the following criteria:

- A decreasing trend of TED rates from more than 25 mrem/IA-yr to less than 25 mrem/IA-yr in at least three directions (vectors) needs to be established sufficiently to determine a correlation to radiation survey isopleths such that a boundary can be determined around the area posing a more-than-25-mrem/yr dose.

- Environmental samples, direct samples of waste, and/or process knowledge is sufficient to predict potential remediation waste types.

- Information is sufficient to determine whether a COC has migrated from the area of original deposition.

The exception to this is Able, where, by definition, a test release occurred; however, available information indicates that soil contamination above FALs is not expected. Therefore, the presence of a COC would be a violation of the CSM. If a COC is present at Able (i.e., a TED greater than the 25-mrem/yr TED is present), then NDEP will be notified and a plan for determining the extent of contamination will be proposed before continuing the CAI at this site. 
To resolve Decision II for non-test release contamination (determine whether sufficient information is available to evaluate potential CAAs at each CAS), samples need to be collected and analyzed to meet the following criteria:

- Samples must be collected in areas contiguous to the contamination but where contaminant concentrations are below FALs.

- Samples of the waste or environmental media must provide sufficient information to determine potential remediation waste types.

- Samples of the waste must provide sufficient information to determine whether they contain PSM.

- The analytical suites selected must be sufficient to detect contaminants at concentrations equal to or less than their corresponding FALs.

\section{A.4.2 Sources of Information}

Information to satisfy Decision I and Decision II will be generated by collecting environmental samples. These samples will be submitted to analytical laboratories meeting the quality criteria stipulated in the Industrial Sites QAPP (NNSA/NV, 2002a). The TLDs will be submitted to the Environmental Technical Services group at the NTS, which is certified by the DOE Laboratory Accreditation Program for dosimetry. Only validated data from analytical laboratories will be used to make DQO decisions. Sample collection and handling activities will follow standard procedures.

\section{A.4.2.1 Sample Locations}

Design of the sampling approaches for the CAU 106 CASs must ensure that the data collected are sufficient for selection of the CAAs (EPA, 2002a). To meet this objective, the samples collected from each site should be either from locations that most likely contain a COC, if present (judgmental), or from locations that properly represent overall contamination at the CAS (probabilistic). These sample locations, therefore, can be selected by means of either (a) biasing factors used in judgmental sampling (e.g., a stain or location of elevated radioactivity) or (b) randomly using a probabilistic sampling design. The implementation of judgmental and probabilistic approaches for sample location selection for CAU 106 CASs is discussed in Section A.8.0. 


\section{A.4.2.2 Analytical Methods}

Analytical methods are available to provide the data needed to resolve the decision statements. The analytical methods and laboratory requirements (e.g., detection limits, precision, and accuracy) for soil samples are provided in Tables 3-3 and 3-4. 


\section{A.5.0 Step 4 - Define the Boundaries of the Study}

Step 4 of the DQO process defines the target population of interest and its relevant spatial boundaries, specifies temporal and other practical constraints associated with sample/data collection, and defines the sampling units on which decisions or estimates will be made.

\section{A.5.1 Target Populations of Interest}

The population of interest to resolve Decision I ("Is any COC present in environmental media within the CAS?”) is any location or area within the site that contains contaminant concentrations exceeding a FAL. The populations of interest to resolve Decision II ("If a COC is present, is sufficient information available to evaluate potential CAAs?”) are:

- Each one of a set of locations bounding contamination in lateral and vertical directions (including migration pathways such as drainages)

- Investigation waste and potential remediation waste

\section{A.5.2 Spatial Boundaries}

Spatial boundaries are the maximum lateral and vertical extent of expected contamination that can be supported by the CSM. The CAS-specific Decision II spatial boundaries are listed in Table A.5-1. Contamination found beyond these boundaries may indicate a flaw in the CSM and may require re-evaluation of the CSM before the investigation could continue. Each CAS is considered geographically independent, and intrusive activities are not intended to extend into the boundaries of neighboring CASs.

\section{A.5.3 Practical Constraints}

The only practical constraint identified that may affect the ability to characterize a site is the structural integrity and access limitations to the bunker located in the HCA at GMX. 
Table A.5-1

Spatial Boundaries

\begin{tabular}{||c|c|c||}
\hline Site & $\begin{array}{c}\text { Vertical Boundary } \\
\text { (bgs) }\end{array}$ & Horizontal Boundary \\
\hline \hline GMX & $\begin{array}{c}\text { Test Release: } 2 \mathrm{ft} \\
\text { Non-Test Release: } 15 \mathrm{ft}\end{array}$ & $\begin{array}{c}\text { Test Release: } 0.5 \mathrm{mi} \\
\text { Non-Test Release: } 0.5 \mathrm{mi}\end{array}$ \\
\hline Able & Test Release: $2 \mathrm{ft}$ & Test Release: $500 \mathrm{ft}$ \\
\hline Hamilton & $\begin{array}{c}\text { Test Release: } 2 \mathrm{ft} \\
\text { Non-Test Release: } 15 \mathrm{ft}\end{array}$ & $\begin{array}{c}\text { Test Release: } 600 \mathrm{ft} \\
\text { Non-Test Release: } 0.5 \mathrm{mi}\end{array}$ \\
\cline { 1 - 2 } $306 \mathrm{GZ}$ & Non-Test Release: $15 \mathrm{ft}$ & Non-Test Release: $500 \mathrm{ft}$ \\
\hline $307 \mathrm{GZ}$ & & \\
\hline
\end{tabular}

\section{A.5.4 Define the Sampling Units}

The scale of decision making in Decision I is defined as the CAS. Any COC detected at any location within the CAS will cause the determination that the CAS is contaminated and needs further evaluation. The scale of decision making for Decision II is defined as a contiguous area bounding COCs originating from the CAS. Resolution of Decision II requires this contiguous area to be bounded laterally and vertically. 


\section{A.6.0 Step 5 - Develop the Analytic Approach}

Step 5 of the DQO process specifies appropriate population parameters for making decisions, defines action levels, and generates an "If ... then ... else" decision rule that involves it.

\section{A.6.1 Population Parameters}

Population parameters are defined for judgmental and probablistic sampling designs in the following sections. Population parameters are the parameters compared to action levels.

\section{A.6.1.1 Judgmental Sampling Design}

For judgmental sampling results, the population parameter is the observed concentration of each contaminant from each individual analytical sample. Each sample result will be compared to the FALs to determine the appropriate resolution to Decision I and Decision II. A single sample result for any contaminant exceeding a FAL would cause a determination that a COC is present within the CAS (for Decision I) or that the COC is not bounded (for Decision II).

\section{A.6.1.2 Probabilistic Sampling Design}

For probabilistic sampling results, the population parameter is the true TED over the area of the sample plot. To resolve DQO decisions associated with the probabilistic sampling design, it must be determined, with a specified degree of confidence, whether the true TED at the site in question exceeds the FAL. Because a measured TED is an estimate of the true (unknown) TED, it is uncertain how well the calculated TED represents the true TED. If the measured TED were significantly different than the true TED, a decision based on the measured TED could result in a decision error. To reduce the probability of making a false negative decision error, a conservative estimate of the true TED, instead of the measured TED, is used to compare to the FAL. This conservative estimate (overestimation) of the true TED will be calculated as the 95 percent UCL of the average TED measurements. By definition, there will be a 95 percent probability that the true TED is less than the 95 percent UCL of the measured TED. At Able, individual sample locations will be established rather than a sample plot. Therefore, the measured TED will be compared directly to the FAL. 
The computation of appropriate UCLs depends upon the data distribution, the number of samples, the variability of the dataset, and the skewness associated with the dataset. A statistical package will be used to determine the appropriate probability distribution (e.g., normal, lognormal, gamma) and/or a suitable non-parametric distribution-free method and then to compute appropriate UCLs. To ensure that the appropriate UCL computational method is used, the sample data will be tested for goodness-of-fit to all of the parametric and non-parametric UCL computation methods described in Calculating the Upper Confidence Limits for Exposure Point Concentrations at Hazardous Waste Sites (EPA, 2002b).

Computation of an appropriate UCL for each of the calculated TED averages requires that:

- A minimum number of samples are collected.

- The data originate from a symmetric, but not necessarily normally distributed, population.

- The estimation of the variability is reasonable and representative of the population being sampled.

- $\quad$ The population values are not spatially correlated.

\section{A.6.2 Action Levels}

The PALs presented in this section are to be used for site screening purposes. They are not necessarily intended to be used as cleanup action levels or FALs. However, they are useful in screening out contaminants that are not present in sufficient concentrations to warrant further evaluation and, therefore, streamline the consideration of remedial alternatives. The RBCA process used to establish FALs is described in the Industrial Sites Project Establishment of Final Action Levels (NNSA/NSO, 2006). This process conforms with NAC Section 445A.227 (NAC, 2008a), which lists the requirements for sites with soil contamination. For the evaluation of corrective actions, NAC Section 445A.22705 (NAC, 2008b) requires the use of ASTM Method E1739 (ASTM, 1995) to "conduct an evaluation of the site, based on the risk it poses to public health and the environment, to determine the necessary remediation standards (i.e., FALs) or to establish that corrective action is not necessary.” 
This RBCA process defines three tiers (or levels) of evaluation involving increasingly sophisticated analyses:

- Tier 1 evaluation - Sample results from source areas (highest concentrations) are compared to action levels based on generic (non-site-specific) conditions (i.e., the PALs established in the CAIP). The FALs may then be established as the Tier 1 action levels, or the FALs may be calculated using a Tier 2 evaluation.

- Tier 2 evaluation - Conducted by calculating Tier 2 SSTLs using site-specific information as inputs to the same or similar methodology used to calculate Tier 1 action levels. The Tier 2 SSTLs are then compared to individual sample results from reasonable points of exposure (as opposed to the source areas as is done in Tier 1) on a point-by-point basis. Total TPH concentrations will not be used for risk-based decisions under Tier 2 or Tier 3 . Rather, the individual chemicals of concern will be compared to the SSTLs.

- Tier 3 evaluation - Conducted by calculating Tier 3 SSTLs on the basis of more sophisticated risk analyses using methodologies described in Method E1739 that consider site-, pathway-, and receptor-specific parameters.

The comparison of laboratory results to FALs and the evaluation of potential corrective actions will be included in the investigation report. The FALs will be defined (along with the basis for their definition) in the investigation report.

\section{A.6.2.1 Chemical PALs}

Except as noted herein, the chemical PALs are defined as the Region 9: Superfund, Preliminary Remediation Goals, Screening Levels for Chemical Contaminants in industrial soils (EPA, 2009). Background concentrations for RCRA metals and zinc will be used instead of screening levels when natural background concentrations exceed the screening level (e.g., arsenic on the NTS). Background is considered the average concentration plus two standard deviations of the average concentration for sediment samples collected by the Nevada Bureau of Mines and Geology throughout the Nevada Test and Training Range (formerly the Nellis Air Force Range) (NBMG, 1998; Moore, 1999). For detected chemical COPCs without established screening levels, the protocol used by the EPA Region 9 in establishing screening levels (or similar) will be used to establish PALs. If used, this process will be documented in the investigation report. 


\section{A.6.2.2 Radionuclide PALs}

The PAL for radioactive contaminants is $25 \mathrm{mrem} / \mathrm{yr}$ based upon the Industrial Area exposure scenario. The Industrial Area exposure scenario is described in Industrial Sites Project Establishment of Final Action Levels (NNSA/NSO, 2006). That document establishes the default exposure conditions and RESRAD computer code input parameters to be used to calculate the potential radiation dose over a land area. Several input parameters are not specified so that site-specific information can be used.

For test releases, the Industrial Area scenario has been modified by pre-specifying values for several input parameters (such as an area of contamination of $1000 \mathrm{~m}^{2}$ and a depth of contamination of $5 \mathrm{~cm}$ ). In addition, DCG values for each individual radionuclide COPC were calculated. The DCG is the value, in $\mathrm{pCi} / \mathrm{g}$ for surface soil, for a particular radionuclide that would result in a dose of $25 \mathrm{mrem} / \mathrm{yr}$. Using DCGs in site evaluation facilitates the determination of a radiation dose estimate for each soil sample.

\section{A.6.3 Decision Rules}

The decision rule applicable to both Decision I and Decision II is:

- If COC contamination is inconsistent with the CSM or extends beyond the spatial boundaries identified in Section A.5.2, then work will be suspended and the investigation strategy will be reconsidered, else the decision will be to continue sampling.

The decision rule for Decision I are:

- If the population parameter of any COPC in the Decision I population of interest (defined in Step 4) exceeds the corresponding FAL, then that contaminant is identified as a COC, and Decision II samples will be collected, else no further investigation is needed for that COPC in that population.

- If a COC exists at any CAS, then a corrective action will be determined, else no further action will be necessary.

- If a waste is present that, if released, has the potential to cause the future contamination of site environmental media, then a corrective action will be determined, else no further action will be necessary. 
The decision rules for Decision II are:

- If the population parameter (the observed concentration of any COC) in the Decision II population of interest (defined in Step 4) exceeds the corresponding FAL or potential remediation wastes have not been adequately defined, then additional samples will be collected to complete the Decision II evaluation, else the extent of the COC contamination has been defined.

- If valid analytical results are available for the waste characterization samples defined in Section A.8.0, then the decision will be that sufficient information exists to determine potential remediation waste types and evaluate the feasibility of remediation alternatives, else collect additional waste characterization samples. 


\section{A.7.0 Step 6 - Specify Performance or Acceptance Criteria}

Step 6 of the DQO process defines the decision hypotheses, specifies controls against false rejection and false acceptance decision errors, examines consequences of making incorrect decisions from the test, and places acceptable limits on the likelihood of making decision errors.

\section{A.7.1 Decision Hypotheses}

The baseline condition (i.e., null hypothesis) and alternative condition for Decision I are:

- $\quad$ Baseline condition - A COC is present.

- Alternative condition - A COC is not present.

The baseline condition (i.e., null hypothesis) and alternative condition for Decision II are as follows:

- $\quad$ Baseline condition - The extent of a COC has not been defined.

- Alternative condition - The extent of a COC has been defined.

Decisions and/or criteria have false negative or false positive errors associated with their determination. The impact of these decision errors and the methods that will be used to control these errors are discussed in the following subsections. In general terms, confidence in DQO decisions based on judgmental sampling results will be established qualitatively by:

- Developing a CSM (based on process knowledge) that is agreed to by stakeholder participants during the DQO process.

- $\quad$ Testing the validity of the CSM based on investigation results.

- Evaluating the quality of data based on DQI parameters.

\section{A.7.2 False Negative Decision Error}

The false negative decision error would mean deciding that a COC is not present when it actually is (Decision I), or deciding that the extent of a COC has been defined when it has not (Decision II). In both cases, the potential consequence is an increased risk to human health and the environment. 


\section{A.7.2.1 False Negative Decision Error for Judgmental Sampling}

In judgmental sampling, the selection of the number and location of samples is based on knowledge of the feature or condition under investigation and on professional judgment (EPA, 2002a).

Judgmental sampling conclusions about the target population depend upon the validity and accuracy of professional judgment.

The false negative decision error (where consequences are more severe) for judgmental sampling designs is controlled by meeting these criteria:

- For Decision I, having a high degree of confidence that the sample locations selected will identify COCs if present anywhere within the CAS. For Decision II, having a high degree of confidence that the sample locations selected will identify the extent of COCs.

- Having a high degree of confidence that analyses conducted will be sufficient to detect any COCs present in the samples.

- Having a high degree of confidence that the dataset is of sufficient quality and completeness.

To satisfy the first criterion, Decision I samples must be collected in areas that are most likely contaminated by COCs (supplemented by random samples where appropriate). Decision II samples must be collected in areas that represent the lateral and vertical extent of contamination (above FALs). The following characteristics must be considered to control decision errors for the first criterion:

- Source and location of release

- Chemical nature and fate properties

- Physical transport pathways and properties

- Hydrologic drivers

These characteristics were considered during the development of the CSM and selection of sampling locations. The field-screening methods and biasing factors listed in Section A.4.2.1 will be used to further ensure that appropriate sampling locations are selected to meet these criteria. Radiological survey instruments and field-screening equipment will be calibrated and checked in accordance with the manufacturer's instructions and approved procedures. The investigation report will present an assessment on the DQI of representativeness that samples were collected from those locations that best represent the populations of interest as defined in Section A.5.1. 
To satisfy the second criterion, Decision I samples will be analyzed for the chemical and radiological parameters listed in Section 3.2. Decision II samples will be analyzed for those chemical and radiological parameters that identified unbounded COCs. The DQI of sensitivity will be assessed for all analytical results to ensure that all sample analyses had measurement sensitivities (detection limits) that were less than or equal to the corresponding FALs. If this criterion is not achieved, the affected data will be assessed (for usability and potential impacts on meeting site characterization objectives) in the investigation report.

To satisfy the third criterion, the entire dataset of soil sample results, as well as individual soil sample results, will be assessed against the DQIs of precision, accuracy, comparability, and completeness as defined in the Industrial Sites QAPP (NNSA/NV, 2002a) and in Section 6.2.2. The DQIs of precision and accuracy will be used to assess overall analytical method performance as well as the need to potentially “flag” (qualify) individual contaminant results when corresponding QC sample results are not within the established control limits for precision and accuracy. Data qualified as estimated for reasons of precision or accuracy may be considered to meet the analyte performance criteria based on an assessment of the data. The DQI for completeness will be assessed to ensure that all data needs identified in the DQO have been met. The DQI of comparability will be assessed to ensure that all analytical methods used are equivalent to standard EPA methods so that results will be comparable to regulatory action levels that have been established using those procedures. Strict adherence to established procedures and QA/QC protocol protects against false negatives. Site-specific DQIs are discussed in more detail in Section 6.2.2.

To provide information for the assessment of the DQIs of precision and accuracy, the following QC samples will be collected as required by the Industrial Sites QAPP (NNSA/NV, 2002a):

- Field duplicates (minimum of 1 per matrix per 20 environmental samples)

- Laboratory QC samples (minimum of 1 per matrix per 20 environmental samples or 1 per CAS per matrix, if less than 20 collected)

\section{A.7.2.2 False Negative Decision Error for Probabilistic Sampling}

The false negative decision error rate goal was established by the DQO meeting participants at 5 percent. Upon validation of the analytical results, statistical parameters will be calculated for each 
significant COPC identified at each site. Protection against a false negative decision error is contingent upon:

- Population distribution

- Sample size

- Actual variability

- Measurement error

Control of the false negative decision error for probabilistic sampling designs is accomplished by ensuring that the following requirements are met for each of the significant COPCs:

- The population distributions fit the applied UCL determination method.

- A sufficient sample size was collected.

- The actual standard deviation is calculated.

- Analyses conducted were sufficient to detect contamination exceeding FALs.

\section{A.7.3 False Positive Decision Error}

The false positive decision error would mean deciding that a COC is present when it is not, or a COC is unbounded when it is not, resulting in increased costs for unnecessary sampling and analysis.

False positive results are typically attributed to laboratory and/or sampling/handling errors that could cause cross contamination. To control against cross contamination, decontamination of sampling equipment will be conducted in accordance with established and approved procedures, and only clean sample containers will be used. To determine whether a false positive analytical result may have occurred, the following QC samples will be collected as required by the Industrial Sites QAPP (NNSA/NV, 2002a):

- $\quad$ Trip blanks (1 per sample cooler containing VOC environmental samples)

- Equipment blanks (1 per sampling event)

- $\quad$ Source blanks (1 per uncharacterized source lot per lot)

- Field blanks (minimum of 1 per CAS, additional if field conditions change)

For probabilistic sampling, false positive decision error rate goal was established by the DQO meeting participants at 0.20 (or 20 percent probability). Protection against this decision error is also afforded by the controls listed in Section A.7.2 for probabilistic sampling designs. 


\section{A.8.0 Step 7 - Develop the Plan for Obtaining Data}

Step 7 of the DQO process selects and documents a design that will yield data that will best achieve performance or acceptance criteria. Judgmental sampling schemes will be implemented to select sample plot locations for the test releases. Probabilistic sampling schemes will be implemented to select the sample locations within each of the sample plots. Judgmental sampling will also be used to investigate any non-test releases as described in Section A.2.2.1. Investigation results will be compared to FALs to determine the need for corrective action. Potential source material sample results will be evaluated against the PSM criteria listed in Section A.3.1 to determine the need for corrective action.

\section{A.8.1 Internal Dose Sampling for Test Releases}

\section{A.8.1.1 Judgmental Sample and Sample Plot Locations}

A judgmental sampling design will be implemented to locate Decision I sample plots for the test release scenario at Hamilton and GMX. At Able, individual judgmental sample locations will be established rather than a sample plot because available information indicates that soil contamination above FALs is not expected. These locations will be selected judgmentally based on radiological survey values in an effort to find the location where the internal dose contributes the greatest amount to TED. At Hamilton and GMX, Decision I sample plots may be established within the area of the highest Am values as determined from the 1994 flyover survey (BN, 1999) and a radiological survey conducted with a handheld instrument. At Able, at least one judgmentally selected sample location will be established, and if no biasing factors are identified, the default sample location will be at the posted ground zero location (Figure A.8-1).

A judgmental sampling design will also be implemented to locate Decision II sample plots at Hamilton and GMX. Sample plot locations will be selected judgmentally based on radiological surveys and applicable historical sampling results (e.g., existing or new aerial radiological surveys; GPS-assisted gamma walkover surveys, NAEG data, and RIDP data). These data will be used to establish patterns of contaminant distribution. At Hamilton, at least two Decision II sample plot locations will be judgmentally established along each of three vectors with the Decision I plot central to all vectors. The same will apply at GMX, except that at least four Decision II sample plot locations 


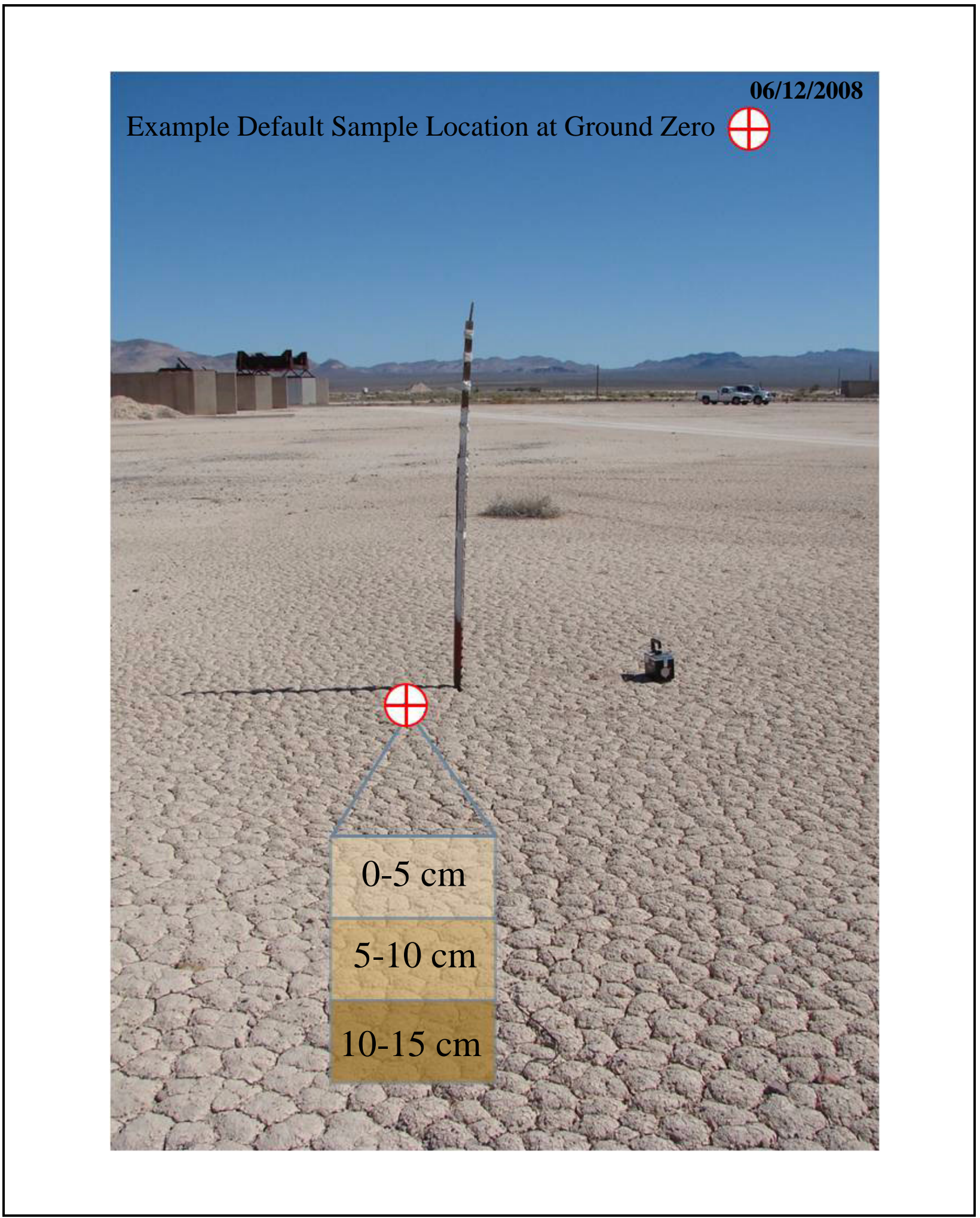

Figure A.8-1

Example Decision I Sample Location at Able 
will be established along each of three vectors with the Decision I plot being included in one of the vectors. Vectors will be oriented approximately normal to the selected radiation survey isopleths with the constraint that, on each vector, at least one sample plot will present a TED less than the FAL. Examples of proposed sampling vectors and Decision I and Decision II sample plots are shown in Figures A.8-2 and A.8-3.

\section{A.8.1.2 Test Release Sampling}

At Able, soil samples will be collected from each established judgmental location as described in Section A.8.1.3.

At Hamilton and GMX, a probabilistic sampling scheme will be implemented to select sample locations within the sample plots and evaluate the analytical results. For each sample collected within the sample plot, randomly selected subsample locations will be chosen using the Visual Sample Plan (VSP) software (PNNL, 2007) based on a random start, triangular pattern (Figure A.8-4). If sufficient sample material cannot be collected at a specified location (e.g., rock, caliche, or buried concrete), the Site Supervisor will establish the location at the nearest place where a surface sample can be obtained.

Statistical methods that generate site characteristics will be used to establish internal dose estimates that represent the sample plot as a whole. Four composite surface (0 to $5 \mathrm{~cm})$ samples will be collected at each 10-by-10-m sample plot in the following manner:

- Each composite sample will be composed of nine aliquots taken from randomly selected locations within each plot. These locations will be predetermined using a random start with a triangular grid pattern.

- Samples will be sieved to eliminate material greater than 0.25 in. diameter that cannot effectively be inhaled or ingested.

- The entire volume of the composited material collected will be submitted to the laboratory for analysis.

As determination of the minimum sample size cannot be accomplished until after the data have been generated, the sufficiency of the number of samples collected will be evaluated. This will be evaluated based on TED results (composed of individual internal dose rates associated with each of 


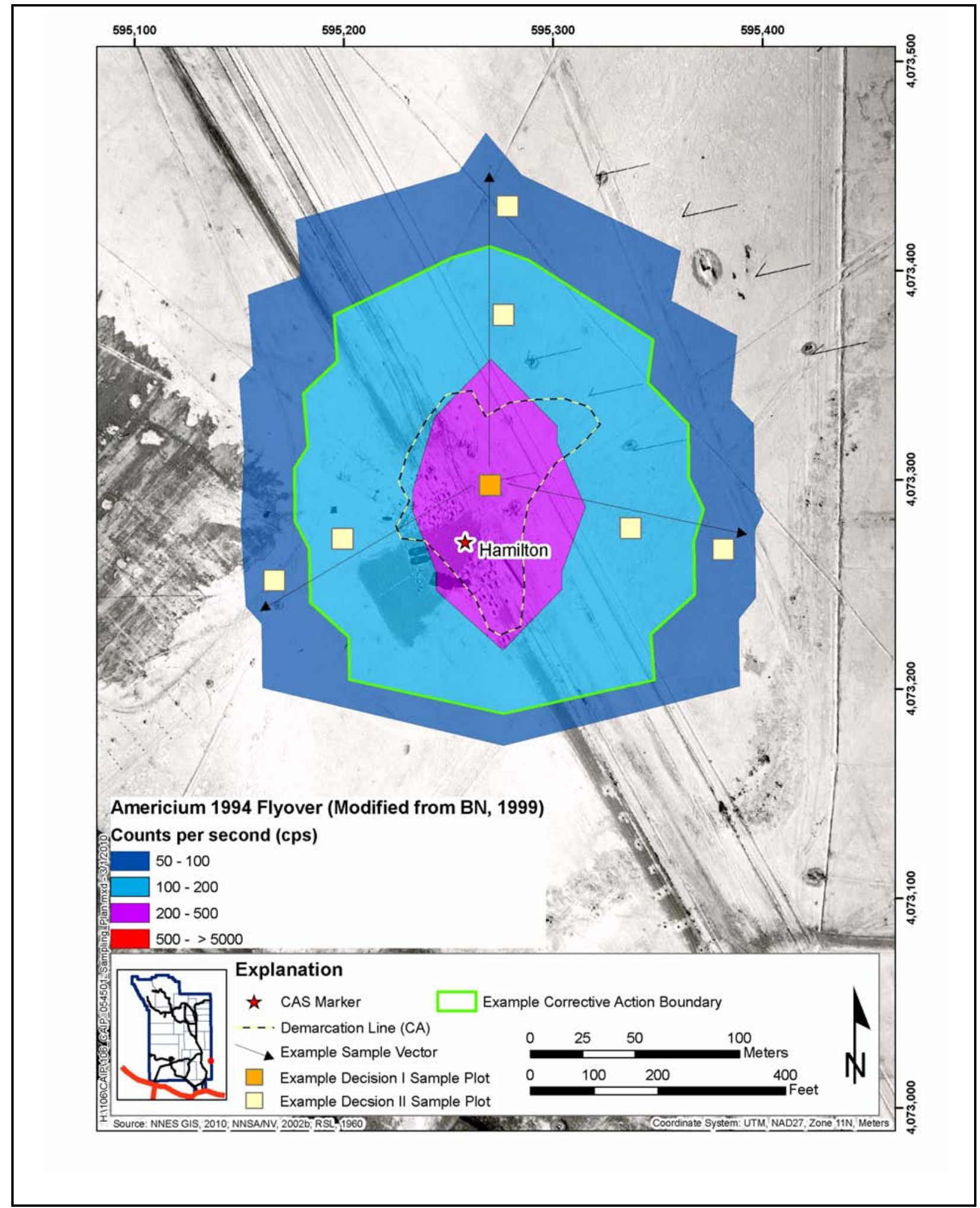

Figure A.8-2

Example Decision I and Decision II Sample Plot Locations at Hamilton 


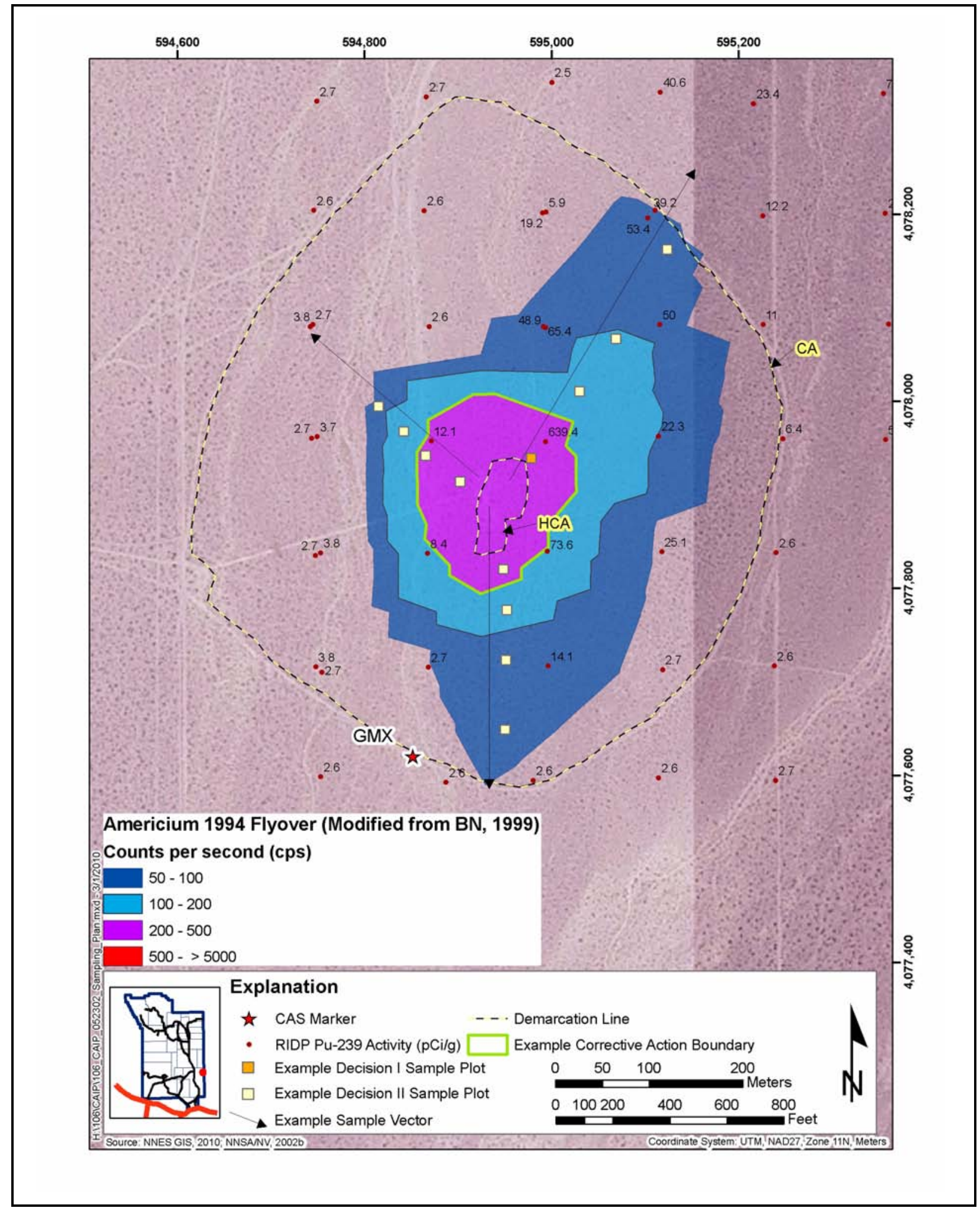

Figure A.8-3

Example Decision I and Decision II Sample Plot Locations at GMX 


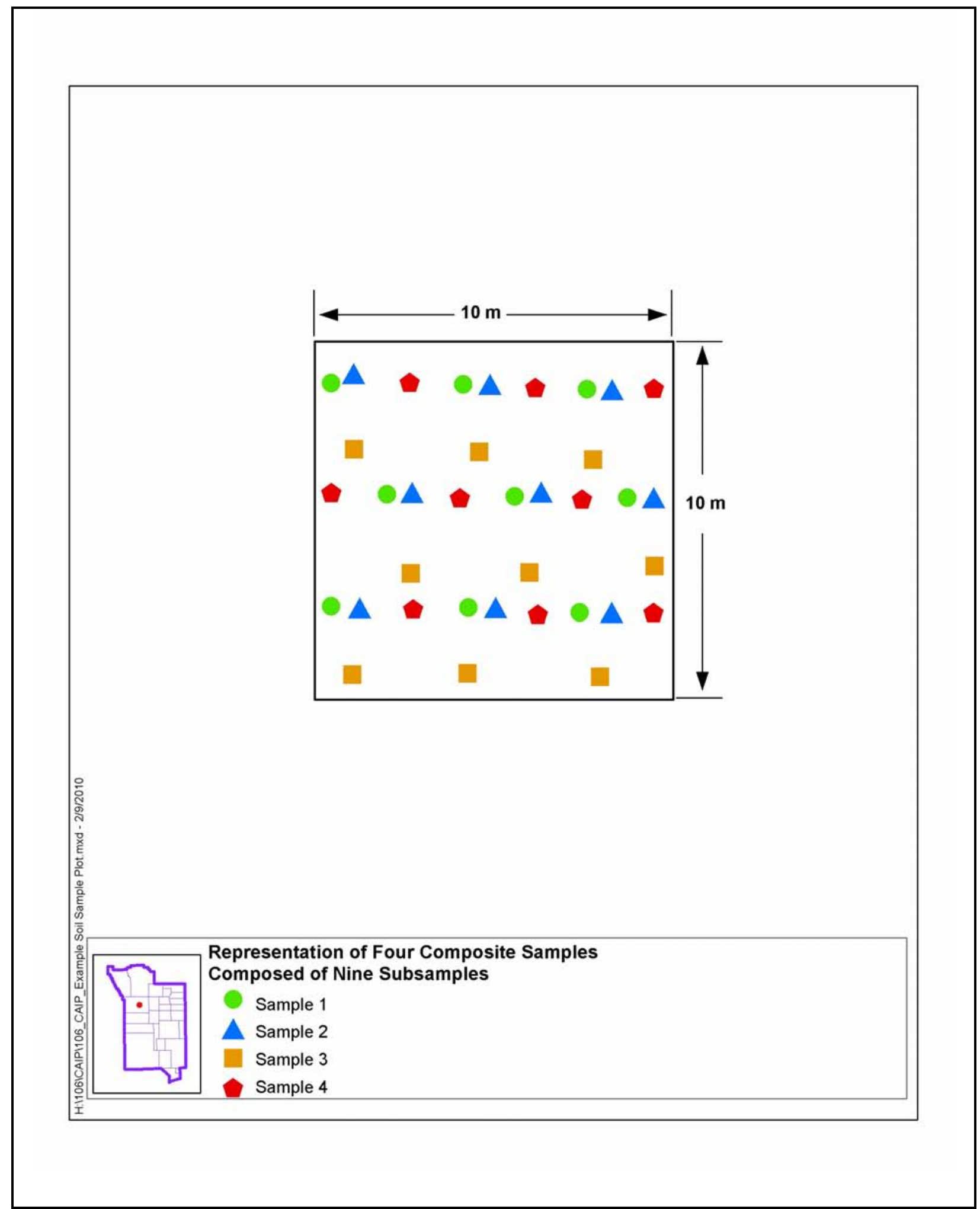

Figure A.8-4

Example Probabilistic Sampling Scheme at a Sample Plot 
the four composite samples added to the external dose rates from the TLD elements). The required number of samples will be calculated using the VSP software (PNNL, 2007). This software was developed by Pacific Northwest National Laboratory for the DOE and EPA to determine the minimum number of samples needed to characterize a site based on the type of test to be performed, the distribution of the data, the variability of the data, and the acceptable false positive and false negative error rates.

The input parameters to be used in calculating the minimum sample size are:

- A confidence level that a false negative error will not occur will be set at 95 percent.

- A confidence level that a false positive error will not occur will be set at 80 percent.

- A gray region width equal to 50 percent of the FAL (12.5 mrem/yr).

- The standard deviation of the TEDs at each plot.

All calculations for the determination of sample size sufficiency will be provided in the investigation report. If the criteria established in this section result in a determination that the minimum sample size was not met for a plot, one of the following actions may be taken:

- Additional composite sample(s) may be collected.

- Conservatively assume that the TED for the plot exceeds the FAL.

If this criteria cannot be met, justifications for using the resulting TED without meeting the criteria will be made in the CADD.

If buried contamination exists (see Section A.8.1.3), it will be conservatively assumed that the highest level of contamination observed (from surface or subsurface samples) provides dose to site workers. Therefore, in addition to the surface samples described above, subsurface samples will be collected at each composite location in 5-cm increments until native soil or buried horizon is encountered. The subsurface soil subsample with the highest screening value at each composite location will be composited into a sample submitted for analysis. 


\section{A.8.1.3 Determination of Buried Contamination}

As the CSM includes the possibility of buried horizons of contamination at Hamilton and Able, it will be determined whether buried contamination exists before sampling. The initially impacted soil is expected to be within the top $15 \mathrm{~cm}$ of soil because of the low sedimentation rates on dry lake beds.

At Hamilton, the process for determining whether buried contamination exists will be as follows:

- Establish a screening plot adjacent to the Decision I sample plot.

- Collect a 5-cm layer of soil from the surface of the plot.

- $\quad$ Field screen the soil with the appropriate radiation instrument.

- Compare the FSRs of the sample to the established background FSLs for the site.

- Continue this process by removing additional 5-cm layers of soil to a depth of at least 15 cm bgs; continue until FSRs are below FSLs.

If all FSRs are below FSLs, it will be assumed that buried contamination does not exist, and only surface samples (from each location in each plot) will be collected and submitted for analyses. If FSRs are greater than FSLs from any horizon of soil deeper than $5 \mathrm{~cm}$ bgs, it will be assumed that buried contamination exists. If it is decided that buried contamination exists, then samples at each of the nine subsample locations for each composite sample in every plot will be collected and field screened in 5-cm layers. The subsurface sample with the highest screening value at each of the nine subsample locations will be composited into a sample submitted for analysis.

At Able, the process will be the same as at Hamilton with the following exception: the samples collected at the actual selected Decision I sample location will be used to determine whether buried contamination exists rather than establishing an adjacent screening plot.

\section{A.8.2 External Dose Sampling for Test Releases}

External dose (penetrating radiation dose for the purposes of this document) will be determined by collecting in situ measurements using TLDs. External dose measurements will be taken at the approximate center of each sample plot (or sample location if plots are not used) at a height of $1 \mathrm{~m}(3.3 \mathrm{ft})$. 
The TLD placement and processing will follow the protocols established in Nevada Test Site Routine Radiological Environmental Monitoring Plan (NNSA/NSO, 2003). The TLDs will be in place for a targeted total exposure time of 2,250 hours, or the resulting data will be adjusted to be equivalent to an exposure time of 2,250 hours.

Estimates of external dose, in mrem/IA-yr, will be presented as net values (e.g., a background has been subtracted from the raw result). Naturally occurring terrestrial and cosmic radiation will be registered on a TLD, and the values can be significant in comparison to the FAL. In addition, the FAL is only applicable to radiation exposure from man-made sources at the NTS and is a value in excess of what would be present if there were no nuclear activities at the site.

The value for the natural background to be subtracted from the TLD results will be obtained from an area determined to be unaffected by man-made activities at the NTS.

The project-specific TLDs are subjected to the same QA checks as the routine NTS environmental monitoring TLDs, as described in Section 6.0. The Panasonic UD-814 TLD used in the NTS environmental monitoring program contains four individual elements. The readings from each element are compared as part of the routine QA checks during the TLD processing. External dose at each TLD location is then determined using the readings from TLD elements 2, 3, and 4. Element 1 is designed to measure dose to the skin and is not relevant to the determination of the external dose.

If buried contamination exists, it will be conservatively assumed that the highest level of contamination observed (from surface or subsurface samples) provides dose to site workers. Therefore, the samples with the highest dose (surface or subsurface) at each plot at Hamilton or sample location at Able will be used for the internal dose estimate. If subsurface samples contain higher levels of contamination (that would result in a higher dose), a TLD-equivalent external dose will be calculated for the sample plot based on the subsurface sample results. This will be accomplished by establishing a correlation between RESRAD-calculated external dose from surface samples and the corresponding TLD readings. The RESRAD-calculated external dose from the subsurface samples will then be adjusted to TLD-equivalent values using this correlation. 


\section{A.8.3 Evaluation of TED for Test Releases}

As discussed in Section A.6.1.2, the 95 percent UCL of the TED from each sample plot will be used to establish the corrective action boundary. The 95 percent UCL of the TED for each sample plot will be established as the sum of the 95 percent UCL of the internal dose and the 95 percent UCL of the external dose. These 95 percent UCL dose estimates will be calculated using the three external dose measurements from the TLD and the four RESRAD-calculated internal dose estimates from the soil samples. At Able, individual sample locations will be established rather than a sample plot; therefore, the measured TED will be compared directly to the FAL.

The initial corrective action boundary area will be calculated using the 95 percent UCL of the TED from each plot along each vector and an appropriate gamma radiation survey isopleth. A relationship will be established between the 95 percent UCL of the TED and gamma radiation survey values along each vector such that a gamma radiation survey value that corresponds to the 25-mrem/yr FAL can be established along each vector (using the appropriate exposure scenario). An isopleth from the radiological survey that encompasses the lowest value corresponding to the 25-mrem/yr FAL will be chosen as the initial corrective action boundary.

\section{A.8.4 Sampling for Non-test Releases}

Sample locations for non-test releases will be determined based upon the likelihood of a contaminant release at the CAS. These locations will be selected based on biasing factors identified during the investigation. Sections A.8.4.1.1 through A.8.4.1.4 present the judgmental sampling plan at CASs where there is evidence of a non-test release. For all non-test releases, the following biasing factors may be used to select the most appropriate samples from a particular location for submittal to the analytical laboratory:

- Process knowledge of the site: Locations for which existing evidence, such as historical photographs, experience from previous investigations, previous sample results, or interviewee's input, suggests that a release of hazardous or radioactive substances may have occurred.

- Process knowledge of the contaminant(s): Locations that are reasonably suspected of contamination based on the chemical and/or physical properties of the contaminant(s) in that environmental setting or knowledge of the source and location of a release. 
- Radiological survey results: Locations for which evidence, such flyover and walkover surveys, and radiological field screening, provides a basis upon which sample plots and sample locations can be designated.

- Geophysical anomalies: Geophysical survey results that are not consistent with the surrounding area (e.g., results indicating buried concrete or metal, surface metallic objects).

- Visual indicators such as stains, discoloration, textural discontinuities, ground disturbance of native soils indicating potential buried materials, or any other indication of potential contamination.

- Presence of debris, equipment, or abandoned waste suspected of containing hazardous or radiological components.

- Lithology: Locations where variations in lithology (soil or rock) indicate that different conditions or materials exist.

- Other biasing factors: Factors not previously defined for the CAI that become evident once the investigation of the site is under way.

\section{A.8.4.1 Decision I}

A judgmental sampling design will be implemented for the non-test releases to establish sample locations and evaluate sample results. Samples will be submitted for the analyses listed in Table A.2-2. For the non-test releases, individual sample results, rather than an average concentration, will be used to compare to FALs. Therefore, statistical methods to generate site characteristics will not be needed. Adequate representativeness of the entire target population may not be a requirement to developing a sampling design. If good prior information is available on the target site of interest, then the sampling may be designed to collect samples only from areas known to have the highest concentration levels on the target site. If the observed concentrations from these samples are below the action level, then a decision can be made that the site contains safe levels of the contaminant without the samples being truly representative of the entire area (EPA, 2006).

All non-test release sample locations will be selected to satisfy the DQI of representativeness in that samples collected from selected locations will best represent the populations of interest as defined in Section A.5.1. To meet this criterion for non-test releases, a biased sampling strategy will be used to target areas with the highest potential for contamination, if it is present anywhere in the CAS. Sample locations will be determined based on process knowledge, previously acquired data, or the 
field-screening and biasing factors listed in Section A.8.4. If biasing factors are present in soils below locations where Decision I samples were removed, additional Decision I soil samples will be collected at depth intervals selected by the Site Supervisor based on biasing factors to a depth where the biasing factors are no longer present. The Site Supervisor has the discretion to modify the judgmental sample locations, but only if the modified locations meet the decision needs and criteria stipulated in this DQO.

\section{A.8.4.1.1 GMX}

At GMX, judgmental sampling is planned for non-test releases associated with the bunker and the nearest prominent drainage. The bunker will be visually inspected and judgmental samples will be collected at locations based on biasing factors, such as radiological survey results, presence of PSM, or other indicators of a release. Areas of ground disturbance indicating the potential of buried materials will also be investigated. Geophysical surveys using instruments appropriate for detecting buried materials and DU will be performed outside the HCA fence out to $100 \mathrm{ft}$. This area may be extended based on survey results. To limit potential contamination of people and equipment, initial geophysical surveys will only be performed outside the HCA.

The nearest prominent drainage (located $185 \mathrm{ft}$ west of the HCA) will be surveyed with the appropriate radiation instrument (e.g., alpha/beta, or FIDLER). Sample locations will be established based on radiological survey results, or at the center of the two nearest sediment accumulation areas down gradient of and outside the initial corrective action boundary. Judgmental samples will be collected as follows:

- At each location, a sample will be collected from each 5-cm-depth interval until native material is encountered.

- Each sample will be field screened with the appropriate radiation instrument, and the sample with the highest FSR above the FSL at each sample location will be submitted for analysis (Figure A.8-5).

- If the FSL is not exceeded in any depth sample, then the surface sample (i.e., 0 to $5 \mathrm{~cm}$ ) will be submitted for analysis.

External dose at sedimentation areas will be determined by collecting in situ measurements using TLDs in accordance with the methods described in Section A.8.2. Because judgmental sample 


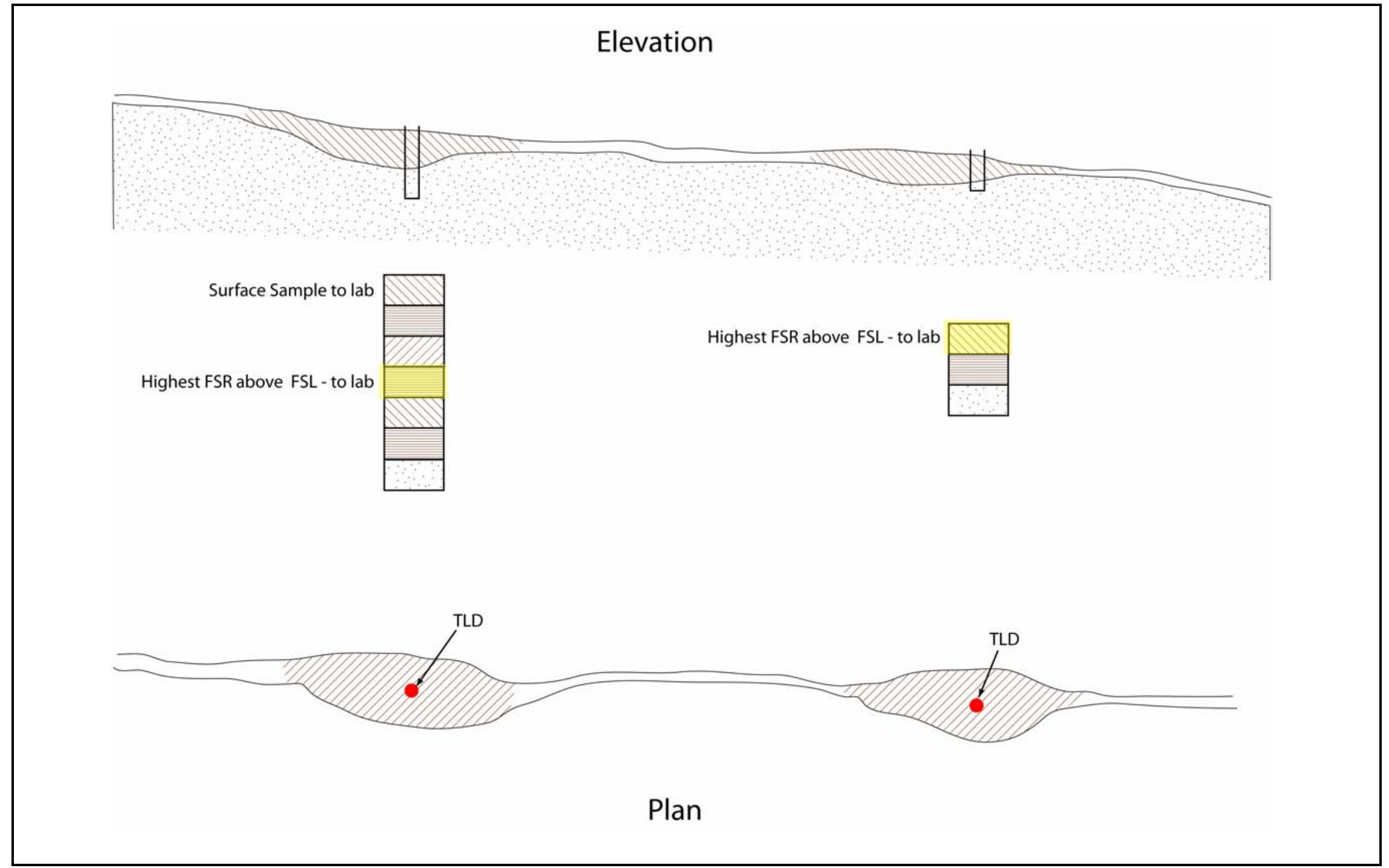

Figure A.8-5

Judgmental Sampling at Drainages

UNCONTROLLED when Printed 
locations are being used instead of a sample plot, the measured TED will be compared directly to the FAL to determine whether a COC exists. If FSRs are greater than FSLs from any horizon of sediment deeper than $5 \mathrm{~cm}$ bgs, it will be assumed that buried contamination exists, and a TLD-equivalent external dose will be calculated for the sample based on the subsurface sample results as described in Section A.8.3. If it is assumed that buried contamination exists, then the surface sample and the sample representing the buried horizon of contamination (i.e., highest FSR) will be submitted for analyses.

\section{A.8.4.1.2 Hamilton}

At Hamilton, non-test releases associated with the large debris pile located within the CA (see Figure A.8-6) will be sampled by collecting environmental and/or PSM samples at judgmental locations established during the CAI based on biasing factors (e.g., visual observations, radiological survey results, presence of PSM or other distinct materials). The specific sampling method will be in accordance with approved sampling procedures and will utilize hand tools in order to limit the amount of material disturbed.

External dose at the debris pile will be determined by collecting in situ measurements using a TLD in accordance with the methods described in Section A.8.2. Because judgmental sample locations are used instead of a sample plot, the measured TED will be compared directly to the FAL to determine whether a COC exists. If FSRs are greater than FSLs from any subsurface horizon within the debris pile, it will be assumed that buried contamination exists, and a TLD-equivalent external dose will be calculated for the sample based on the subsurface sample results as described in Section A.8.3. If it is determined that buried contamination exists, then the surface sample and the sample representing the buried horizon of contamination (i.e., highest FSR) will be submitted for analyses.

\section{A.8.4.1.3 306 GZ and $307 \mathrm{GZ}$}

At $306 \mathrm{GZ}$ and $307 \mathrm{GZ}$, judgmental sampling is planned for non-test surface releases associated with site activities and subsurface releases associated with buried wastes (if present) within the boundary of the posted URMAs. 


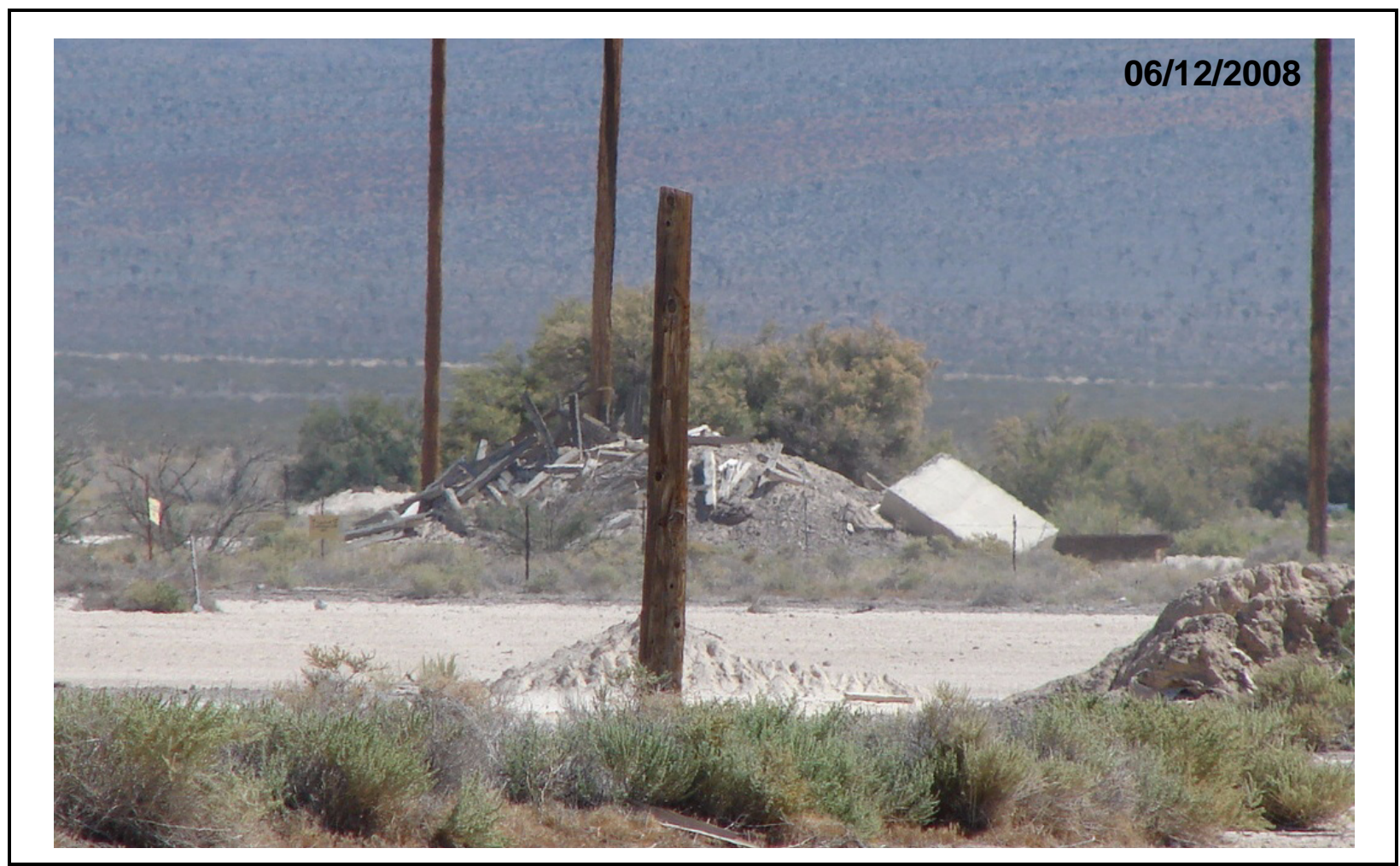

\section{Figure A.8-6 \\ Hamilton Debris Pile}

For surface releases at each site, a surface sample will be collected from a minimum of two locations of highest radioactivity above the FSLs following removal of identified PSM (e.g., DU, previously melted metal). These biased locations will be based on a radiological walkover survey of the area within and surrounding the posted URMAs (at 306 GZ and 307 GZ) and CA (at 306 GZ only), or based on other biasing factors. These locations may or may not be at locations where PSM was located (see Figure A.8-7). Potential source material will be removed as it is identified to an extent that is feasible. Geophysical surveys using instruments appropriate for detecting DU may be used. The following approach will be used:

- An initial 100-ft radius of the posted URMA or CA will be surveyed using appropriate geophysical and radiological instruments.

- If PSM is identified within $50 \mathrm{ft}$ of the initial boundary, then the boundary will be extended in 50-ft increments (arcs) from the PSM location until PSM is no longer present. Figure A.8-7 illustrates how the boundary may extend in a biased direction based on the distribution of PSM on the surface. 


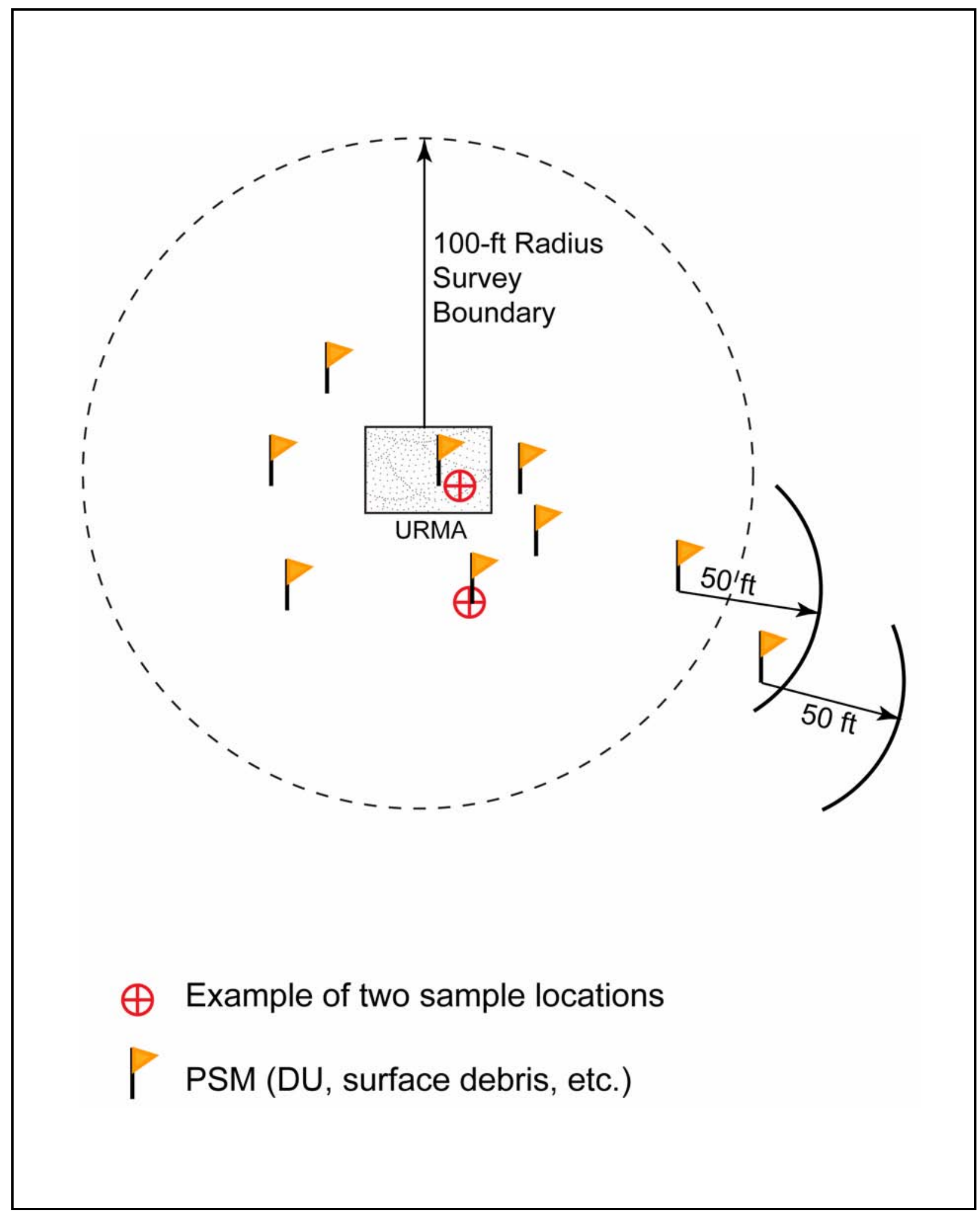

Figure A.8-7

Example Probabilistic Sampling Scheme for Surface Releases at 306 GZ and 307 GZ 
For subsurface releases at $306 \mathrm{GZ}$ and $307 \mathrm{GZ}$, a geophysical survey will be conducted within and surrounding the posted URMAs to investigate potential buried wastes. If geophysical anomalies that are consistent with the presence of buried objects/waste are detected, then soil at these locations will be excavated up to $10 \mathrm{ft}$ bgs, or until the object is uncovered (not to exceed $15 \mathrm{ft}$ bgs [CSM boundary]). If no anomalies are detected, then soil will be excavated from the center of the posted URMA. Figure A.8-8 illustrates both scenarios. Judgemental samples will be collected as follows:

- The excavated soil and the soil profile will be continuously monitored for visual biasing factors.

- Soil will be collected a minimum of every $2 \mathrm{ft}$ bgs and field screened for alpha/beta contamination.

- $\quad$ The sample with the highest FSR above the FSL will be submitted for analysis.

- Additional soil samples will be submitted for analysis based on FSRs and visual biasing factors.

\section{A.8.4.1.4 Other Potential Releases}

Additional judgmental sample locations may be identified during the CAI if there is evidence of a release. During the course of the CAU 106 investigation, the identification of any biasing factors will be used to determine whether a potential release is present (e.g., stains, spills, debris). Samples will be collected from the material that presents the greatest degree of the biasing factor (surface or subsurface as discussed above). Specific analyses requested for these samples will be determined based on the nature of the potential release (e.g., hydrocarbon stain, lead bricks).

\section{A.8.4.2 Decision II}

Decision II samples for non-test releases will be collected from judgmental sampling locations selected based on locations where COCs were detected, the CSM, and other field-screening and biasing factors listed in Section A.8.4. In general, sample locations will be arranged in a triangular pattern around the area containing COCs at distances based on site conditions, process knowledge, and biasing factors. If COCs extend beyond the initial step-outs, Decision II samples will be collected from incremental step-outs. Initial step-outs will be at least as deep as the vertical extent of 


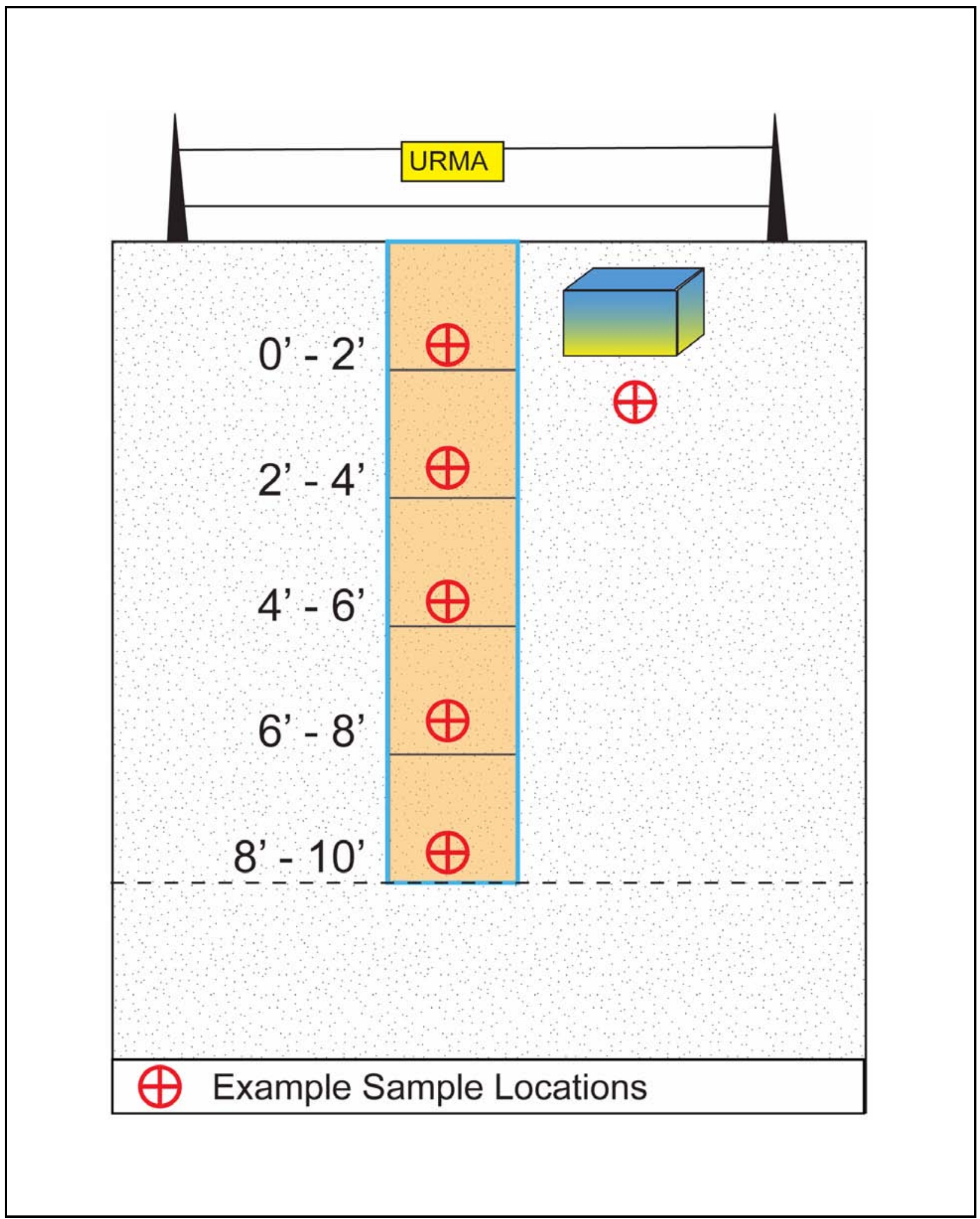

Figure A.8-8

Example Probabilistic Sampling Scheme for URMAs at 306 GZ and 307 GZ 
contamination defined at the Decision I location, and the depth of the incremental step-outs will be based on the deepest contamination observed at all locations. A clean sample (i.e., COCs less than FALs) collected from each step-out direction (lateral or vertical) will define extent of contamination in that direction. The Task Manager or Site Supervisor may modify the number, location, and spacing of step-outs as warranted by site conditions.

For drainages, if a COC is present at a sediment collection area sampling location, then additional sediment depth samples will be collected until two consecutive samples have analytical results less than FALs. Downstream accumulation areas also will be sampled until two consecutive areas have analytical results less than FALs. Other drainages will be assessed for the potential to have sediment collection areas that contain a COC. Decision II will be resolved by the assumption that the entire volume of sediment in each sediment collection area where a COC was identified contains the COC.

\section{A.8.5 Establishment of Final Corrective Action Boundary}

The final corrective action boundary will be established to include the initial corrective action boundary, any additional areas where COCs are expected to migrate in the future, any additional areas that exceed the FAL based on Pu contamination (sample plots based on the Am-241 survey or other radiological surveys), and any COCs identified from the non-test releases. 


\section{A.9.0 References}

ARL/SORD, see Air Resources Laboratory/Special Operations and Research Division.

ASTM, see American Society for Testing and Materials.

Air Resources Laboratory/Special Operations and Research Division. 2009. "NTS Climatological

Rain Gauge Data.” As accessed at http://www.sord.nv.doe.gov/home_climate_rain.htm on

7 January 2010.

American Society for Testing and Materials. 1995 (reapproved 2002). Standard Guide for

Risk-Based Corrective Action Applied at Petroleum Release Sites, ASTM E1739 - 95(2002).

Philadelphia, PA.

BN, see Bechtel Nevada.

Bechtel Nevada. 1999. An Aerial Radiological Survey of the Nevada Test Site, DOE/NV/11718--324. Prepared for U.S. Department of Energy, Nevada Operations Office. Las Vegas, NV: Remote Sensing Laboratory.

DOE/NV, see U.S. Department of Energy, Nevada Operations Office.

EPA, see U.S. Environmental Protection Agency.

Moore, J., Science Applications International Corporation. 1999. Memorandum to M Todd (SAIC) titled "Background Concentrations for NTS and TTR Soil Samples,” 3 February.

Las Vegas, NV: IT Corporation.

Murphy, T., Bureau of Federal Facilities. 2004. Letter to R. Bangerter (NNSA/NSO) titled "Review of Industrial Sites Project Document Guidance for Calculating Industrial Sites Project Remediation Goals for Radionuclides in Soil Using the Residual Radiation (RESRAD) Computer Code,” 19 November. Las Vegas, NV.

NAC, see Nevada Administrative Code.

NBMG, see Nevada Bureau of Mines and Geology.

NNES GIS, see Navarro Nevada Environmental Services Geographic Information Systems.

NNSA/NSO, see U.S. Department of Energy, National Nuclear Security Administration Nevada Site Office. 
NNSA/NV, see U.S. Department of Energy, National Nuclear Security Administration Nevada Operations Office.

Navarro Nevada Environmental Services Geographic Information Systems. 2010. ESRI ArcGIS Software.

Nevada Administrative Code. 2008a. NAC 445A.227, “Contamination of Soil: Order by Director for Corrective Action; Factors To Be Considered in Determining Whether Corrective Action Required.” Carson City, NV. As accessed at http://www.leg.state.nv.us/nac on 7 January 2010.

Nevada Administrative Code. 2008b. NAC 445A.22705, “Contamination of Soil: Evaluation of Site by Owner or Operator; Review of Evaluation by Division.” Carson City, NV. As accessed at http://www.leg.state.nv.us/nac on 7 January 2010.

Nevada Bureau of Mines and Geology. 1998. Mineral and Energy Resource Assessment of the Nellis Air Force Range, Open-File Report 98-1. Reno, NV.

PNNL, see Pacific Northwest National Laboratory.

Pacific Northwest National Laboratory. 2007. Visual Sample Plan, Version 5.0 User's Guide, PNNL-16939. Richland, WA.

RSL, see Remote Sensing Laboratory.

Remote Sensing Laboratory. 1960. Aerial Photograph

“RSL-Area5_NTS-681-A_1-9_HAMILTON,” 16 April, Las Vegas, NV.

SNJV, see Stoller-Navarro Joint Venture.

Stoller-Navarro Joint Venture. 2004. Phase II Hydrologic Data for the Groundwater Flow and Contamination Transport Model of Corrective Action Unit 98: Frenchman Flat, Nevada, S-N/99205-032. Las Vegas, NV.

Thompson, J.L., M.A. Guell, and J.R. Hunt. 1997. Subsurface Nobel Gas Transport at the Nevada Test Site, LA-UR-97-3255. Los Alamos, NM: Los Alamos National Laboratory.

USGS and DOE, see U.S. Geological Survey and U.S. Department of Energy.

U.S. Department of Energy, National Nuclear Security Administration Nevada Operations Office. 2002a. Industrial Sites Quality Assurance Project Plan, Nevada Test Site, Nevada, Rev. 3, DOE/NV--372. Las Vegas, NV.

U.S. Department of Energy, National Nuclear Security Administration Nevada Site Office. 2002b. Nevada Test Site Orthophoto Site Atlas, DOE/NV/1178--604. Aerial photos acquired Summer 1998. Prepared by Bechtel Nevada, Las Vegas, NV. 
U.S. Department of Energy, National Nuclear Security Administration Nevada Site Office. 2003. Nevada Test Site Routine Radiological Environmental Monitoring Plan, DOE/NV/11718--804. Las Vegas, NV.

U.S. Department of Energy, National Nuclear Security Administration Nevada Site Office. 2006. Industrial Sites Project Establishment of Final Action Levels, Rev. 0, DOE/NV--1107. Las Vegas, NV.

U.S. Department of Energy, Nevada Operations Office. 1992. Remedial Investigation and Feasibility Study for the Plutonium Contaminated Soils at Nevada Test Site, Nellis Air Force Range and Tonopah Test Range. April. Las Vegas, NV.

U.S. Department of Energy, Nevada Operations Office. 1996. Final Environmental Impact Statement for the Nevada Test Site and Off-Site Locations in the State of Nevada, DOE/EIS 0243. Las Vegas, NV.

U.S. Environmental Protection Agency. 2002a. Guidance for Quality Assurance Project Plans, EPA QA/G5. Washington, DC.

U.S. Environmental Protection Agency. 2002b. Calculating Upper Confidence Limits for Exposure Point Concentrations at Hazardous Waste Sites, OSWER 9285.6-10. December. Washington, DC: Office of Emergency and Remedial Response.

U.S. Environmental Protection Agency. 2006. Guidance on Systematic Planning Using the Data Quality Objectives Process, EPA QA/G-4. Washington, DC.

U.S. Environmental Protection Agency. 2009. Region 9: Superfund, Preliminary Remediation Goals, Screening Levels for Chemical Contaminants. As accessed at http://www.epa.gov/region09/waste/sfund/prg/index.html on 7 January 2010. Prepared by EPA Office of Superfund and Oak Ridge National Laboratory.

U.S. Geological Survey and U.S. Department of Energy. 2009. “USGS/DOE Cooperative Studies in Nevada; Water-Level Wells, Nevada Test Site.” As accessed at http://nevada.usgs.gov/doe_nv/ntsmap.htm on 15 December.

Yucel, V., National Security Technologies, LLC. 2009. Memorandum to R.L. Kidman (SNJV) regarding PET data, 30 April. Las Vegas, NV. 


\section{Appendix B}

\section{Project Organization}




\section{B.1.0 Project Organization}

The NNSA/NSO Federal Sub-Project Director is Kevin Cabble. He can be contacted at (702) 295-5000.

The identification of the project Health and Safety Officer and the Quality Assurance Officer can be found in the appropriate plan. However, personnel are subject to change, and it is suggested that the NNSA/NSO Federal Sub-Project Director be contacted for further information. The Task Manager will be identified in the FFACO Monthly Activity Report before the start of field activities. 


\section{Appendix C}

\section{Nevada Division of Environmental Protection Comment Responses}

(2 Pages) 


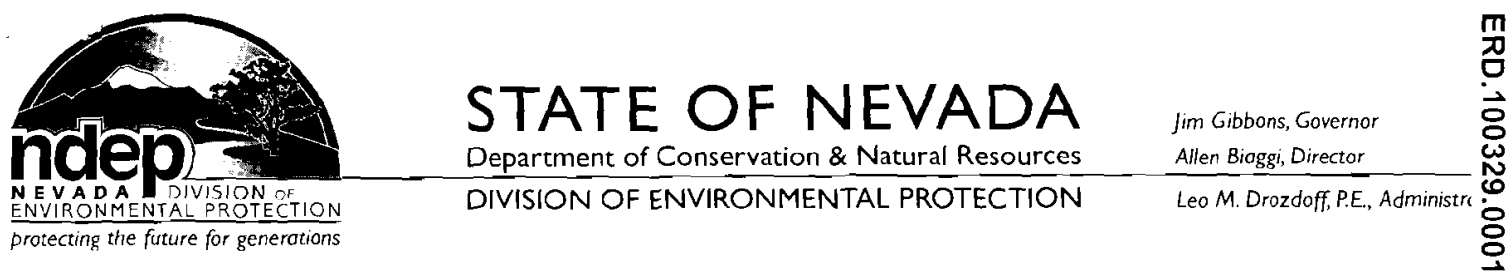

March 23, 2010

Robert F. Boehlecke

Federal Project Director

Environmental Restoration Project

National Nuclear Security Administration

Nevada Site Office

P. O. Box 98518

Las Vcgas, NV 89193-8518

RE: Review of Draft Corrective Action Investigation Plan (CAIP) for Corrective Action Unit (CAU) 106: Areas 5, 11 Frenchman Flat Atmospheric Sites,

Nevada Test Site, Nevada

Federal Facility Agreement and Consent Order

Dear Mr. Boehlecke,

The Nevada Division of Environmental Protection, Bureau of Federal Facilities (NDEP) staff has received and reviewed the draft CAIP for CAU 106: Areas 5, 11 Frenchman Flat Atmospheric Sites. NDEP's review of this document did not indicate any deficiencies.

If you have any questions regarding this matter contact me at (702) 486-2850 ext. 233.

Sincerely,

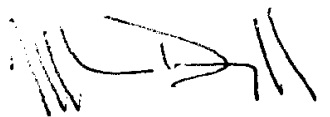

Jeff MacDougall, Ph.D., CPM

Supervisor

Bureau of Federal Facilities

$\mathrm{JW} / \mathrm{DN} / \mathrm{KC}$

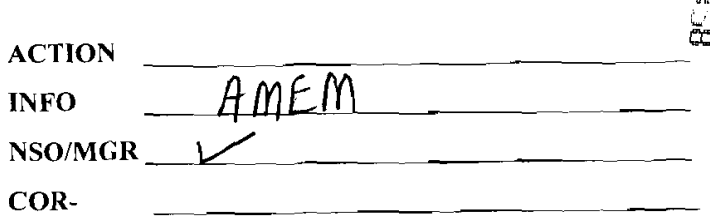

File Code 
Robert F. Boehlecke

Page 2

March 23, 2010

cc: $\quad$ K. J. Cabble, ERP, NNSA/NSO, Las Vegas, NV

E. F. Di Sanza, WMP, NNSA/NSO, Las Vegas, NV

FFACO Group, PSG, NNSA/NSO, Las Vegas, NV

I. T. Fraher, DTRA/CXTS, Kirtland AFB, NM

J. A. Ciucci, NSTec, Las Vegas, NV

A. L. Primrose NSTec, Las Vegas, NV

P. K. Matthews, NNES, Las Vegas, NV

T. D. Taylor, NNES, Las Vegas, NV 


\title{
Library Distribution List
}

\author{
$\underline{\text { Copies }}$ \\ U.S. Department of Energy \\ 1 (Uncontrolled, electronic copy) \\ National Nuclear Security Administration \\ Nevada Site Office \\ Technical Library \\ P.O. Box 98518, M/S 505 \\ Las Vegas, NV 89193-8518 \\ U.S. Department of Energy \\ Office of Scientific and Technical Information \\ 1 (Uncontrolled, electronic copy) \\ P.O. Box 62 \\ Oak Ridge, TN 37831-0062 \\ Southern Nevada Public Reading Facility \\ 2 (Uncontrolled, electronic copies) \\ c/o Nuclear Testing Archive \\ P.O. Box 98521, M/S 400 \\ Las Vegas, NV 89193-8521 \\ Manager, Northern Nevada FFACO \\ 1 (Uncontrolled, electronic copy) \\ Public Reading Facility \\ c/o Nevada State Library \& Archives \\ 100 N Stewart Street \\ Carson City, NV 89701-4285
}

